Universidad deValladolid

PROGRAMA DE DOCTORADO EN INFORMÁTICA

TESIS DOCTORAL:

\title{
DEFINICIÓN DE CONTEXTO POR MEDIO DE ONTOLOGÍAS COMO MEJORA DE SERVICIOS Y APLICACIONES EN DISPOSITIVOS MÓVILES
}

Presentada por D. Víctor Daniel Aréchiga Cabrera

para optar al grado de

Doctor por la Universidad de Valladolid

Dirigida por:

Dr. D Jesús M. Vegas Hernández 


\section{Dedicatoria}

Cuando nos fijamos una meta a cumplir seguramente encontraremos un camino donde habrá contratiempos, pero cuando se tiene certeza de que el esfuerzo, los sacrificios y sufrimientos valen la pena, cualquier obstáculo podrá ser superado.

Pero ¿Que sería de ese recorrido si fuéramos solos? Sin lugar a dudas muy diferente, por eso hay que agradecer a quienes confiaron, apoyaron y motivaron a seguir, por más difícil que fuera el trayecto.

Quiero agradecer a mi familia, mi esposa e hijas, por haber estado siempre al lado, por brindarme todo su apoyo, hacer sacrificios con tal de ver que este sueño se llevara a cabo y darme los alientos necesarios para continuar cuando tenía dudas, indiscutiblemente el resultado de este esfuerzo es compartido y se los debo a ustedes. A mis padres, ya que sin sus enseñanzas no sería la persona que soy, por haber predicado con el ejemplo y haber siempre confiado en mí. A mi Alma Mater, la Universidad de Guadalajara, por brindarme la oportunidad de crecer y desarrollarme profesional y personalmente, por todo el aprendizaje que me ha otorgado desde mi infancia y las que me faltan por recibir. 
A Jesús, mi director del presente trabajo por el trabajo especial que dedicó para mí, su paciencia y las lecciones aprendidas, por su dedicación y apoyo aun cuando la distancia hacía algunas de las tareas más complicadas.

Finalmente, a los amigos del LAB216, a Pablo de la Fuente por su apoyo y la orientación; a Miguel Angel, Jorge, Mario, Zubi, Javi y Alejandro, quienes sin saberlo me entregaron muchas enseñanzas que atesoro, al mostrarme su dedicación y el esfuerzo que dedican día con día a cumplir con sus sueños, además de compartir los inolvidables momentos de café y sobre todo su amistad, la que atesoro. ¡Son todos geniales! 


\section{Resumen}

El uso de los dispositivos móviles es el medio preferido por los usuarios alrededor del mundo como medio de conexión a Internet y para la utilización de aplicaciones en aspectos de ocio, entretenimiento y laborales. El contexto en la utilización de estos dispositivos tiene un valor primordial al ser medios de acceso en los que la ubicación, características del uso en determinado momento, las preferencias del usuario o los aspectos temporales pueden ser factores a considerar que permitan a una aplicación determinada ofrecer una experiencia de uso mejorada o esperada por el usuario.

La presente tesis plantea en primer lugar el desarrollo de una ontología que permita definir el contexto en dispositivos móviles, entendiendo al contexto como el conjunto de factores o condiciones interrelacionadas en las que algo ocurre, de forma que este pueda ser utilizado en aplicaciones en las que considerar el contexto pueda ser un factor de mejora en la experiencia para el usuario. La ontología propuesta establece 6 elementos base para la definición del contexto, los cuales permiten definir de forma completa los elementos necesarios para hacer uso del contexto como mejora de servicios o aplicaciones móviles. 
De la misma forma, en el presente trabajo se hace uso de la ontología de definición del contexto en dos actividades que se llevan a cabo comúnmente en los dispositivos móviles, la escritura de texto y el envío de mensajes o notificaciones a los dispositivos móviles, buscando, en ambos casos, obtener una mejora en la percepción del usuario.

Los resultados obtenidos en el presente trabajo nos demostraron que la utilización del contexto definido utilizando una ontología ha sido de utilidad, ya que se obtuvieron mejoras en las dos acciones mencionadas: en la escritura de texto se obtuvo un impacto de un $45 \%$ de mejora en promedio, mientras que en el envío de mensajes la mejora fue de un $58 \%$. 


\section{Abstract}

The use of mobile devices is the preferred medium for users around the world as a means of connecting to the Internet and for the use of applications in leisure, entertainment and work. The context in the use of these devices has a primordial value to be means of access in which the location, characteristics of use at a certain time, user preferences or temporary aspects may be factors to consider that allow a given application to offer an experience of use improved or expected by the user.

This thesis firstly proposes the creation of an ontology that allows defining the context in mobile devices, so that it can be used in applications in which considering the context can be a factor in improving the experience for the user. The proposed ontology establishes 6 basic elements for the definition of the context, which allow to define in a complete way the elements necessary to make use of the context as the best of services or mobile applications.

In the same way, the present work uses the ontology of context definition in two activities that are commonly carried out on mobile devices, writing text and sending messages or notifications to mobile devices, in both cases, obtain an improvement in the user's perception. 
The results obtained in the present work showed us that the use of the context that has been defined using an ontology has been useful, since improvements were obtained in the two mentioned actions: in text writing an impact of $45 \%$ on average improvement was obtained, while in the messages sending the improvement was $58 \%$. 


\section{Tabla de Contenidos}

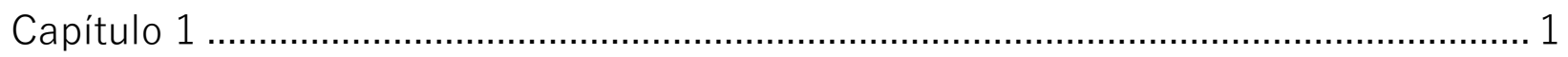

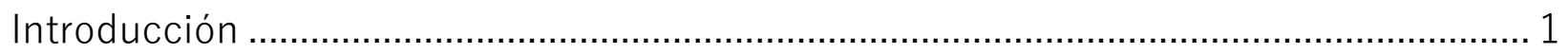

1.1 Objetivos de este trabajo ................................................................................... 5

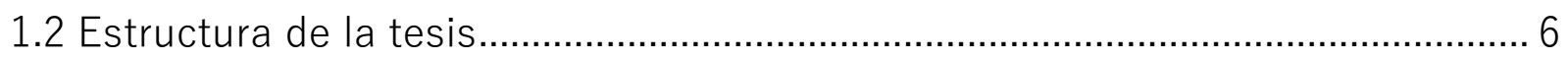

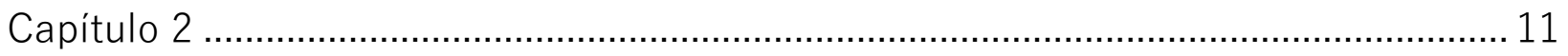

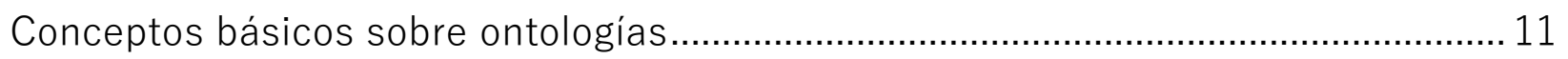

2.1 Ontologías en las ciencias computacionales y de la información ....................... 13

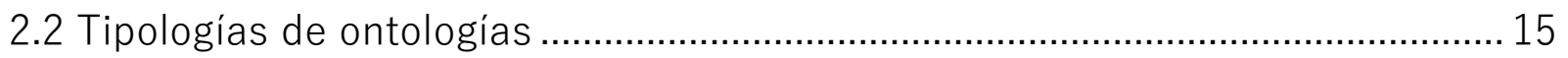

2.3 Proceso de desarrollo de una ontología ............................................................... 17

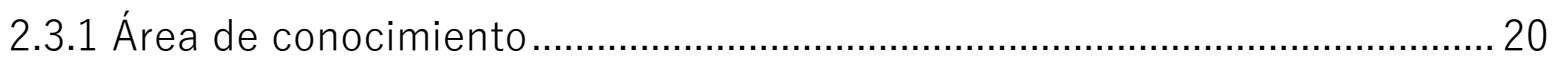

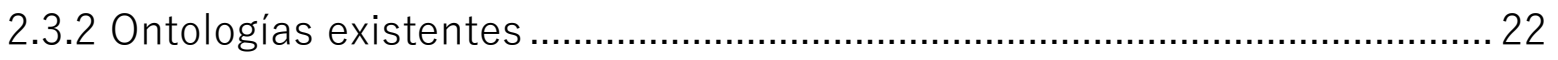

2.3.3 Términos del área de conocimiento ............................................................... 23

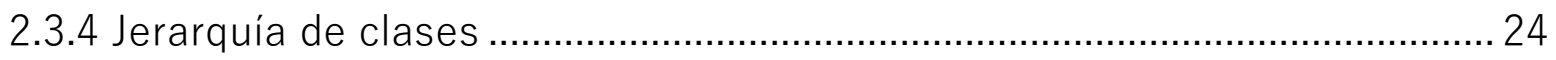

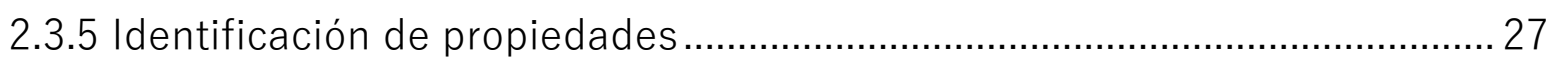

2.3.6 Definición de características ....................................................................... 28

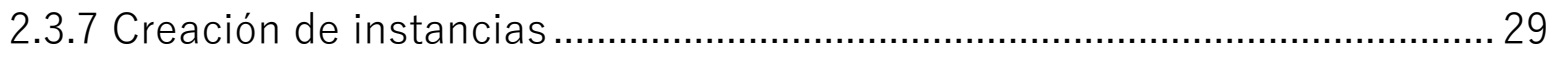

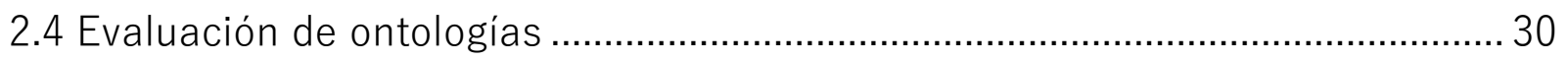

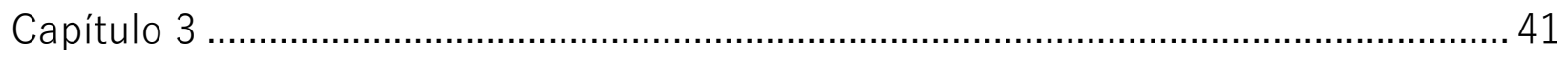

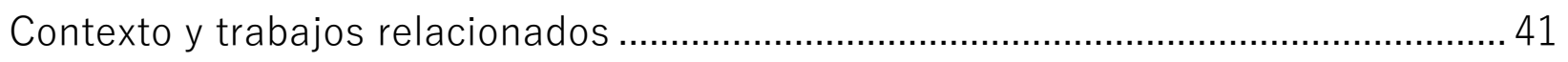

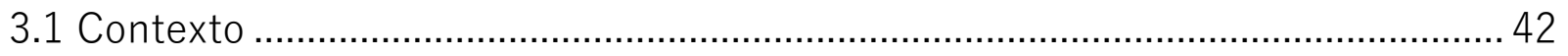

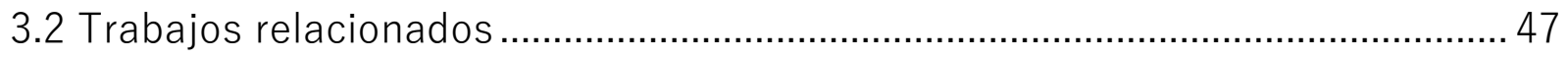

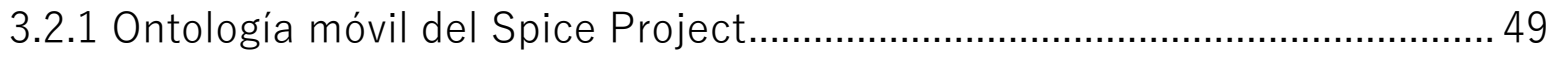


3.2.2 Ontologías del Proyecto MYMOSE............................................................. 52

3.2.3 Ontología de Contexto de Entrega del W3C................................................. 55

3.2.4 Ontología de Contexto para Entornos Móviles (mlO!) ................................. 58

3.2.5 Modelo de Ontología Multidimensional para soporte de Sistemas Sensibles

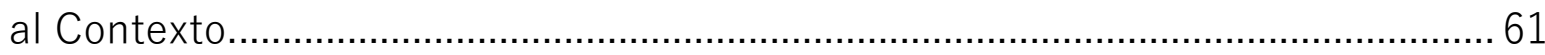

3.2.6 Entorno Flexible de Gestión de Servicios Web Semánticos.......................... 62

3.2.7 Context Broker Architecture (COBRA-ONT) ................................................ 64

3.2.8 AWARE: Marco de Instrumentación de Contexto Móvil................................ 65

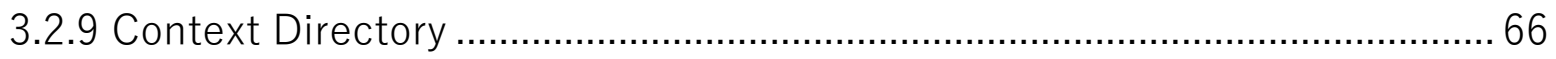

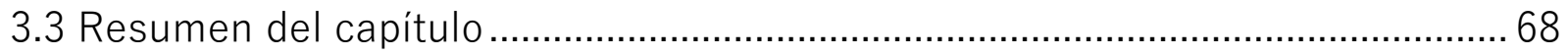

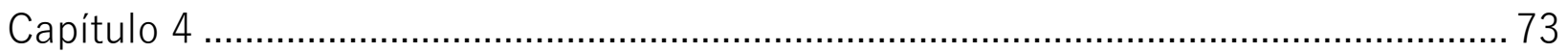

Proceso de desarrollo de la ontología COMoDE ......................................................... 73

4.1 Proceso de desarrollo de la ontología COMoDE ............................................... 74

4.1.1 Paso uno: Identificación del dominio de la ontología ....................................75

4.1.2 Paso dos: Verificación de ontologías existentes ............................................ 77

4.1.3 Paso tres: Identificación de los términos del área de competencia ..........112

4.1.4 Paso cuatro: Jerarquización de las clases .............................................. 116

4.1.5 Paso cinco: Identificación de las propiedades ........................................... 119

4.1.6 Paso seis: Definición de características de las propiedades ..................... 120

4.1.7 Paso siete: Creación de las instancias ....................................................... 121

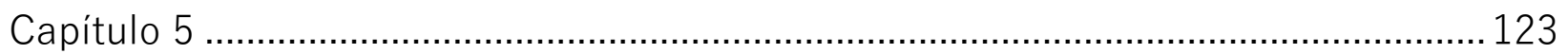

5.1 Mejora en la recomendación de palabras en dispositivos móviles mediante la aplicación de la ontología de contexto COMoDE. ....................................................... 126

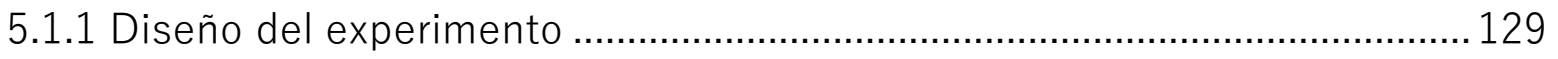


5.2 Mejora de un sistema de envío de mensajes mediante la aplicación de la ontología de contexto COMoDE......................................................................... 146

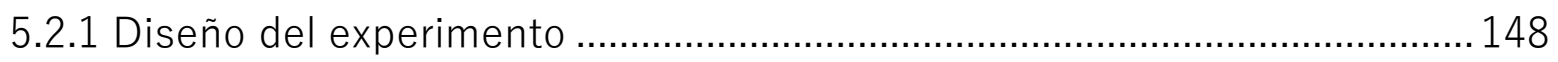

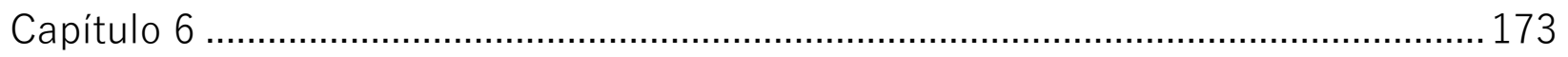

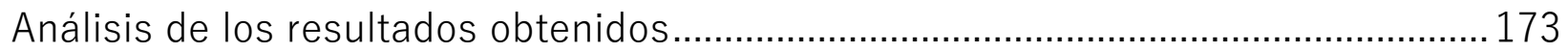

6.1 Resultados en un experimento de recomendación de palabras ........................ 174

6.2 Resultados en un experimento de envío de mensajes a dispositivos móviles178

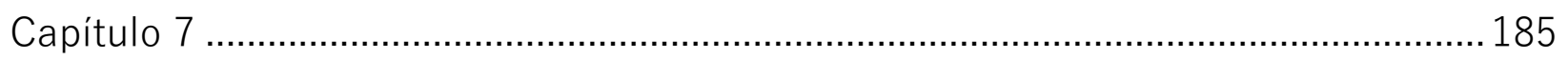

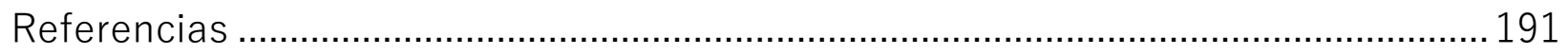

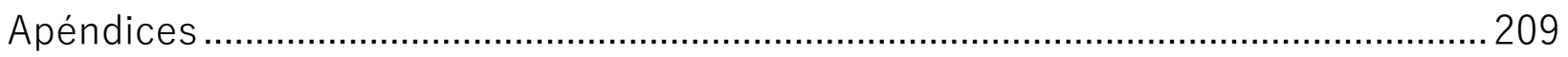

Apéndice A: Estructura base de la ontología COMoDE.......................................... 209

Apéndice B: Preguntas del cuestionario de validación de los grupos de elementos

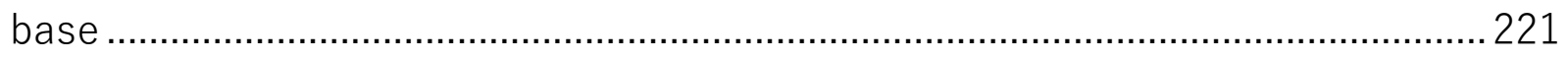

Apéndice C: Elementos imaginarios utilizados en el experimento de mejora en la recomendación de palabras en dispositivos móviles.............................................. 231 Apéndice D: Resultados completos en el experimento del sistema de envío de

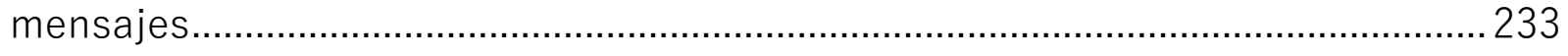




\section{Lista de tablas}

Tabla 1. Diferentes aproximaciones y combinaciones en la evaluación de ontologías de acuerdo a Brank 38

Tabla 2. Listado de las diversas características de contexto de acuerdo con los

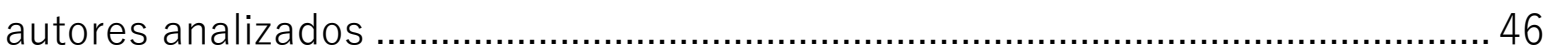

Tabla 3. Lista de las diferentes propuestas de ontologías analizadas en el capítulo 68

Tabla 4. Preguntas básicas para la creación de una ontología. ................................... 76

Tabla 5. Análisis de los resultados obtenidos en el grupo 3 de preguntas:

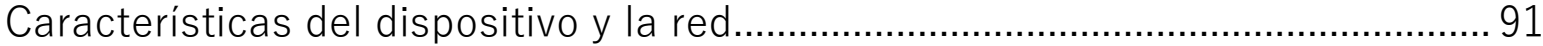

Tabla 6. Análisis de los resultados obtenidos en el grupo 4 de preguntas: Preferencias del usuario.

Tabla 7. Análisis de los resultados obtenidos en el grupo 5 de preguntas: Situación física. 96

Tabla 8. Análisis de los resultados obtenidos en el grupo 6 de preguntas: Condiciones y circunstancias temporales. 99

Tabla 9. Análisis de los resultados obtenidos en el grupo 7 de preguntas: Condiciones y circunstancias del entorno. 101

Tabla 10. Análisis de los resultados obtenidos en el grupo 8 de preguntas: Características del movimiento. 104

Tabla 11. Análisis de los resultados obtenidos en los grupos de preguntas del 3 al 8.

Tabla 12. Primera estructura de conceptos agrupados y jerarquizados mediante el uso de WordNet y Yahoo

Tabla 13. Cantidad, tipo y secuencia de los ítems de evaluación en el experimento. 


\section{Lista de figuras}

Figura 1 Proceso de creación de una ontología descrito por Noy y Mcguinness 2001 20

Figura 2 Interface del recomendador de palabras del proyecto MYMOSE ..................54

Figura 3 Ejemplo de la Ontología de Contexto de Entrega del W3C ............................56

Figura 4 Descripción de la clase referente a la ubicación en la Ontología de Contexto

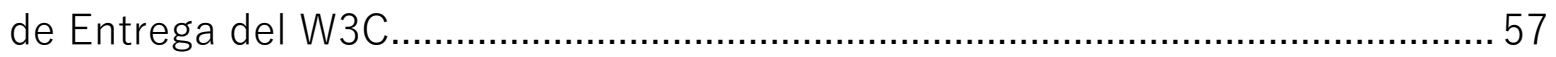

Figura 5 Ejemplo de la taxonomía relacionada con los dispositivos de la ontología mIO! 60

Figura 6. Porcentaje de usuarios que hacen uso del Internet móvil 89

Figura 7. Media aritmética y desviación estándar para el grupo de conceptos:

Características del dispositivo y la red. 93

Figura 8. Media aritmética y desviación estándar para el grupo de conceptos:

Preferencias del usuario 95

Figura 9. Media aritmética y desviación estándar para el grupo de conceptos: Situación física. 98

Figura 10. Media aritmética y desviación estándar para el grupo de conceptos: Condiciones temporales. 100

Figura 11. Media aritmética y desviación estándar para el grupo de conceptos: Condiciones y circunstancias del entorno. 103

Figura 12. Media aritmética y desviación estándar para el grupo de conceptos: Características del movimiento... 105

Figura 13. Media aritmética y desviación estándar por grupo de conceptos. 108

Figura 14. Subdominios generales de la ontología COMoDE para la definición del contexto móvil. 
Figura 15. Ejemplo de la estructura inicial para las clases de la ontología COMoDE. 118

Figura 16. Ejemplo de relaciones entre clase en la ontología COMoDE. 119

Figura 17. Ejemplo de definición de características de propiedades en la ontología COMoDE. 121

Figura 18. Muestra de la medición de la carga de trabajo. 135

Figura 19. Página de bienvenida para el experimento, vista desde un ordenador de escritorio. 138

Figura 20 Ejemplo de instanciación en la ontología COMoDE utilizada en un contexto simulado. 144

Figura 21 Ejemplo de una regla aplicada a la ontología COMoDE 145

Figura 22. Captura de pantalla del sitio web destinado a la información sobre el experimento y descarga de la aplicación. 156

Figura 23. Captura de pantalla (versión escritorio) del sitio web destinado a la información del experimento. 157

Figura 24. Captura de pantalla (versión escritorio) del sitio web destinado a la información sobre la descarga e instalación de la aplicación móvil del experimento. 159

Figura 25. Captura de pantalla del detalle donde se explica la interacción con la aplicación para los usuarios del experimento. 160

Figura 26. Vista general del proceso realizado en el servidor de envío de mensajes. 163

Figura 27. Captura de preferencias en la aplicación móvil, para su registro en el servidor. 165

Figura 28. Página de captura de mensajes de la aplicación servidor. 167

Figura 29. Vista general del proceso que se lleva a cabo en la aplicación móvil del experimento. 170 
Figura 30. Promedio de los resultados obtenidos para la variable KSPQ por tipo de

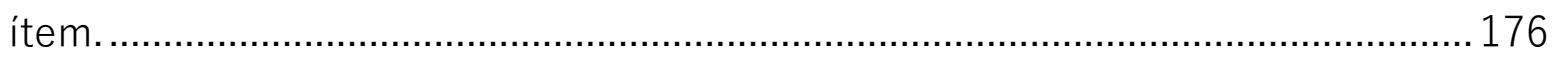

Figura 31. Promedio de teclas pulsadas para obtener el texto solicitado en un texto de 18 caracteres de longitud. ............................................................................... 177

Figura 32. Valor de $E R$ durante el transcurso del experimento y línea de tendencia. 180

Figura 33. Media de los valores obtenidos en $T_{M}$ por tipo de mensaje...................... 182 


\section{Capítulo 1}

\section{Introducción}

Los modernos dispositivos móviles han evolucionado respecto al tamaño de su pantalla, capacidad de procesamiento y las posibilidades de conexión, así como en la cantidad de aplicaciones disponibles, transformándolos en poderosos dispositivos para acceder a Internet en cualquier lugar, por lo que se han convertido en uno de los hechos tecnológicos de mayor impacto social.

El crecimiento en el uso de los dispositivos móviles ha sido de los más contundentes entre los equipos tecnológicos actuales, tal como lo mostró la tendencia indicada en 2014 por el reporte Gartner (Gartner Press Release, 2014) y que fuera reforzado por el más reciente reporte generado por Akamai sobre el estado de Internet (The State Of The Internet, 2017). En 2009 existían cerca de cuatro mil millones de subscriptores a servicios de telefonía móvil a nivel mundial, actualmente son más de siete mil millones de suscriptores ( $5 \mathrm{G}$ Americas, 2017). De acuerdo a la Organización de las Naciones Unidas (United Nations Organization, Department of Economic and Social Affairs, 2015) en 2015 la población total mundial se estimaba en cerca de 7,350 millones de 
habitantes, por lo que en números aproximados se podría considerar que cerca del 95\% cuenta con servicio de telefonía móvil y en consecuencia la posibilidad de obtener acceso a Internet desde un dispositivo móvil y a toda una extensa variedad de aplicaciones que en ellos se pueden utilizar. Y este número continúa creciendo.

Portabilidad y facilidad de uso son factor clave en el éxito de los dispositivos móviles y sus aplicaciones y servicios, unido al hecho de que sin importar el tema de interés de cualquier usuario, es altamente probable que existan muchas aplicaciones relacionadas. De igual forma las capacidades de procesamiento de estos dispositivos se han visto incrementadas de forma significativa en los últimos años (Singh \& Jain, 2014), convirtiendo a los actuales dispositivos en un ordenador de pequeñas dimensiones, más potentes inclusive que los ordenadores de hace algunos años.

Por las características propias de este tipo de dispositivos, un elemento que ha sido considerado como importante en la mejora del funcionamiento de en sus actividades y/o aplicaciones ha sido el contexto, elemento que es definido por Merriam-Webster (Merriam-Webster OnLine "context", 2018) como las 
condiciones interrelacionadas en las que algo existe u ocurre (características del dispositivo, intereses del usuario, condiciones del entorno o cualquier otro elemento cuando se refiere a los dispositivos móviles).

Lathia (Lathia, 2015) y Biancalana y colegas (Biancalana, Claudio, Gasparetti, Micarelli, \& Sansonetti, 2013) muestran pautas sobre los aspectos a tomar en cuenta en sistemas que proporcionan información en dispositivos móviles, ya que el contexto debe considerar, además de los servicios basados en la ubicación, los elementos tales como las preferencias, acciones y el histórico.

Igualmente Bouidghaghen y colegas (Bouidghaghen, Tamine, \& Boughanem, 2011) demostraron que los intereses del usuario pueden ser utilizados como herramienta en la personalización de la búsqueda en dispositivos móviles, tal como igualmente fue demostrado por Missaoiu y colegas (Missaoiu \& Faiz, 2015) y en la propuesta de Bouneffouf (Bouneffouf, Bouzeghoub, \& Gancarski, 2012) que utiliza los intereses del usuario como parte del contexto móvil que sirve de soporte en un sistema de recomendaciones. Inclusive se ha utilizado el contexto en la propia funcionalidad de los dispositivos móviles, tanto en un sistema que sugiere al usuario del dispositivo móvil que aplicación utilizar de 
acuerdo al contexto, como fuera propuesto por Shin y colegas (Shin, Hong, \& Dey, 2012) o en las búsquedas de información contenida dentro del propio dispositivo propuesto por Shin y colegas (Shin, Ko, Shin, Jung, \& Lee, 2013).

Todas estas propuestas permiten identificar diversas formas de utilización del contexto dentro de aplicaciones o servicios en los dispositivos móviles. El contexto es una parte fundamental en el entorno de las aplicaciones y servicios en los dispositivos móviles debido a la propia naturaleza de los dispositivos, las condiciones y características en que son utilizados y el factor movilidad que conllevan de forma intrínseca.

Las ontologías son un elemento importante en las aplicaciones semánticas, la definición más comúnmente aceptada sobre las ontologías explica que "una ontología es una especificación formal y explícita de una conceptualización de un dominio de interés" (Gruber, 1993), de forma tal que la creación de una estructura ontológica específica permitiría modelar conceptos relacionados con el contexto móvil, que a su vez permitiría a las aplicaciones y servicios móviles implementar mejoras en su funcionamiento o interacción con el usuario al contar con acceso a dicha información del contexto. 


\subsection{Objetivos de este trabajo}

El objetivo general del presente trabajo es establecer que el contexto en dispositivos móviles puede ser representado por medio de una ontología, de modo que permita representar las condiciones particulares del dispositivo y del usuario en un determinado momento o situación, para que este contexto pueda ser utilizado en la mejora u optimización en servicios y aplicaciones móviles, en este caso en dos escenarios como es la escritura de texto en búsquedas y el envío de mensajes o notificaciones personalizadas a los dispositivos móviles.

Nuestra hipótesis puede ser resumida como sigue:

Es posible diseñar una estructura ontológica que defina el contexto en los dispositivos móviles, y pueda ser utilizada para establecer una mejora en la escritura de texto en una situación particular, así como en una aplicación de envío de mensajes o notificaciones a dispositivos móviles.

Para conseguirlo, hemos considerado los siguientes objetivos particulares a llevar a cabo para la tesis:

1. Especificar una estructura semántica por medio de una ontología que permita definir el contexto en dispositivos móviles. 
2. Probar mediante un experimento que la utilización del contexto en la escritura de texto en búsquedas aporta una mejora para el usuario al reducir los caracteres que debe introducir.

3. Probar mediante un experimento que la utilización de contexto en el envío de notificaciones a dispositivos móviles permite establecer una mejora para que los mensajes sean recibidos con pertinencia.

\subsection{Estructura de la tesis}

El presente documento tiene la finalidad de presentar la propuesta de la creación de una ontología para la definición del contexto en dispositivos móviles, así como los experimentos llevados a cabo para probar su aplicación en dos escenarios diferentes y la evaluación de dichos experimentos.

La tesis se ha estructurado en 7 capítulos, incluyendo el presente capítulo introductorio. El resto del documento contiene los conceptos básicos sobre las ontologías (capítulo 2), el estado del arte y trabajos relacionados (capítulo 3), el proceso de desarrollo de la ontología COMoDE (capítulo 4), la evaluación de la utilización del contexto representada por medio de la ontología, a través de 2 diferentes experimentos (capítulo 5), el análisis de los resultados obtenidos 
(capítulo 6) y finalmente un espacio para las conclusiones y el trabajo futuro (capítulo 7). A continuación, se presenta un esquema más detallado sobre el contenido del resto del presente documento:

En el capítulo 2 se establecen los conceptos básicos relacionados con las ontologías desde su origen en las ciencias computacionales, conceptos básicos sobre su utilización, descripción del proceso básico de creación de este tipo de estructura, así como una descripción de las características relacionadas con las formas en que estas pueden ser evaluadas.

El estado del arte y trabajos relacionados con el tema de la tesis son descritos en el capítulo 3, comenzando con el concepto de "contexto" y su aplicación en las ciencias computacionales, para posteriormente mostrar diversos proyectos previos que han llevado a cabo la utilización del contexto en dispositivos móviles como una herramienta de mejora en alguna aplicación o servicio.

En el capítulo 4 se describe el proceso de creación de la ontología denominada Context Ontology for Mobile Devices (COMoDE), propuesta del presente trabajo. Se detalla el proceso mediante el cual se llegó a la obtención de la 
estructura final de esta propuesta e igualmente se describe la estructura base de la ontología.

En el capítulo 5 se detallan los procesos experimentales de evaluación llevados a cabo a través de la aplicación de la ontología de definición de contexto en 2 diferentes experimentos para determinar si la utilización del contexto definido mediante la ontología propuesta puede significar una mejora en dos actividades particulares que son llevadas en dispositivos móviles.

El capítulo 6 presenta y analiza los resultados obtenidos en los experimentos mostrados en el anterior capítulo, de forma que permitan identificar la posible mejora que pueda representar la utilización de la ontología como medio para la definición del contexto en dispositivos móviles en dos actividades específicas.

Finalmente, el capítulo 7 presenta las conclusiones finales del presente trabajo, detallando las experiencias obtenidas desde el proceso de creación de la ontología, el diseño de los experimentos y los resultados obtenidos, así como posibilidades de trabajo futuro relacionado con esta tesis. 
De igual forma se incluye un listado de las referencias utilizadas para la presente investigación, las que han servido en su totalidad como soporte para el trabajo realizado, así como orientación y guía para los procesos que en los experimentos fueron realizados.

Finalmente, se incluye una sección de apéndices que muestra información complementaria relacionada con esta investigación y que funciona como complemento de información. 


\section{Capítulo 2}

\section{Conceptos básicos sobre ontologías}

Este capítulo muestra los conceptos básicos relacionados con las ontologías, desde su clasificación y características, incluyendo igualmente el proceso para la creación de una ontología, para finalmente mostrar elementos relacionados con la evaluación de ontologías.

El concepto de ontología tiene sus orígenes como término en el siglo XVII, siendo primeramente utilizado por Jacob Lorhard en su texto Ogdoas Scholastica (Lorhard, 1606), dentro del estudio filosófico de la naturaleza del ser, del devenir, de la existencia o de la realidad, así como de las categorías básicas del ser y de sus relaciones. Un estudio muy detallado sobre la evolución en la utilización del término dentro del área filosófica se puede encontrar en el escrito de Vélez (Vélez León, 2014) aunque no será el objeto de estudio del presente trabajo. 
En el ámbito de las ciencias computacionales y de la información, la definición más aceptada sobre el concepto de ontología nos dice que una ontología es una especificación formal y explícita de una conceptualización compartida (Gruber, 1993), sobre esta definición Fensel (Fensel, 2001) hace un análisis detallado, del que se desprende que una Conceptualización se refiere al modelado abstracto de un fenómeno del mundo que identifica los conceptos relevantes de ese fenómeno, Explicito significa que el tipo de conceptos utilizados y las restricciones en su uso son explícitamente definidas, Forma/hace referencia al hecho de que la ontología deberá ser legible a la computadora, finalmente Compartida refleja la noción de que una ontología debe representar el conocimiento consensuado, no restrictivo a un solo individuo. De igual forma Gruber (Gruber, 2001) posteriormente describe a las ontologías como una especificación de una conceptualización, haciendo referencia al ámbito del intercambio de conocimiento o información.

Las ciencias computacionales abordan el concepto de ontología de una forma diferente frente a la filosofía, ya que las ciencias computacionales tienen un enfoque más dirigido hacia la creación de vocabularios controlados, mientras que la filosofía se preocupa por los principios. Fundamentalmente, el rol de las ontologías en los procesos de ingeniería es el de facilitar la construcción de 
modelos de representación de un dominio por medio de un vocabulario de términos y relaciones. Un trabajo de Øhrstrøm y colegas (Øhrstrøm, Andersen, \& Schärfe, 2005) busca establecer esa vinculación o comunicación deseable entre el concepto de ontología desde ambos puntos de vista, es decir, desde la filosofía y las ciencias computacionales.

\subsection{Ontologías en las ciencias computacionales y de la información}

Fue a mediados de la década de los 1970's cuando los científicos dedicados a la inteligencia artificial (IA) reconocieron que como un cimiento fuerte para el desarrollo de poderosos sistemas de IA se requería la captura del conocimiento de un campo en particular. En la década de los 1980's el término de ontología comenzó a ser utilizado por los científicos de la IA para hacer referencia a componentes en sistemas de conocimiento e igualmente como una teoría para modelar el mundo. Fue al inicio de la década de los 1990's cuando Gruber (Gruber, 1995) introdujo el término de ontología para definir una especificación de una conceptualización. 
Las aplicaciones semánticas tienen como base fundamental el uso de ontologías. Como se puede observar, la definición de ontología hace hincapié en dos elementos centrales.

- La definición de los conceptos es formal, una estructura es creada para representar todos los elementos relacionados, que puede permitir que se pueda realizar algún tipo de razonamiento sobre ellos. Una ontología es un archivo o documento que define formalmente las relaciones entre términos (Berners-Lee, Hendler, \& Lassila, 2001).

- Una ontología es diseñada para un dominio en particular o un campo de conocimiento.

En las ciencias computacionales, existe además una definición de Stabb y Studer (Staab \& Studer, 2004) que define una ontología como una 4-tupla (C, $\mathrm{R}, \mathrm{I}, \mathrm{A}$ ), en las que "C" es un conjunto de conceptos (también conocidos como clases), "R" es un conjunto de relaciones (propiedades), "I" es el conjunto de instancias y finalmente "A" es el conjunto de axiomas (restricciones de roles). 
Desde este punto de vista, son cuatro los ingredientes que componen la estructura de una ontología, los que en conjunto permiten representar enteramente un dominio particular de interés, estos elementos son:

- Clases: Las clases representan la descripción de conceptos principales de un dominio de conocimiento, estas pueden definir los elementos básicos en los que el campo de conocimiento puede ser desmenuzado.

- Propiedades: Las características y atributos de estos conceptos son definidos como propiedades; las cuales especifican características o parámetros de las clases.

- Instancias: Las instancias son elementos específicos y particulares de la "vida real" que pueblan la ontología.

- Restricciones de roles: Las restricciones de roles identifican las restricciones que aplican tanto para las clases como para las propiedades.

\subsection{Tipologías de ontologías}

Las ontologías representan conceptos que pertenecen y se encuentran relacionados con una parte del mundo real. Mizoguchi e Ikeda (Mizoguchi \& Ikeda, Towards ontology engineering, 1998) mencionaron que las ontologías 
pueden ser clasificadas desde el punto de vista de su utilización en diferentes tipologías, por lo que se pueden encontrar las siguientes clasificaciones:

- Ontología de lugar de trabajo (Workplace ontology). Son ontologías que determinan las características de la tarea en la que se estará desempeñando la ontología, ya que especifican las condiciones del límite y el comportamiento específico para dicha tarea (Vanwelkenhuysen \& Riichiro, 1994).

- Ontología de tareas (Task ontology). En el caso de las ontologías de tareas, el concepto hace referencia a un sistema de vocabulario para describir estructuras enfocadas a la resolución de problemas de tareas específicas que son independientes del dominio, de utilidad para llevar a cabo una conexión o un mejor entendimiento entre vacíos al momento de compartir el conocimiento de un dominio (Mizoguchi, Tijerino, \& Ikeda, 1992) (Hoehndorf, 2010).

- Ontología de dominio (Domain ontology). Las ontologías de dominio son creadas para una tarea o necesidad muy específica o particular, por lo que distintas ontologías pueden resultar incompatibles entre sí debido a sus especificidades en el diseño de sus elementos, de esta forma, 
pueden existir diversas ontologías de dominio para un dominio de interés similar (Gruber, 2001) (Grüninger \& Fox, 1995).

\subsection{Proceso de desarrollo de una ontología}

El proceso de desarrollo de una ontología es una tarea muy subjetiva, simplemente porque una ontología es una conceptualización de conocimiento, en un dominio de interés en particular, por lo tanto, no existe una y sólo una forma de crearla. Si se crearan dos diferentes equipos de trabajo por separado para la creación de una ontología, seguramente ambos resultados tendrían coincidencias, pero de igual forma contarían con muchas diferencias, ya que la estructura y elementos de la ontología son muy subjetivos y su creación se verá afectada por los puntos de vista, experiencias y diversos factores.

Inclusive, al crear las ontologías seguramente puede variar la razón por la que se desea crear, ya que pueden existir diversos puntos de vista o diversas necesidades relacionadas con un mismo dominio de interés para el que se desea desarrollar la ontología. Claramente se puede apreciar que diversos factores se deben considerar cuando se desarrolla una ontología. 
Suárez y colegas (Suárez-Figueroa, Gómez-Pérez, \& Fernández-López, 2011) han propuesto una metodología denominada $\mathrm{NeOn}$, la que no provee de un flujo fijo para el desarrollo de una ontología, sino que sugiere diversos caminos a seguir en el desarrollo de las ontologías. La metodología NeOn provee de:

- Un glosario de procesos y actividades involucradas en el desarrollo de ontologías,

- Dos modelos de ciclo de vida de ontologías,

- Un conjunto de guías metodológicas para diferentes procesos y actividades relacionadas con el desarrollo de la ontología.

Existen muchas otras coincidencias en los métodos de desarrollo de ontologías de acuerdo a diversas investigaciones, tal como se ha descrito por Noy (Noy \& Mcguinness, 2001), o lo hicieran Grüninger y Fox (Grüninger \& Fox, 1995) en el proyecto de desarrollo TOVE, o Uschold y King (Uschold \& King, 1995) en la Enterprise Ontology, de los cuales se pueden resumir en siete pasos que un desarrollador de ontologías debe seguir para completar el proceso de creación de una ontología. 
Existen otras metodologías más específicas, como la propuesta por Berneras (Berneras, 1996) que se enfoca en el reuso de información por medio del desarrollo de ontologías, las que se desarrollan de forma muy intrínseca a la aplicación que hará uso de la propia ontología.

Fernandez (Fernández-López, 1999) Ilevó a cabo un extensivo análisis de éstas y otras metodologías para el desarrollo de ontologías, mediante una revisión que busca aplicar congruentemente el estándar IEEE 1074-1995 para el desarrollo de software en el desarrollo de ontologías.

El desarrollo de ontologías es un proceso iterativo, como lo describe Noy (Noy \& Mcguinness, 2001) al proponer la metodología de 7 pasos, detallando que el desarrollo de ontologías es un proceso perfectible que evoluciona (Figura 1). Este modelo para el desarrollo de ontologías será utilizado en el presente trabajo de tesis y será descrito a detalle en las siguientes páginas. 


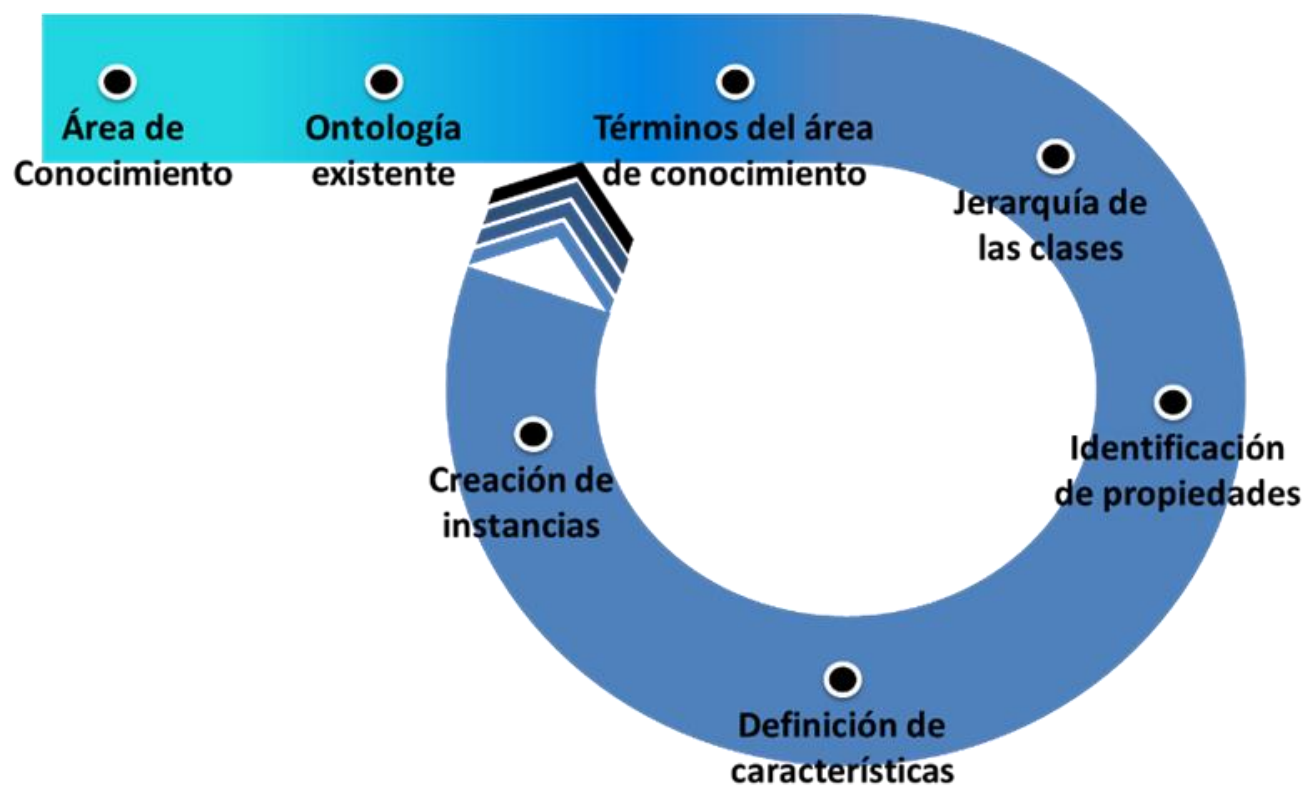

Figura 1 Proceso de creación de una ontología descrito por Noy y Mcguinness 2001

\subsection{1 Área de conocimiento}

El primer paso para la creación de ontologías es el de mayor importancia ya que es el que define con mayor claridad la temática y la amplitud en la que se tratará el área de conocimiento para la que deseamos generar la ontología.

Cómo parte de este primer paso se requiere dimensionar el alcance de la ontología, a través de dar respuesta a las siguientes preguntas: 
- ¿Cuál será el dominio que deberá cubrir la ontología? Se refiere al área de conocimiento a la que deseamos conceptualizar para ponerla a disposición en algún sistema, aplicación o como medio para el intercambio de dicho conocimiento.

- ¿Cuál será el uso de la ontología? Permite identificar con claridad el sentido que tendrá la ontología que se desea generar, en el ejemplo previo de la ontología sobre el café, se debería identificar si la ontología será utilizada en términos de la producción o en aspectos del consumidor final.

- ¿Para qué tipo de preguntas deberá proveer de información la ontología? La respuesta a esta pregunta permitirá identificar o determinar cómo es que serán establecidas las relaciones y su estructura para dar soporte al uso para el que será destinada la ontología.

- ¿Quién dará mantenimiento a la ontología? Aunque pareciera una pregunta para un aspecto secundario, en la vida real no lo es, ya que las ontologías tienen la tendencia a crecer, desarrollarse, evolucionar y adaptarse; se encuentran en constante desarrollo, por lo que es importante definir cómo es que se dará seguimiento a dicha actividad.

Las respuestas provistas para estas preguntas permitirán crear el alcance en el desarrollo de la ontología, aunque es necesario considerar que dichas 
respuestas podrán ir cambiando conforme vaya evolucionando el proceso de creación de la ontología, pero dan claridad en todo momento sobre su objetivo, límites y utilidad.

\subsubsection{Ontologías existentes}

El segundo paso en la creación de ontologías nos lleva a la identificación de ontologías existentes que se encuentren relacionadas con el área de conocimiento que deseamos abarcar. Identificar trabajos existentes se convierte en una actividad importante ya que permite identificar trabajos previamente hechos que podrían proporcionarnos una base sólida y probada, que además podría ser un requisito si se desea que la ontología que se pretende crear lleve a cabo interacción con otras ontologías o aplicaciones.

Cuando se buscan ontologías existentes, es posible encontrar librerías con acceso a cierta cantidad de ontologías que pudieran ser reutilizadas en algunos de sus componentes, adicionalmente pueden existir librerías comerciales que incluyan ontologías disponibles públicamente para su uso. 
Es posible que se encuentren ontologías cercanas a la representación deseada para el área de conocimiento que se desea trabajar, por lo que es posible tomar como base dichas ontologías o partes de ellas, para armar la estructura deseada de acuerdo a las necesidades que nos llevan a crear la ontología, por supuesto considerando siempre los temas de derechos de autor.

Lozano-Tello y Gómez-Pérez (Lozano-Tello \& Gómez-Pérez, 2004) diseñaron la metodología ONTOMETRIC, que permite obtener una medición de la conveniencia o idoneidad de una ontología existente para ser aplicada a algún problema o sistema específico, por lo que también puede ser utilizada en la toma de decisiones en la búsqueda de ontologías para una aplicación especifica.

\subsubsection{Términos del área de conocimiento}

El tercer paso referente a la creación de ontologías es fundamental, ya que es el que nos permitirá delimitar y dimensionar con mayor claridad el área de conocimiento que se desea representar a través de la ontología, lo que se consigue a través del establecimiento de los términos o conceptos que se verán reflejados en la estructura y organización de nuestra ontología. En este paso no 
tiene importancia si un término o concepto se verá reflejado finalmente en nuestra ontología como una clase o una propiedad, ni se requiere definir cómo será la interacción entre dichos términos, sólo se requiere identificar lo más completo posible todos los términos que aportan en el desarrollo de la ontología.

Para esta tarea se crea una lista de términos relacionados con el área de conocimiento, la que será el sustento o materia prima para los siguientes pasos. Este proceso es en cierta medida dinámico, ya que, aunque se debe buscar la representación más certera de los términos del área de conocimiento que se desea representar, también es posible que en los siguientes pasos de la creación de ontologías se puedan agregar o eliminar términos conforme se lleven a cabo las tareas del análisis de las clases, propiedades y axiomas.

\subsubsection{Jerarquía de clases}

A partir de la lista de términos relacionados con el área de conocimiento que se desea representar a través de la ontología, obtenida mediante el paso anterior, se debe determinar cuáles de estos términos representarán clases y cuál será la estructura de éstas. Para llevar a cabo la jerarquización de términos para la obtención de la estructura de clases de la ontología, Uschold y Grüninger 
(Uschold \& Grüninger, 1996) propusieron tres aproximaciones en la resolución de la tarea, las que se describen en términos generales como sigue:

- Arriba-abajo. Inicia con la identificación de los conceptos más generales a partir de la lista de términos del paso anterior, para luego determinar los elementos que corresponden al siguiente nivel, y posteriormente continuar de la misma forma de acuerdo a los niveles que resulten necesarios para integrar la estructura de clases.

- Abajo-arriba. Se busca iniciar con el descubrimiento de los términos que son más específicos y que identificarán a los niveles más bajos en la jerarquía de clases, para posteriormente llevar a cabo el agrupamiento de conceptos por medio de términos más generales, siguiendo esta tarea hasta llegar al nivel de más alta jerarquía de las clases.

- Combinación. En esta aproximación es necesario identificar de la lista de conceptos o términos del paso anterior, cuáles serán las clases de más alto nivel y las de más bajo nivel para posteriormente llevar a cabo la organización del resto de la jerarquía de clases mediante la definición de la estructura intermedia que permite unir a los niveles superior e inferior de una forma ordenada y lógica, creando la estructura completa de clases. 
No existe un método específico para ninguna de las aproximaciones expuestas anteriormente, la elección de alguna de ellas para resolver las tareas relacionadas con este paso puede ser elegida de acuerdo a las necesidades particulares de creación de la ontología o inclusive puede considerar las habilidades y preferencias de los creadores de la misma.

A partir de la lista generada en el paso anterior se podrán descubrir e identificar los términos que identifican objetos que son independientes, en lugar de términos que describen a estos objetos. Es en este paso donde se definen las relaciones entre clases, por ejemplo, las relaciones "es-un" o "tipo de".

Existen varios métodos que permiten evaluar las características de los términos y que permiten identificar si dicho término se considerará como una clase o una propiedad, así como algunos otros que permiten asegurar que la estructura jerárquica es consistente y ha sido desarrollada de forma adecuada, pero no serán descritos en el presente documento. 


\subsubsection{Identificación de propiedades}

Una vez que las clases han sido definidas a través de los pasos previamente descritos, es necesario llegar a la determinación sobre el resto de los términos definidos en el tercer paso, de forma que se pueda identificar cuáles de ellos serán considerados como propiedades dentro de la ontología.

Las propiedades deben ser adjuntadas a las clases, ya que permiten representar características del concepto al que se encuentran relacionadas. Por ejemplo, en la ontología del café, el término "café" será una clase y las características como "acidez", "tueste" o "aroma" forman parte de las propiedades del café, todos estos términos podrían haber sido obtenidos en el listado que se genera en el tercer paso.

Es importante destacar que todas las clases obtendrán las propiedades a través de la herencia a partir de la clase superior de la que se desprenden, es decir, su clase superior o clase padre. De esta forma, se debe considerar que una propiedad debe ser asignada a la clase más general o de más alto nivel posible, asegurando que todas las clases en los niveles subsecuentes cuenten entre sus características con la inclusión de dicha propiedad. 
En este paso puede llegar a ocurrir que se llegan de descubrir términos que no fueron considerados en los pasos anteriores, por lo que deberán ser adicionados a la ontología, ya sea como clase o propiedad o considerarlo dentro de los términos que todavía no han sido asignados. Recordemos que la creación de ontologías es un proceso iterativo, cíclico.

Para este paso también existen varios métodos que permiten identificar qué términos se transformarán en propiedades y a cuáles clases deberían ser asociados, se puede encontrar extensa literatura sobre el tema y para el proceso de creación de ontologías.

\subsubsection{Definición de características}

Es en este paso donde se describen las características de las propiedades definidas en el paso anterior, es decir, se identifican o referencian los valores que pueden obtener, tales como el tipo, la cardinalidad, valores permitido o algunos otros.

En este sentido, es en este momento donde en la ontología del café se podría identificar que la propiedad "tueste" será del tipo cadena de caracteres, con 
una cardinalidad de 1 (ya que sólo puede tener un único valor), o inclusive determinar que los posibles valores a designar para esta propiedad serán "ligero", "medio", "medio obscuro" u "obscuro".

Estas definiciones permiten al desarrollador la creación de los límites y restricciones al momento de la creación de las instancias de la ontología, por lo que es necesario tomar el tiempo necesario para analizar y determinar cuáles y de qué tipo serán las restricciones implementadas en la definición de las características de las propiedades en la ontología.

\subsubsection{Creación de instancias}

En el paso final del método para la creación de ontologías aquí descrito, es en el que se crean las instancias para las clases definidas en la ontología. Una ontología es finalmente una estructura, una conceptualización de conceptos de un dominio o área de conocimiento, pero el proceso de instanciación es cuando a esta estructura se le agregan elementos de la "vida real" para generar un sentido en una aplicación real. En el ejemplo de una ontología del café, la creación de las instancias sería ya la implementación y uso de la ontología en un entorno de producción y el consecuente agregado de datos o instancias a la 
estructura de la ontología, por ejemplo, al definir que la propiedad "aroma" tiene el valor "afrutado" estamos creando una instancia en dicha ontología.

Cabe mencionar que pueden existir instancias que son creadas previamente a la aplicación de la ontología mientras esta se encuentra en desarrollo, aunque el común denominador es que las aplicaciones generen las instancias que se requieren en la ontología.

A pesar de ser el paso final en el método de creación de ontologías, no es posible considerarlo como el último, ya que el proceso de creación de ontologías es iterativo y en términos generales se regresa a pasos anteriores para ir ajustando o actualizando la estructura de la ontología, es decir, la creación de una ontología es un proceso continuo.

\subsection{Evaluación de ontologías}

La evaluación de las ontologías es un proceso que puede cubrir diversos aspectos a evaluar, tales como la validación de su estructura conformada por las clases, propiedades, relaciones y demás elementos, sus relaciones taxonómicas, los contenidos y la población de las mismas, inclusive desde el 
impacto de las ontologías en su utilización (Hartmann, y otros, 2005). Inclusive se considera la evaluación de las propias herramientas de creación y manipulación de las ontologías (Staab, y otros, 2004).

Cuando se habla de la evaluación de ontologías existen diversos enfoques o acercamientos para realizar la tarea. Se pueden encontrar las propuestas como la metodología OntoClean presentada por Guarino (Guarino \& Welty, 2002) (Guarino \& Welty, 2004), la cual se encuentra enfocada en la validación de las taxonomías por medio de la exposición de las elecciones impropias o inconsistentes tomadas en el proceso de creación de la ontología. Se fundamenta en conceptos heredados de la filosofía: Esencia, Identidad y Unidad y puede ser sintetizada en dos pasos primordiales.

El primer paso está relacionado con el etiquetado de todos los conceptos de la ontología que es analizada, estas etiquetas representan alguna de las cuatro posibles metapropiedades posibles de Rigidez (R), Identidad (I), Unidad (U) y Dependencia (D). 
En el segundo paso del método OntoClean se lleva a cabo la verificación de las relaciones de las subclases de la ontología. Este análisis formal permite descubrir las inconsistencias en las subclases en la taxonomía.

Otro punto de vista en la evaluación de ontologías fue propuesto por Maedche y Staab (Maedche \& Staab, 2002), que establece métricas para la medición de proximidad entre ontologías o análisis de la similitud de las ontologías, como una útil herramienta para proveer de elementos para la comparación de ontologías. El método de comparación propuesto provee de herramientas para realizar medición de similitudes entre ontologías por medio de un análisis léxico y de conceptos. Permite describir el grado en que una especificación de una ontología está cubierta por otra y viceversa, dividido esencialmente en dos niveles:

- Nivel de comparación léxica. Basado en el método Levenshtein (Levenshtein, 1966) para medición de las diferencias entre dos cadenas de texto, proponen una medición de similitud léxica entre cadenas de texto que tendría como resultado un grado de similitud entre 0 y 1 , donde 1 representa una similitud perfecta mientras que 0 representa una mala coincidencia. 
- Nivel de comparación conceptual. En este nivel existen dos pasos de comparación entre las ontologías a analizar, los que son soportados sus estructuras semánticas, los que son representados por las taxonomías y las relaciones de los conceptos.

- Comparación de taxonomías. Primer paso, el análisis de las taxonomías proporciona como resultado el traslape taxonómico, que representa la similitud entre ambas ontologías relacionada respecto a sus conceptos y estructura taxonómica.

- Comparación de relaciones. En el segundo paso, la se obtiene la precisión o traslape de las relaciones, que muestra las coincidencias entre relaciones en un valor, que representa la similitud existente entre los conceptos de dominio y rango.

Porzel y Malaka (Porzel \& Malaka, 2004) y de una forma similar Völker y colegas (Völker, Vrandečić, \& Sure, 2005) describieron una evaluación en diferentes características para las ontologías, ya que sus evaluaciones están basadas en el rendimiento en tareas específicas. De igual forma Green (Green, 2004) demostró que las ontologías pueden ser utilizadas en una aplicación o tarea en particular de forma que se pueda evaluar la efectividad que implica su utilización, esta evaluación puede ser llevada a cabo por medio de la utilización 
de un prototipo que permita a los usuarios evaluar de acuerdo a su punto de vista sobre la efectividad de la utilización de la ontología en una tarea o aplicación particular

Igualmente Gómez-Perez (Gómez-Pérez, 1995) (Gómez-Pérez, 2001) realizó propuestas sobre criterios a considerar cuando se trata de la evaluación de ontologías, e inclusive existe la propuesta más reciente de Shangavarapu (Sanagavarapu, Gollapudi, Chimalakonda, Raghu Reddy, \& Choppella, 2017) que propone evaluar las ontologías desde el punto de vista de la suficiencia, entendiendo esta como la cobertura adecuada de un dominio particular mediante los conceptos y relaciones de la ontología.

Poveda-Villalón y colegas (Poveda-Villalón, Suárez-Figueroa, \& Gómez-Pérez, 2012) diseñaron la herramienta OOPS!, una aplicación basada en web que tiene como objetivo llevar a cabo la validación de ontologías detectando peligros potenciales, funcionando como un auxiliar para los desarrolladores en el análisis de las ontologías en desarrollo. 
De forma más sintética Brank (Brank, Grobelnik, \& Mladenic, 2005) realizaron un resumen o clasificación de la evaluación de ontologías de acuerdo al enfoque utilizado para evaluar, así como el nive/de evaluación aplicado a las ontologías. Esta clasificación provee de un punto de vista más amplio que permite identificar el tipo de evaluación que mejor se adapte para las necesidades particulares, requerimientos o características particulares en cada caso.

Desde el punto de vista del enfoque, las ontologías pueden ser evaluadas bajo los siguientes elementos:

- Comparando la ontología con una ontología estándar. En este punto se refiere a ontologías estándar o definiciones base en las que será creada la ontología, por ejemplo, el lenguaje que será utilizado para desarrollar la ontología.

- Utilización de la ontología en una aplicación para evaluar los resultados. La evaluación basada en tareas o en la implementación en una aplicación analiza los resultados obtenidos en una aplicación real para identificar el rendimiento obtenido en la utilización de la ontología.

- Comparación con una fuente de datos del dominio a cubrir por la ontología. Se puede realizar una comparación con alguna ontología o un conjunto de datos estructurados relacionados con el dominio a tratar por 
la ontología a ser evaluada, tal y como fuera propuesto por Brewster y colegas (Brewster, Alani, Dasmahapatra, \& Wilks, 2004).

- Evaluación hecha por humanos. En este aspecto de la evaluación de una ontología, el conocimiento propio de los expertos del tema en cuestión es la base para determinar que la estructura, consistencia y las relaciones entre conceptos de la ontología a evaluar se encuentren apegados a la realidad que se quiere representar.

De igual forma, desde el punto de vista del nive/la evaluación de las ontologías puede identificarse como:

- Capa de datos, léxica o de vocabulario. En este nivel de evaluación de conceptos, instancias, hecho, etc. Que con incluidos en la ontología son observados y evaluados, incluyendo el vocabulario utilizado para representar o identificar estos elementos.

- Jerarquía o taxonomía. La evaluación en este nivel se enfoca en la estructura de la ontología desde el punto de vista de las relaciones del tipo "is-a".

- Otras relaciones semánticas. A diferencia de la evaluación vista desde el nivel de la jerarquía o la taxonomía previamente mencionada, las otras 
relaciones semánticas evalúan de forma separada cualquier otra relación además de las relaciones del tipo "is-a".

- Nivel de contexto o de aplicación. Este tipo de evaluación se refiere a la que se lleva a cabo a la ontología de acuerdo al entorno o sistema en que sea utilizada, ya sea mediante la interacción con otras ontologías o una aplicación que pudiera ser afectada por la utilización de la ontología a evaluar.

- Nivel sintáctico. Evalúa si la ontología es descrita mediante la utilización de un lenguaje formal en particular e identifica las concordancias con los requerimientos sintácticos propios del lenguaje en cuestión.

- Estructura, arquitectura o diseño. En el caso de este nivel de evaluación, es de utilidad cuando se requiere que la ontología satisfaga ciertos parámetros predefinidos.

No todas las aproximaciones o enfoques son compatibles con todos los niveles de evaluación, Brank diseñó una tabla (Tabla 1) que permite identificar las combinaciones posibles entre niveles y enfoques en que pueden ser aplicados cuando existe un proceso de evaluación de ontologías. 


\begin{tabular}{|c|c|c|c|c|}
\hline \multirow[b]{2}{*}{ Nivel } & \multicolumn{4}{|c|}{ Enfoque } \\
\hline & $\begin{array}{l}\text { Ontología } \\
\text { estándar }\end{array}$ & Aplicación & $\begin{array}{l}\text { Fuente de } \\
\text { datos }\end{array}$ & $\begin{array}{l}\text { Hecha por } \\
\text { humanos }\end{array}$ \\
\hline $\begin{array}{l}\text { Capa de datos, léxica o } \\
\text { vocabulario }\end{array}$ & $x$ & $x$ & $x$ & $x$ \\
\hline Jerarquía o taxonomía & $x$ & $x$ & $x$ & $x$ \\
\hline Relaciones semánticas & $x$ & $x$ & $x$ & $\mathrm{x}$ \\
\hline Contexto o de aplicación & & $x$ & & $x$ \\
\hline Sintáctico & $x$ & & & $x$ \\
\hline $\begin{array}{l}\text { Estructura, arquitectura } 0 \\
\text { diseño }\end{array}$ & & & & $x$ \\
\hline
\end{tabular}

Tabla 1. Diferentes aproximaciones y combinaciones en la evaluación de ontologías de acuerdo a Brank

De igual forma Gangemi (Gangemi, Catenacci, Ciaramita, \& Lehmann, 2006) mostró un análisis muy extensivo acerca la evaluación y validación de ontologías, el cual identifica tres dimensiones para su evaluación:

- Evaluación estructural,

- Evaluación funcional y

- Evaluación de su usabilidad. 
Cabe mencionar que dentro de la evaluación funcional se hace un reconocimiento detallado de la evaluación de ontologías a través de la utilización de la ontología en una aplicación, que concuerda con la evaluación mediante aplicación propuesto por Brank como segundo elemento de caracterización de la evaluación de ontologías por su enfoque, situación que será de utilidad posteriormente en el presente trabajo. 


\section{Capítulo 3}

\section{Contexto y trabajos relacionados}

En este capítulo se busca precisar el término de Contexto que forma parte fundamental de nuestra propuesta de tesis, de igual forma se plantea un análisis de diversas propuestas o trabajos relacionados que guardan una similitud con nuestro proyecto y que sirven como una referencia importante.

En primera instancia se analiza el concepto de Contexto desde el punto de vista de los sistemas informáticos en general y más específicamente en los dispositivos móviles, buscando identificar las coincidencias entre las diversas propuestas y consideraciones hechas por los autores analizados, de forma que permita crear una base de referencia para el trabajo propio del proyecto que se presenta en este documento.

En la segunda parte de este capítulo se analizan diversas propuestas que hacen uso del contexto como una forma de mejora u optimización a servicios o 
aplicaciones, identificando las similitudes o coincidencias, así como la diversidad de enfoques que presentan las propuestas.

En el cierre del capítulo encontramos un breve análisis de las coincidencias encontradas en las propuestas de definición del contexto móvil, así como de los trabajos relacionados que fueran analizados. Con esto se crea la base que da soporte en la generación de la propuesta de nuestro proyecto sobre los elementos que debe considerar un contexto en la búsqueda de ser funcional para la mejora de las aplicaciones o servicios móviles.

\subsection{Contexto}

Una aplicación o servicio que considera el contexto se le conoce como aplicación/servicio sensible al contexto (context-aware en inglés). Este término fue discutido por primera ocasión en 1994 por Schillit y Theimer (Schilit \& Theimer, 1994), aunque es relativamente reciente que el concepto se ha vuelto utilizado y demandado principalmente por el auge los dispositivos móviles, en los que el elemento de movilidad genera mayor sentido a la utilización de este componente. 
El contexto en una aplicación o servicio de acuerdo a las ideas propuestas por Schillit y Theimer (Schilit \& Theimer, 1994) se refiere a la información relacionada con las características del dispositivo, la situación geográfica, la hora y las características ambientales del entorno y cómo estos elementos permiten a dicha aplicación o servicio ofrecer una experiencia personalizada o acotada a dicho contexto. De forma complementaria Bellavista y colegas (Bellavista, Corradi, Fanelli, \& Foschini, 2012) mencionaron además que el contexto implica considerar los intereses particulares del usuario y cualquier otro elemento relevante que pueda ser tomado en cuenta con la finalidad de establecer diferencias en la experiencia de uso de las aplicaciones o servicios móviles, propiciando una mejora en la percepción de su utilización ante los usuarios. Gauch y colegas (Gauch, Chaffee, \& Pretschner, 2003) le dan un valor especial a las preferencias del usuario como elemento para la mejora en servicios de búsqueda o navegación web, siendo para ellos este elemento el más relevante a considerar dentro de este ámbito.

Continuando con esta línea nos encontramos a Lathia (Lathia, 2015) que en su propuesta, al igual que Biancalana y colegas (Biancalana, Claudio, Gasparetti, Micarelli, \& Sansonetti, 2013), nos muestran que el contexto debe considerar, además de los servicios basados en la ubicación, de los elementos tales como 
las preferencias, también considerar algunos otros atributos relacionados con el comportamiento del usuario del servicio o aplicación en cuestión, como una especie de perfil ampliado de preferencias del usuario.

Dey (Dey, 2000) consideró que un sistema es sensible al contexto si utiliza el contexto para proveer de información o servicios relevantes para el usuario, donde la relevancia depende de la actividad, situación o necesidades del propio usuario, donde se incluyen los propios intereses del usuario, como lo establecen las propuestas de Bouidghaghen y colegas (Bouidghaghen, Tamine, \& Boughanem, 2011), Missaoiu y colegas (Missaoiu \& Faiz, 2015) y muy similar al trabajo de Bouneffouf (Bouneffouf, Bouzeghoub, \& Gancarski, 2012), tres propuestas que nos muestran la relevancia de los intereses del usuario como factor de contexto con la finalidad de ofrecer una mejora a un servicio o aplicación.

Por otra parte, Chen y Kotz (Chen \& Kotz, 2000) presentan al contexto como el conjunto de estados y configuraciones del entorno que determinan el comportamiento de una aplicación o en el que se produce un evento de aplicación y es interesante para el usuario. Por otra parte, Desmet y colegas (Desmet, Vallejos, \& Costanza, 2007) abordan el uso del contexto como una forma de llevar a cabo modificación de configuraciones o funcionamiento de 
dispositivos, resaltando también la complejidad que requiere llevar a cabo el monitoreo y la consecuente adaptación de la aplicación sensible al contexto.

El contexto es un mecanismo que enriquece la interacción entre los humanos y las computadoras, una premisa descrita por Abowd y colegas (Abowd, y otros, 1999), que finalmente repercute en una mejora de los servicios computacionales que ofrece, a través de este conocimiento del contexto o mejor dicho, de conseguir que una aplicación o servicio sea sensible al contexto. Esta relación entre el contexto y su relevancia como facilitador en la interacción humano computadora también fue descrita por Göker y Myrhaug (Göker \& Myrhaug, 2002), quienes abordaron el tema de la importancia de la personalización como herramienta para satisfacer las necesidades de los usuarios y cómo esta personalización basada en el contexto es una forma conseguir este fin. Por su parte Rios y colegas (Rios, y otros, 2003) consideran que una aplicación sensible al contexto debe ayudar a proveer servicios que cuenten con un valor agregado.

Finalmente, en el caso de Löwe y colegas (Löwe, Mandl, \& Weber, 2012) han visualizado al contexto como cualquier información que puede ser utilizada para 
caracterizar la situación del usuario, una definición mucho más simple que las identificadas por los demás autores pero que se enfoca en reconocer al contexto como el factor preponderante en la mejora de la interacción humano computadora.

Un listado general de las características identificadas en los autores analizados relacionados con el contexto se encuentra en la Tabla 2

\begin{tabular}{|c|c|}
\hline Nivel & Principales características del contexto definido \\
\hline Schillit (1994) & $\begin{array}{l}\text { Información relacionada con el entorno utilizada en la } \\
\text { mejora de la experiencia del usuario }\end{array}$ \\
\hline Bellavista (2012 & Considera los intereses del usuario \\
\hline Gauch (2003) & $\begin{array}{l}\text { Preferencias de usuario en la búsqueda y navegación } \\
\qquad \text { web }\end{array}$ \\
\hline Lathia (2015), Biancalana (2013) & Perfil ampliado del usuario \\
\hline $\begin{array}{l}\text { Dey (2000), Bouidghaghen (2011), Missaoiu } \\
\text { (2015), Bouneffouf (2012) }\end{array}$ & $\begin{array}{l}\text { Utilizan los intereses del usuario como contexto para } \\
\text { mejora de servicios o aplicaciones }\end{array}$ \\
\hline Chen (2000) & $\begin{array}{l}\text { Conjunto de estados y configuraciones del entorno que } \\
\text { determinan el comportamiento de una aplicación }\end{array}$ \\
\hline Desmet (2007) & $\begin{array}{l}\text { Modificación de configuraciones o funcionamiento de } \\
\text { dispositivos }\end{array}$ \\
\hline Abowd (1999) & $\begin{array}{l}\text { Mecanismo que enriquece la interacción entre humano y } \\
\text { computadora }\end{array}$ \\
\hline Göker (2002) & $\begin{array}{l}\text { Personalización como herramienta para satisfacción de } \\
\qquad \text { necesidades de los usuarios }\end{array}$ \\
\hline Rios (2003) & Como obtener servicios de valor agregado \\
\hline Löwe (2012) & $\begin{array}{l}\text { Cualquier información utilizada para caracterizar al } \\
\text { usuario }\end{array}$ \\
\hline
\end{tabular}

Tabla 2. Listado de las diversas características de contexto de acuerdo con los autores analizados 
La definición o identificación del contexto es entonces un elemento importante en las aplicaciones y servicios modernos, situación que se vuelve más evidente cuando se trata de dispositivos móviles que hacen uso de dichas aplicaciones o servicios. Por sus propias características, los dispositivos móviles se encuentran en situaciones cambiantes a cada momento, en las que se vuelve relevante la identificación del contexto, con la oportunidad de mejorar las aplicaciones y servicios que son utilizados en dicho dispositivo, buscando finalmente que estos sean más relevantes o adecuados para el usuario.

\subsection{Trabajos relacionados}

En términos generales se han encontrado diversas propuestas relacionadas con esta tesis, siendo el caso de algunas de ellas que hacen utilización de ontologías para la definición del contexto móvil, por lo que pueden ser consideradas como cercanas a lo buscado en la presente tesis, una de ellas es el Spice Project (Su, Alapnes, \& Shiaa, 2009), al igual que la propuesta del MYMOSE Project (MYMOSE, My Mobile Search Project, 2010) (Cantera Fonseca, Guido García, \& Vegas Hernández, 2008), una propuesta más realizada por Poveda y colegas (Poveda Villalon, Suárez-Figueroa, García-Castro, \& Gómez-Pérez, 2010), igualmente la Ontología de Contexto de Entrega del W3C (Delivery Context 
Ontology, 2017), la propuesta de un Modelo de Ontología Multidimensional para soporte de Sistemas Sensibles al Contexto realizada por Rodriguez y colegas (Rodríguez, Bravo, \& Guzmán, 2013), el Entorno Flexible de Gestión de Servicios Web Semánticos denominado, FLAME2008 propuesto por Weißenberg y colegas (Weißenberg, Voisard, \& Gartmann, 2004) y la Context Broker Architecture (COBRA-ONT) propuesta por Chen y colegas (Chen, Finin, \& Joshi, 2003).

De la misma forma se encontraron el proyecto AWARE de Ferreira y colegas (Ferreira, Kostakos, Dey, \& K., 2015) que ofrece un marco de instrumentación para el contexto móvil, pero descartando la utilización de ontologías, las que son substituidas por el uso de un sistema gestor de bases de datos, similar a la propuesta de Löwe y colegas (Löwe, Mandl, \& Weber, 2012) que define un servicio de soporte para el contexto, aunque no se determina como es que este contexto es representado.

En la siguiente parte de este capítulo se hace una revisión de las propuestas anteriormente mencionadas, con la finalidad de identificar las diferencias y 
coincidencias, así como las ventajas y/o desventajas que presentan cada una de las propuestas analizadas.

\subsubsection{Ontología móvil del Spice Project}

La Ontología Móvil definida en el Spice Project ${ }^{1}$ (Villalonga, y otros, 2009) es una propuesta generada desde en el marco del European Community's Sixth Framework Programme, creada como un marco de referencia para servicios móviles, en el que el uso de las ontologías es esencial para obtener una visión compartida y acordada en la definición de los elementos que se requerían para el proyecto. La premisa es la elaboración de una ontología móvil estandarizada para cualquier necesidad relacionada con los dispositivos móviles. La ontología fue generada utilizando el Lenguaje de Ontología Web.

La arquitectura de la ontología SPICE está estructurada en tres niveles de ontologías, un nivel principal o núcleo que incluye la ontología base, otro nivel de sub-ontologías que incluye todas las definiciones de ontologías de funciones específicas y que hereda desde la ontología núcleo, finalmente un nivel de

\footnotetext{
${ }^{1}$ http://www.ist-spice.org/
} 
agrupamiento de todas las ontologías externas que son referenciadas o utilizadas.

El conjunto de ontologías de SPICE están enfocadas a los entornos móviles, el concepto fundamental es el establecer una colaboración estrecha entre usuario, dispositivo y los servicios. Existen algunas definiciones de clases con intereses similares a lo que se ha identificado como necesidad para nuestro proyecto, aunque el contexto de usuario y de entrega tiene diferentes prioridades y enfoque a lo que se ha considerado como elementos necesarios para una definición de contexto que permita optimizar servicios o aplicaciones móviles, como es la propuesta de este proyecto.

- La ontología de contexto del proyecto SPICE contempla más de 200 definiciones de clases, la mayoría de estas son esencialmente tomadas de fuentes externas de ontologías, el proyecto Amigo (Janse, 2008) y otros proyectos europeos relacionados a las definiciones del contexto del dispositivo móvil dentro de los hogares, que resulta no aplicable cuando el usuario se encuentra en movimiento en el exterior de su hogar. 
- Las definiciones de contexto contienen clases y propiedades básicas relacionadas con la ubicación, basadas primordialmente en la posición geográfica desde un punto de vista de interiores de edificios, apoyados inclusive a través de etiquetas RFID, lo que limita la obtención de la ubicación a los entornos que cuenten cobertura de dicha infraestructura.

- Las definiciones de contexto se concentran en las características de los dispositivos dejando de lado el entorno del propio dispositivo y el usuario. Un ejemplo son las definiciones de clases como "Speaker" (altavoz) que es derivada de la clase "OutputDevice" (dispositivo de salida).

Este esfuerzo se encuentra perfectamente estructurado e implica la colaboración de diversos equipos de trabajo, aunque el enfoque de movilidad se encuentra acotado a espacios físicos que cumplen con características específicas que condicionan la utilización de la ontología para otros fines diferentes para los que fue creada. Otro aspecto es la nula consideración del perfil o preferencias del usuario, limitándose a la localización física como medio para establecer el contexto de soporte para las aplicaciones sensibles al contexto. 
En esta propuesta la fortaleza radica en el establecimiento de una base común que puede ser utilizada por diversas aplicaciones o servicios, con las debilidades previamente mencionadas

\subsubsection{Ontologías del Proyecto MYMOSE}

En el caso de las ontologías propuestas por el proyecto MYMOSE² se encuentra otro punto de vista, ya que las ontologías fueron diseñadas para la mejora de la búsqueda web desde dispositivos móviles, desde el punto de vista de dos componentes básicos:

- Uno relacionado con los conceptos de dominio que el sistema puede utilizar como elementos de optimización para la consulta, contiene asociaciones entre términos y el contexto en el que los términos pueden ser permitidos. De igual forma contiene propiedades relacionadas con los términos, por ejemplo, el término "restaurant" está relacionado con "japonés", "italiano" y "mexicano" ya que son tipos de restaurantes. Este elemento está conceptualizado como la ontología de dominio en el caso de este proyecto.

\footnotetext{
${ }^{2}$ http://mymobileweb.morfeo-project.org/
} 
- Otro componente es lo relacionado con la definición del contexto. En este es donde se encuentra la conceptualización del contexto que será utilizado para la mejora de la búsqueda web a través de la definición de tres ontologías, la ontología del contexto de entrega (similar a la definida por el W3C), la ontología del perfil del usuario y finalmente la ontología de localización.

Las ontologías del proyecto MYMOSE consideran la clasificación del dispositivo o contexto de entrega, utilizando como base las especificaciones que fueron determinadas por el trabajo de la Iniciativa de la Web Móvil del Consorcio Mundial de la Web (W3C Mobile Web Initiative, 2017).

Esta ontología presenta una estructura y diseño que cumple con los requerimientos para los que fue desarrollada, sus principales fortalezas se encuentran en la definición del contexto de entrega y lo detallado de las características técnicas y físicas del dispositivo móvil. Aun cuando el contexto móvil que se define en este proyecto se encuentra enfocado en la optimización de las búsquedas web (Figura 2), existen elementos que no fueron bastante 
desarrollados y explotados, tales como el perfil del usuario y sus intereses o los conceptos relacionados con la movilidad como un factor de relevancia.

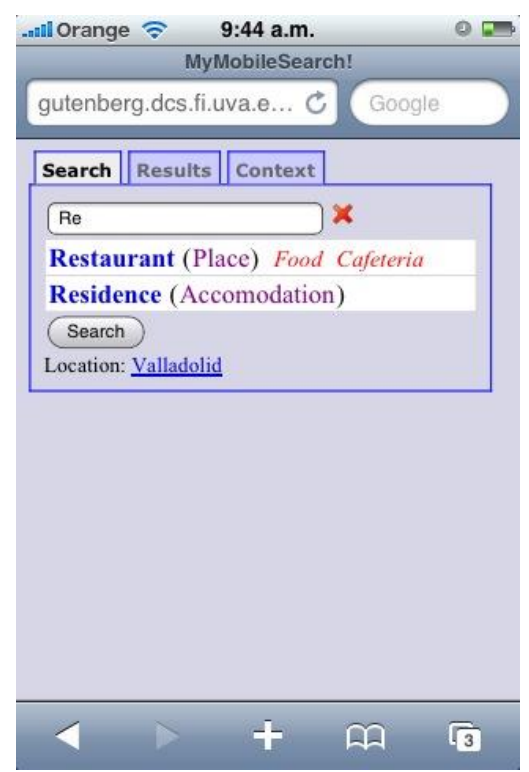

Figura 2 Interface del recomendador de palabras del proyecto MYMOSE

De forma similar, Sieg y colegas (Sieg, Mobasher, \& Burke, 2007) propusieron el uso de ontologías para la creación de perfiles de usuarios, los cuales sirven como contexto para la mejora de las búsquedas web. 


\subsubsection{Ontología de Contexto de Entrega del W3C}

Un gran esfuerzo realizado por el Consorcio del World Wide $W^{3} b^{3}$ se ve reflejado en la definición de la Ontología de Contexto de Entrega (Delivery Context Ontology, 2017) que fuera propuesta inicialmente por Cantera y Lewis (Cantera Fonseca \& Lewis, 2010). En este proyecto el enfoque de la utilización de la ontología está relacionado con las características propias de los dispositivos móviles en los que será entregado contenido, similar a la propuesta anterior, incluyendo las características que pudieran ser relevantes para la mejor experiencia de usuario al desplegar y adaptar el contenido que en el dispositivo es mostrado. Este trabajo refleja un claro entendimiento de la relevancia del reconocimiento del contexto en el que será entregada la información.

Con una estructura bastante bien diseñada, las clases y propiedades que incluyen las particularidades del dispositivo, el software utilizado para acceder a los servicios y las características propias de la red que proveed la conectividad, entre otros. A través de 8 clases base, cada concepto es

\footnotetext{
${ }^{3}$ https://www.w3.org/ (World Wide Web Consortium)
} 
exhaustivamente analizado para finalmente ser modelado en esta ontología (Figura 3).

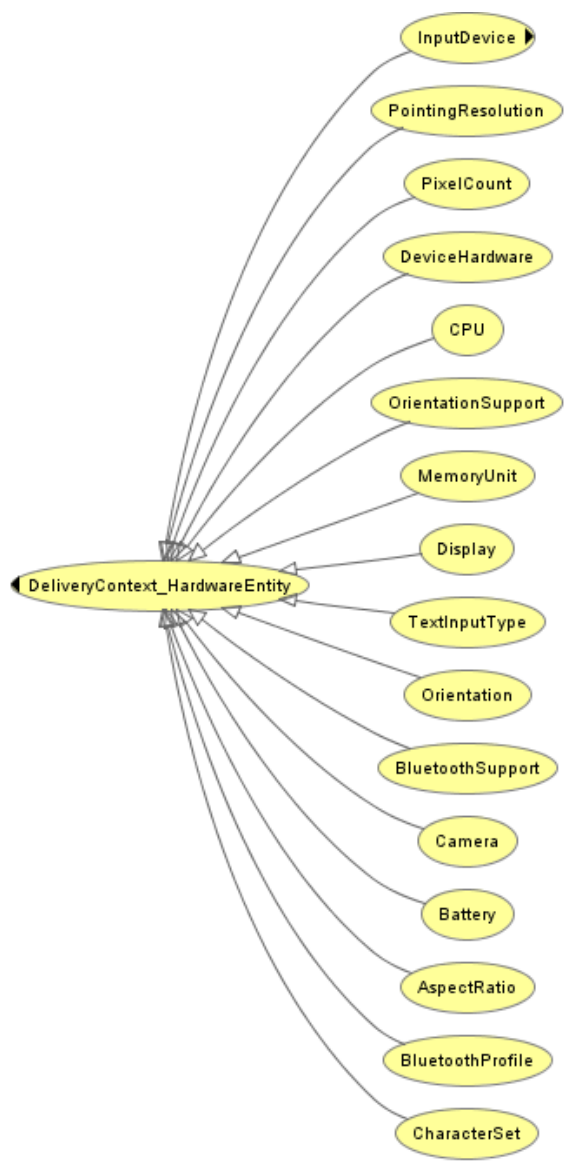

Figura 3 Ejemplo de la Ontología de Contexto de Entrega del W3C

Por ejemplo, la clase que hace referencia a la ubicación (Figura 4) contiene subclases que describen la información más obvia, como las coordenadas geográficas (GeoCoordinates), pero de igual forma contiene clases para 
modelar conceptos como el método para obtenerla o el proveedor de la ubicación.

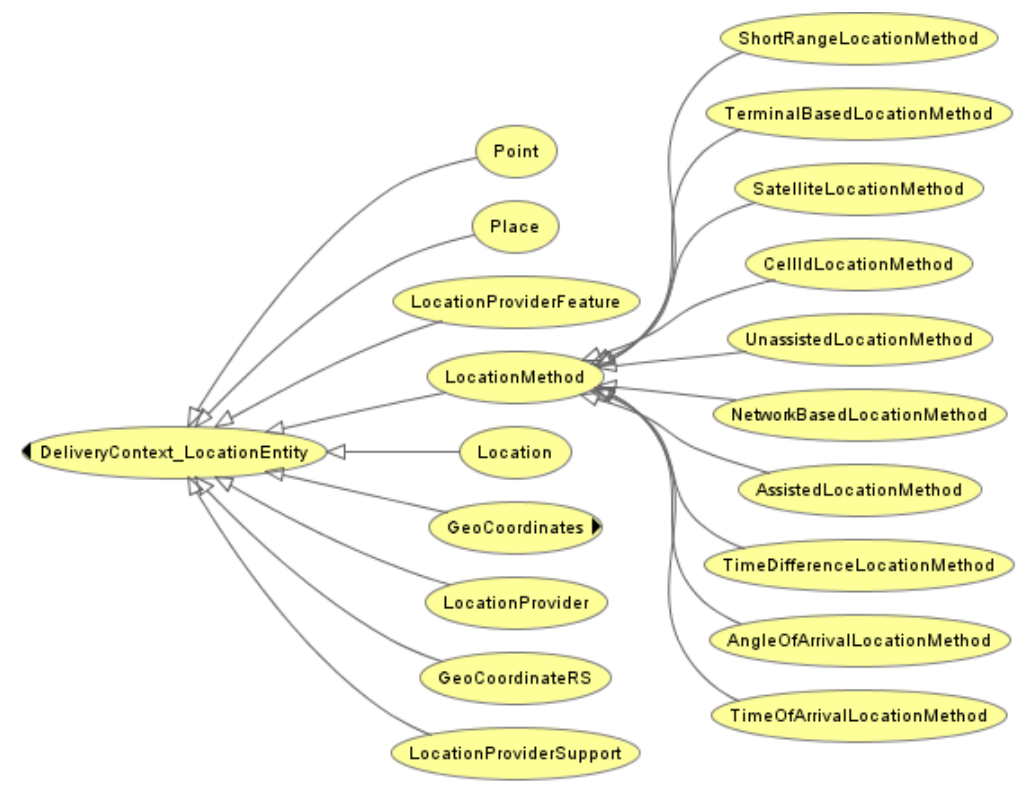

Figura 4 Descripción de la clase referente a la ubicación en la Ontología de Contexto de Entrega del W3C

Aun cuando la ontología describe perfectamente los conceptos relacionados con el dispositivo móvil, que es su principal fortaleza, el contexto se limita a las características propias del dispositivo y no toma en cuenta elementos que pudieran ser considerados como relevantes y que, en otras ontologías de 
definición de contexto móvil si son consideradas, tales como el entorno de utilización del dispositivo o las preferencias del usuario.

El enfoque de esta definición del contexto es entonces más relacionado con el dispositivo, sus capacidades y como estas pueden resultar relevantes al desplegar contenido.

\subsubsection{Ontología de Contexto para Entornos Móviles (mIO!)}

La Ontología de Contexto para Entornos Móviles (mlO!) ${ }^{4}$ creada por Poveda y colegas (Poveda Villalon, Suárez-Figueroa, García-Castro, \& Gómez-Pérez, 2010) representa un gran esfuerzo para establecer una ontología para entornos móviles.

La ontología mlO! contiene 11 subdominios para definir el contexto en dispositivos móviles, los cuales se enfocan a elementos como:

- El dispositivo

- El entorno
- El rol

- El servicio

\footnotetext{
${ }^{4}$ http://mayor2.dia.fi.upm.es/oeg-upm/index.php/en/ontologies/82-mio-ontologies/
} 
- La interfaz

- La Ubicación

- La red de datos

- El proveedor del servicio
- La fuente

- El tiempo y

- El usuario

Está conformada a su vez por 433 clases, 277 propiedades, 156 propiedades de tipos de datos, 364 instancias, lo que le permite cubrir muchos elementos previamente no considerados en otros trabajos, tales como los subdominios del proveedor y la fuente, ofreciendo además una gran diversidad de elementos que hacen de esta estructura muy completa, lo que es una fortaleza, pero a su vez genera una estructura muy compleja. Un ejemplo de esta complejidad puede ser visualizado (Figura 5) al analizar la taxonomía relacionada con las características del dispositivo, que ofrece una gran variedad de elementos. 


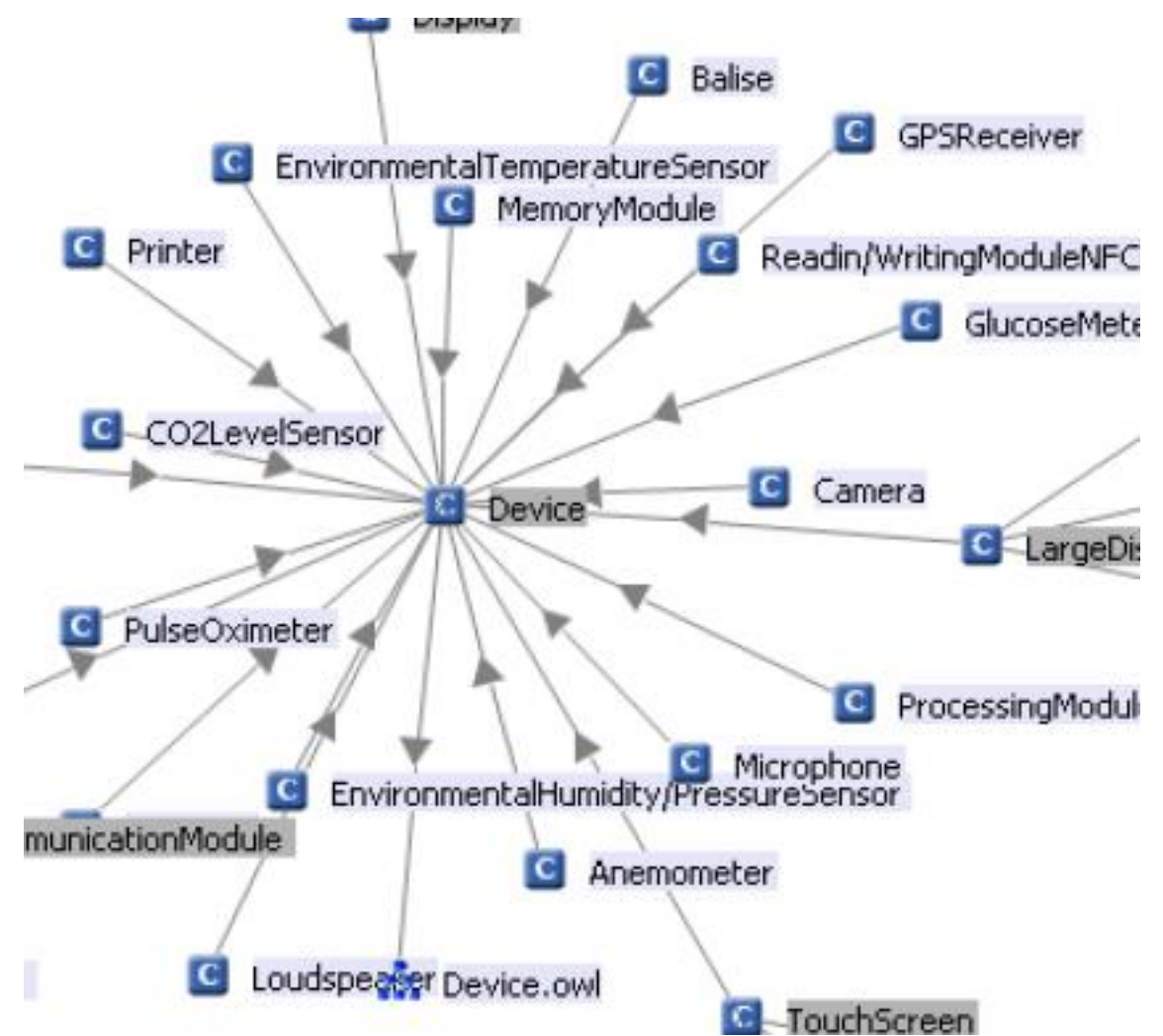

Figura 5 Ejemplo de la taxonomía relacionada con los dispositivos de la ontología m/O!

Cabe mencionar también que en este caso y respecto a la Ontología de Contexto de Entrega del W3C previamente descrita, la descripción del contexto es mucho más descriptiva y no tan limitada solamente a las características del dispositivo, sino que tiene una gran fortaleza en la consideración de otros elementos del entorno, aunque igualmente el perfil del usuario o sus preferencias no juegan un papel relevante en la estructura de la ontología. 


\subsubsection{Modelo de Ontología Multidimensional para soporte de Sistemas Sensibles al Contexto.}

En esta propuesta de Rodríguez y colegas (Rodríguez, Bravo, \& Guzmán, 2013) considera la creación de un modelo de ontología multidimensional para dar soporte a sistemas sensibles al contexto a través de tres diferentes aspectos:

- El contexto del usuario

- El dominio de la aplicación

- Los servicios semánticos web disponibles

La estructura multidimensional está diseñada para funcionar modular y dinámicamente, buscando que se facilite la adaptación y actualización de la estructura que define el contexto, para que finalmente pueda ser utilizada por las aplicaciones de los servicios semánticos web registrados en su plataforma.

En esta propuesta se presenta el caso de uso mediante un sistema de recomendación de servicios para el usuario, el cual se basa en el contexto y fundamentalmente en las preferencias del usuario. Para hacer posible las recomendaciones, un conjunto de reglas de inferencia lleva a cabo el análisis 
del contexto y sugiere al usuario el servicio a utilizar, de los servicios que se encuentran registrados en el sistema.

Esta propuesta es la que más cercanía guarda respecto a la del presente proyecto, siendo las principales diferencias que está dirigida a la recomendación por medio del contexto (básicamente las preferencias) de servicios, que deben ser previamente registrados, mientras que los experimentos que nosotros hemos realizado hacen la recomendación de palabras o la entrega de mensajes de acuerdo con el contexto del usuario/dispositivo.

\subsubsection{Entorno Flexible de Gestión de Servicios Web Semánticos.}

El Entorno Flexible de Gestión de Servicios Web Semánticos denominado, FLAME2008 propuesto por Weißenberg y colegas (Weißenberg, Voisard, \& Gartmann, 2004), fue un prototipo de la integración de una plataforma personalizada de servicios web especialmente diseñada para las Olimpiadas de Beijing de 2008. En este proyecto, los servicios web y el contexto del usuario eran elementos fundamentales. 
Esta plataforma estaba basada en la definición de perfiles de usuarios y servicios, administrando el emparejamiento entre ambos elementos para mostrar servicios que hicieran mayor sentido de acuerdo las características del usuario.

El perfil del usuario era una definición semántica de preferencias y la ubicación, aunque se mencionaba que podía contener alguna otra información obtenida por otros medios, aunque no se declaró qué tipo de información, la forma en que podía ser obtenida, procesada o inclusive asignada al perfil del usuario.

De forma similar, los servicios contaban con un perfil definido de forma semántica y eran marcados o etiquetados por los proveedores definiendo o utilizando perfiles de situación existentes. Los perfiles de situación estaban vinculados con el perfil del servicio para definir las características sobre en qué situación particular el servicio sería adecuado.

Una vez que los servicios y situaciones eran definidos, y el perfil del usuario era identificado, el sistema estaría ofreciendo servicios que cumplieran con el contexto definido para el usuario. 
En este caso en particular, la plataforma brindaba un soporte muy bien estructurado para la definición del perfil de los usuarios, aunque el resto de elementos del contexto no eran considerados como un factor preponderante 0 de alto valor y consideración como elementos para la definición del contexto.

\subsubsection{Context Broker Architecture (COBRA-ONT)}

Es una propuesta llevada a cabo por Chen ${ }^{5}$ y colegas (Chen, Finin, \& Joshi, 2003) que presenta una ontología desarrollada para soportar sistemas sensibles al contexto.

En su propuesta se establece a creación de un sistema intermediario que tiene la función de gestionar el contexto entre agentes y dispositivos, soportado por medio de ontologías y que tiene la finalidad de dar a los sistemas el soporte de acción sensible al contexto.

\footnotetext{
${ }^{5}$ http://daml.umbc.edu/ontologies/cobra/
} 
El proyecto se diseñó pensando en espacios inteligentes que cuentan con etiquetas inteligentes, sensores y dispositivos, los que proporcionan la información de contexto que, gestionada por medio del agente, proporcionará información relevante a las aplicaciones.

La aplicación de esta propuesta es muy específica, enfocada a espacios inteligentes como oficinas, casas o vehículos que cuenten con las condiciones requeridas para su funcionamiento, tales como dispositivos, etiquetas inteligentes y sensores con los que se pueda interactuar, lo que puede representar una limitante en condiciones generales, pero que a su vez permitió mostrar que una ontología puede ser una poderosa herramienta para la creación de aplicaciones sensibles al contexto.

\subsubsection{AWARE: Marco de Instrumentación de Contexto Móvil}

Este es quizás el más sofisticado esfuerzo por crear una herramienta para la gestión de contexto en dispositivos móviles, con la finalidad de dar soporte a aplicaciones o servicios. 
La propuesta de Ferreira ${ }^{6}$ y colegas (Ferreira, Kostakos, Dey, \& K., 2015) busca generar un marco de soporte para la creación de herramientas de utilidad para la definición, representación y utilización del contexto en aplicaciones y servicios móviles.

El desarrollo de este proyecto es muy completo y han considerado las formas en que las aplicaciones o servicios pueden sacar provecho del contexto identificado. Aunque uno de sus posibles aspectos a mejorar es la forma en que el contexto es representado y manipulado, ya que se ha hecho utilización de un sistema gestor de bases de datos que no permite visualizar el aspecto de escalabilidad, al contar con estructuras rígidas de manipulación de la información.

\subsubsection{Context Directory}

La propuesta del Context Directory generada por Löwe y colegas (Löwe, Mandl, \& Weber, 2012) consiste en una arquitectura para recuperar el contexto en dispositivos móviles, representar dicho contexto que posteriormente puede ser

${ }^{6}$ http://www.awareframework.com/science/ 
interpretado y adaptado, con la finalidad de establecer una base en que las aplicaciones puedan hacer uso de dicho contexto.

No quedan bien establecidos los mecanismos propuestos para la representación del contexto, sólo se menciona que utilizan un modelo de llave/valor pero no establece con claridad en la forma en que este contexto es almacenado ni cómo podría ser o no fácilmente actualizable, escalable o aprovechado por diversas aplicaciones o servicios en los dispositivos móviles.

También como aspecto particular de esta propuesta, los elementos que considera como relevantes para el contexto en dispositivos móviles no quedan del todo establecido por lo que no se logra identificar cómo es posible que sean aprovechados en situaciones específicas.

En resumen, se encontraron diversas propuestas para el desarrollo de ontologías que tienen como finalidad la definición del contexto en el ámbito de los dispositivos móviles, pero todas también tienen en común que fueron diseñadas para una aplicación particular, no consideran el uso de la ontología y 
el contexto que define como una herramienta para un uso generalizado de aplicaciones de diversos ámbitos dentro de los dispositivos móviles.

\begin{tabular}{|c|c|}
\hline Proyecto analizado & Características principales \\
\hline SPICE & Enfocada a entornos móviles en espacios establecidos \\
\hline MYMOSE & $\begin{array}{c}\text { Contexto de entrega especialmente diseñado para } \\
\text { búsquedas web }\end{array}$ \\
\hline Contexto de Entrega & $\begin{array}{c}\text { Especialmente diseñada para considerar las } \\
\text { características físicas del dispositivo de entrega de la } \\
\text { información }\end{array}$ \\
\hline Contexto para Entornos Móviles mIO! & $\begin{array}{l}\text { Gran detalle en la definición del contexto, tanto en el } \\
\text { dispositivo como el entorno }\end{array}$ \\
\hline Ontología Multidimensional & $\begin{array}{l}\text { Recomendación de servicios en base al contexto, } \\
\text { considera las preferencias del usuario }\end{array}$ \\
\hline Entorno Flexible de Gestión FLAME2008 & Identifica servicios de acuerdo al perfil del usuario \\
\hline COBRA & $\begin{array}{c}\text { Gestor de contexto para interacción entre espacios físicos } \\
\qquad y \text { aplicaciones }\end{array}$ \\
\hline AWARE & $\begin{array}{c}\text { No escalable, utiliza un gestor de base de datos para } \\
\text { definir, representar y el contexto en aplicaciones y } \\
\text { servicios }\end{array}$ \\
\hline Context Directory & $\begin{array}{c}\text { No escalable, esquema llave/valor para almacenar la } \\
\text { información del contexto }\end{array}$ \\
\hline
\end{tabular}

Tabla 3. Lista de las diferentes propuestas de ontologías analizadas en el capitulo

\subsection{Resumen del capítulo}

Comenzamos el capítulo haciendo un estudio sobre el concepto de Contexto desde el punto de vista informático que diversos autores han expuesto, el cual 
nos permitió identificar las características comunes y demostrar la importancia que representa la utilización del contexto en las aplicaciones o servicios actuales, sobre todo desde la visión propia que implican los dispositivos móviles.

En la segunda parte del capítulo mostramos algunos proyectos que guardan alguna similitud con la propuesta que muestra el presente documento, son propuestas que a pesar de tener diversos objetivos entre si contaban con diversas similitudes que al igual nos permitieron establecer el marco de referencia para nuestro proyecto.

En base al análisis de las definiciones de contexto y las propuestas de trabajos relacionados con la utilización del contexto como un factor de relevancia en la mejora u optimización del funcionamiento de servicios o aplicaciones, se pudieron identificar los grandes elementos o grupos de elementos que son compartidos por la mayoría de los estudios y propuestas en este ámbito, los cuales se pueden agrupar como sigue:

- Características del dispositivo, son todos aquellos componentes del contexto que reflejan información sobre el dispositivo y sus 
características propias, tales como los elementos del hardware, software y conectividad.

- La situación geográfica, son los elementos relacionados con la ubicación física del dispositivo, aunque existen marcadas diferencias en el punto de vista observado por las diversas propuestas, la ubicación física es un factor relevante,

- La hora, este también es un elemento de constante aparición en las propuestas y que se utiliza de forma muy similar en todas ellas,

- Las características ambientales del entorno, es otro elemento de constante aparición, aunque al igual que la situación geográfica, son diversos componentes de este elemento los que son considerados en las diversas propuestas,

- Los intereses particulares del usuario, un elemento menos común en las referencias, pero que de igual forma aparece en varias de las menciones del contexto, aunque cabe mencionar que es uno de los factores que marca una diferencia importante cuando se trata de brindar al usuario un valor agregado más notable, desde su punto de vista.

- Características del movimiento del usuario/dispositivo, fue el elemento que menos apareció en las referencias y propuestas analizadas, pero 
igual es considerando un elemento que puede aportar un cierto nivel de mejor de los servicios o aplicaciones que hacen uso del contexto.

Estos elementos que son compartidos por lo analizado en este capítulo, serán la base para el siguiente capítulo donde se establece el proceso de creación de la ontología que dará soporte al presente proyecto 


\section{Capítulo 4}

\section{Proceso de desarrollo de la ontología COMoDE}

El presente capítulo describe el proceso seguido para el desarrollo de la ontología Context Ontology for Mobile Devices (COMoDE). Para su desarrollo se utilizaron como fundamento los procesos identificados y mostrados en el capítulo 2 en la sección "Proceso de desarrollo de una ontología", donde se detallan los pasos a seguir para la creación de una ontología.

De igual forma, se utilizó la información recabada por medio del análisis de los trabajos relacionados y que fuera mostrada en el resumen del capítulo 3, a fin de identificar los elementos que han sido utilizados de forma generalizada como definiciones de contexto, con la intención de establecer la estructura inicial para la ontología COMoDE.

Finalmente se utilizó una encuesta entre usuarios para identificar lo que desde su criterio consideran como elementos de valor que debería tomar en cuenta la ontología en proceso de creación, estableciendo que dichos elementos servirán 
como definición del contexto que será utilizada para la mejora de servicios o aplicaciones móviles. Los resultados de la encuesta permiten identificar los elementos prioritarios del contexto de acuerdo a los usuarios, quienes finalmente son los beneficiados por las mejoras en los servicios o aplicaciones móviles.

Además del proceso de creación de la ontología, se describen las herramientas y tecnologías utilizadas para esta tarea, la estructura básica de la ontología, así como algunos ejemplos muy puntuales. En el Apéndice A se puede ver la estructura principal de la ontología.

\subsection{Proceso de desarrollo de la ontología COMoDE}

Como se describió en el capítulo 2, el proceso de desarrollo de una ontología viene descrito en siete pasos mediante los cuales se determina o acota el objetivo de la ontología, su estructura y características. A continuación se detalla el proceso seguido para la creación de la ontología COMoDE, que incluye la verificación llevado a cabo para la estructura base de la ontología. 


\subsubsection{Paso uno: Identificación del dominio de la ontología}

Tal como se describiera en el capítulo 2, el primer paso para el desarrollo de ontologías es el más relevante, ya que permite acotar el sentido propio de la ontología que se desea crear; determina la temática o área de conocimiento que se desea representar, así como la amplitud en que será tratada.

Dentro de este primer paso se dimensiona el alcance de la ontología a crear a través de las preguntas guía que permiten delimitarlo, las cuales son representadas y han sido respondidas en la (Tabla 4), identificando el objetivo inicial de la ontología a crear. 


\begin{tabular}{|c|c|}
\hline $\begin{array}{l}\text { Pregunta guía } \\
\text { (modelo de } \\
\text { desarrollo de Noy } \\
\text { (Noy \& } \\
\text { Mcguinness, 2001)) }\end{array}$ & Respuesta obtenida \\
\hline $\begin{array}{l}\text { ¿Cuál será el dominio } \\
\text { que deberá cubrir la } \\
\text { ontología? }\end{array}$ & $\begin{array}{l}\text { La definición del contexto en dispositivos móviles que puede } \\
\text { ser utilizada por aplicaciones y servicios como una } \\
\text { herramienta de mejora. }\end{array}$ \\
\hline $\begin{array}{l}\text { ¿Cuál será el uso de } \\
\text { la ontología? }\end{array}$ & $\begin{array}{l}\text { Podrá ser utilizada por aplicaciones o servicios en } \\
\text { dispositivos móviles como una herramienta de apoyo para la } \\
\text { mejora de resultados o funcionalidades. }\end{array}$ \\
\hline $\begin{array}{lr}\text { ¿Para qué tipo de } \\
\text { preguntas } & \text { deberá } \\
\text { proveer } & \text { de } \\
\text { información } & \text { la } \\
\text { ontología? } & \end{array}$ & $\begin{array}{l}\text { Deberá ser capaz de brindar información relevante sobre el } \\
\text { contexto del dispositivo móvil o el usuario a las aplicaciones } \\
\text { o servicios que lo requieran, buscando identificar los } \\
\text { elementos básicos que identifican dicho contexto. }\end{array}$ \\
\hline $\begin{array}{ll}\text { ¿Quién } & \text { dará } \\
\text { mantenimiento a la } \\
\text { ontología? }\end{array}$ & $\begin{array}{l}\text { Aunque la ontología estará abierta para uso de cualquier } \\
\text { desarrollador, será utilizada en diversas aplicaciones del } \\
\text { Centro Universitario del Sur (CUSUR) de la Universidad de } \\
\text { Guadalajara, por lo que el seguimiento a su desarrollo y } \\
\text { utilización se dará por el área de desarrollo del CUSUR. }\end{array}$ \\
\hline
\end{tabular}

Tabla 4. Preguntas básicas para la creación de una ontología. 
Como fue descrito, el proceso de creación de ontologías es continuo, en el que existen cambios y ajustes conforme va evolucionando el proyecto, pero este primer paso es el que permite dar mayor claridad sobre el objetivo, límites y utilidad de la ontología a diseñar.

En este paso se obtiene como resultado información que sirve para determinar el objetivo, alcance y expectativas claras esperadas para la ontología, lo que permite tener mayor claridad y soporte para los siguientes pasos del desarrollo de la ontología.

\subsubsection{Paso dos: Verificación de ontologías existentes}

Siguiendo con el proceso de creación de la ontología COMoDE, en el segundo paso se llevó a cabo una revisión de ontologías para definición de contexto en dispositivos móviles o que tuvieran alguna similitud con este concepto. Tal y como se mencionó en el capítulo 3, se han encontrado proyectos que tienen algún nivel de aproximación con el planteado por el presente proyecto; en los proyectos encontrados se identificaron diversas orientaciones, complejidades y objetivos, los cuales ya han sido descritos en el capítulo mencionado. 
Como resultado del proceso de revisión y análisis de las ontologías existentes, encontramos un conjunto de elementos que aparecen de forma común y que no son específicos de alguno de los proyectos en particular, los cuales podríamos considerar como los elementos fundamentales o elementos base.

Los elementos descubiertos podrian agruparse en seis grandes grupos o conjuntos de elementos de la ontología, los que describen un área en particular del dominio que se desean representar con la ontología COMoDE, estos grupos son:

1. Caracteristicas del dispositivo y la red. Los elementos de este grupo identifican valores relacionados con las características del equipo como la resolución de la pantalla, la compatibilidad del navegador o los tipos de sensores con que cuenta. De igual forma se identifican características propias de la red que utiliza el dispositivo, tal como WiFi o 4G, entre otros. Todos estos conceptos son elementos que tienen un posible valor para ser considerados como contexto con utilidad para un servicio o aplicación móvil, por lo que inicialmente no han sido considerados detalles más específicos del dispositivo como la carga de la batería o la resolución de la cámara. 
2. Preferencias del usuario. En este grupo se identifican las características relacionadas con las preferencias del usurario, aquí es donde se perfilan los elementos que permiten identificar al usuario en particular.

3. Situación física. En este conjunto de elementos se encuentran los relacionados con la situación particular del dispositivo, tales como la ubicación y coordenadas, entre otros.

4. Circunstancias y condiciones temporales. Esta sección se refiere a todos los elementos que tienen relación con las características relacionadas con el tiempo, tales como la fecha, hora, día de la semana o estación del año, entre otros.

5. Circunstancias y condiciones del entorno. Aquí se encuentran agrupados los elementos que tienen que ver con el entorno externo al dispositivo, tales como las condiciones del clima, la temperatura, entre otros.

6. Características del movimiento del usuario. Finalmente, este grupo de elementos corresponde con los términos relacionados con la descripción del movimiento del usuario/dispositivo, tales como velocidad, la dirección, entre otros. 
Estos grupos o conjuntos de elementos para la ontología COMoDE fueron evaluados a través de una encuesta con usuarios para identificar si se considera que son los adecuados e inclusive para priorizar entre estos grupos.

Los resultados de le encuesta permiten determinar si, desde el punto de vista de los usuarios, los elementos que se han considerado para identificar el contexto en dispositivos móviles son oportunos o acertados.

\subsubsection{Encuesta para validación de los grupos de elementos base}

Una encuesta es un conjunto formal de preguntas desarrolladas para obtener información de los entrevistados, en este caso intenta evaluar si la agrupación y clasificación de los elementos base a utilizar para el desarrollo de la ontología podrían ser considerados como elementos que representan el contexto desde el punto de vista del usuario final.

Se determinó mantener la encuesta lo más reducida posible con la finalidad de evitar que se convirtiera en una tarea tediosa para el usuario, lo que finalmente repercute en la calidad de los resultados obtenidos. La encuesta se dividió en 8 secciones: las primeras dos secciones fueron consideradas para realizar la 
definición del perfil de los usuarios de la encuesta, buscando obtener los diferentes grupos de usuarios y sus características, así como datos que permitieran identificar las características del uso de la conectividad a Internet de forma móvil. Las siguientes seis secciones permitieron evaluar los conceptos relacionados con la definición del contexto para los usuarios móviles.

Para la encuesta se diseñaron 46 preguntas agrupadas de la siguiente forma:

- 6 preguntas para definir el perfil del participante en la encuesta,

- 7 preguntas para determinar las características del uso de Internet móvil entre los usuarios encuestados,

- 8 preguntas relacionadas con las características del dispositivo y la red,

- 4 preguntas relacionadas con conceptos referentes a el perfil de usuario,

- 5 preguntas para evaluar los conceptos relacionados con la situación física,

- 5 preguntas con conceptos relacionados con las circunstancias y condiciones temporales,

- 4 preguntas más para evaluar los conceptos referentes a las circunstancias y condiciones del entorno,

- Finalmente, 4 elementos más asociados con los conceptos referentes a las características del movimiento. 
El listado completo de las preguntas en sus versiones en inglés y en español se encuentra en el Apéndice B del presente documento.

Al inicio de la encuesta los usuarios visualizaron una introducción que de forma clara y precisa indicaba el objetivo de la encuesta y cómo el contexto podría influir en los resultados obtenidos en aplicaciones y servicios en dispositivos móviles. La encuesta fue diseñada en español e inglés como lenguajes de soporte, pudiendo elegir el propio usuario el lenguaje con el que deseaba trabajar desde el inicio de su participación.

La encuesta fue aplicada a través de una plataforma en línea, en la que se invitó a participar a personas de todo el mundo por medio de invitaciones expresas vía correo electrónico, blogs, microblogging y redes sociales. Esta forma de invitar tenía como objetivo que participaran personas que tienen conocimiento y hacen uso de aplicaciones y servicios para usuarios con algún nivel de entendimiento de la tecnología. 
Para la encuesta se utilizó la aplicación para encuestas Lime Survey ${ }^{7}$, que es un software de uso libre que funciona como servidor para la administración de encuestas en línea. La aplicación fue instalada y quedó operacional en un equipo del Departamento de Ciencias Computacionales de la Universidad de Valladolid, disponible durante tres semanas para ser atendida por las personas que fueron invitadas.

Para el diseño de la encuesta se consideró que las primeras dos secciones serían de utilidad para identificar el perfil del usuario que está participando. El perfil básico del usuario incluyó los siguientes elementos:

- Edad: Un ítem que permitía identificar la edad del encuestado por medio de rangos de edades, los cuales se distribuyeron como menores de 25 años, entre 25 y 39 años, y 40 años o más.

- Sexo: Ítem para identificar entre hombre o mujer de los participantes.

- Nivel de estudios: Permitió identificar entre los diversos niveles de estudios de los participantes, con opciones como secundaria, bachillerato, universidad o posgrado.

\footnotetext{
${ }^{7}$ https://www.limesurvey.org/
} 
- Estudiante o trabajador relacionado con las ciencias computacionales: En este ítem se pretendía identificar si el encuestado se encuentra relacionado con las ciencias computacionales ya que podría ser un factor que implicara alguna tendencia en el resultado.

La segunda sección relacionada con el perfil del usuario encuestado contenía preguntas relacionadas con los hábitos relacionados con el entorno móvil y la utilización del acceso a Internet, identificando al usuario desde los siguientes aspectos:

- Servicios de Internet utilizado en equipo de escritorio: Aquí se buscó identificar los servicios que más comúnmente son utilizados por el usuario cuando se encuentra en un entorno de un equipo de escritorio, tales como la búsqueda web, correo electrónico, blogs, etc.

- Perfil de utilización de conexión móvil: Un conjunto de preguntas en las que el usuario detalló si hacía uso de la conexión a Internet desde dispositivos móviles, así como la frecuencia y el tipo de uso.

- Servicios de Internet en dispositivos móviles: Permitió identificar las diferencias de uso entre los dispositivos móviles y los equipos de escritorio. 
- Tipo de contenido: Sirvió para identificar el tipo de contenido que el usuario accede desde los dispositivos móviles.

- Intención de la utilización a futuro del servicio de Internet desde dispositivos móviles

- Identificar si el usuario considera que los servicios en los dispositivos móviles que consideran el contexto podrían ser de utilidad. Es una pregunta expresamente aplicada para identificar la disposición del usuario para utilizar aplicaciones o servicios en dispositivos móviles que contemplan una mejora a través de la consideración del contexto.

Las siguientes seis secciones contenían preguntas para evaluar los términos relacionados con el contexto, agrupados en los 6 grandes grupos de elementos que consisten en:

- Características del dispositivo y la red,

- Conceptos referentes a el perfil de usuario,

- Conceptos relacionados con la situación física,

- Conceptos relacionados con las circunstancias y condiciones temporales,

- Conceptos referentes a las circunstancias y condiciones del entorno,

- Conceptos referentes a las características del movimiento 
En cada grupo se presentaron términos o elementos más representativos, los cuales fueron calificados para determinar desde el punto de vista del usuario acerca de su importancia, se utilizó una escala del tipo Likert en la que las opciones a elegir consistían en valores del 1 al 5 puntuados de la siguiente forma:

1. Totalmente desacuerdo

2. Principalmente en desacuerdo

3. Indiferente

4. Principalmente de acuerdo

5. Totalmente de acuerdo

Al final de cada grupo de conceptos evaluados se introdujo una pregunta opcional abierta con la finalidad de recibir como respuesta elementos que el usuario considera como apropiados y que no vio reflejados en las propuestas mostradas.

Con la finalidad de no extender demasiado la encuesta y provocar el desinterés de los participantes, sólo algunos conceptos representativos fueron utilizados en cada grupo de conceptos, el resto de los términos o conceptos no evaluados 
tienen una relación jerárquica con los elementos evaluados. La encuesta completa puede ser encontrada en línea8.

\subsubsection{Resultados de la encuesta}

Como participación a la encuesta para determinar la viabilidad de utilizar los grupos de elementos propuestos para ser considerados como parte del contexto en dispositivos móviles, se recibieron un total de 60 participaciones desde distintas partes del mundo, por lo que la encuesta nos permitió obtener algunos datos que resultaron interesantes. Los resultados generales obtenidos de la encuesta se pueden visualizar en línea para su consulta?

\subsubsection{Perfil de los encuestados}

Las preguntas relacionadas con la obtención del perfil de los participantes en la encuesta nos proporcionaron información que permite identificar las características de los encuestados, por ejemplo, nos aportaron información que

\footnotetext{
${ }^{8}$ http://sites.google.com/site/danielarechiga/research/comode/SurveyFV.pdf

${ }^{9}$ http://sites.google.com/site/danielarechiga/research/comode/SurveyResults.pdf
} 
indica que la mayoría de los encuestados son adultos jóvenes, con estudios universitarios o de posgrado y como dato muy relevante y revelador, 55 de los 60 participantes cuenta con estudios o trabajos relacionados con las ciencias computacionales. Este último dato, más la forma de invitación utilizada para participar en la encuesta nos permite suponer que los participantes son usuarios asiduos de la tecnología.

Otro elemento para considerar en la definición del perfil de los encuestados es la utilización de la conexión a Internet desde dispositivos móviles, ya que 29 de ellos (48\%) hace uso de este servicio (Figura 6). 


\section{Utilización de Internet móvil}

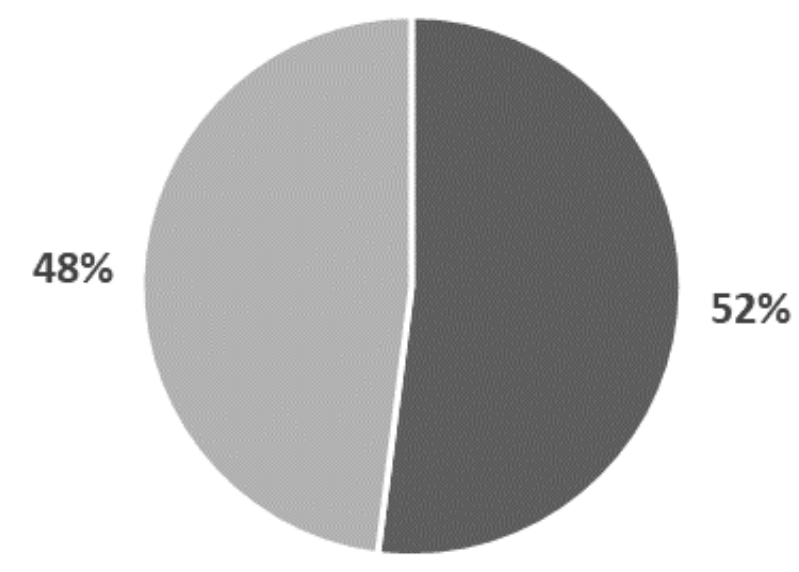

- No utiliza el servicio n Utiliza el servicio

Figura 6. Porcentaje de usuarios que hacen uso del Internet móvil

De los participantes que hacen uso de la conexión a Internet desde dispositivos móviles, la distribución permitió identificar que 21 de ellos (72\%) lo hacen desde teléfonos celulares, mientras que 18 lo hacen desde una computadora portátil, que representa un $62 \%$ de los que usan el servicio. Estos datos nos indican que aproximadamente la mitad de los encuestados son usuarios del Internet móvil y que un buen porcentaje de estos lo hacen desde teléfonos celulares. 
Posterior a la obtención del perfil de los participantes en las primeras 2 secciones de la encuesta, se llevó a cabo el análisis del resto de las secciones que nos permitió evaluar la pertinencia de los grupos de conceptos propuestos como posibles elementos de definición del contexto móvil, esto desde el punto de vista de los usuarios participantes.

En las secciones de la 3 a la 8 cada ítem y grupo de ítems de la encuesta fue analizado por medio de la media aritmética que nos permite identificar en términos generales la opinión de los usuarios, la desviación estándar que permite identificar la dispersión que tienen éstos los resultados y finalmente su coeficiente de variación, siendo este último una representación de medida normalizada para la dispersión y que permite identificar el punto de acuerdo de los resultados de una encuesta. Los resultados obtenidos se describen a continuación.

Para estos resultados, cuando la media aritmética sea mayor indica que el ítem es mejor calificado, mientras que la desviación estándar y el coeficiente de variación deben tender a cero para representar un mejor resultado, es decir, que existe mayor coincidencia entre los resultados de los encuestados. 
En el tercer grupo de elementos de la encuesta que contenía los conceptos relacionados con las características del dispositivo y la red, que incluyó 8 ítems además de la pregunta opcional, se obtuvieron los resultados mostrados en la Tabla 5.

\begin{tabular}{|c|c|c|c|}
\hline Ítem & $\begin{array}{c}\text { Media } \\
\text { aritmética }\end{array}$ & $\begin{array}{c}\text { Desviación } \\
\text { estándar }\end{array}$ & $\begin{array}{l}\text { Coeficiente de } \\
\text { variación }\end{array}$ \\
\hline 3,1 & 4,02 & 1,08 & 0,27 \\
\hline 3,2 & 3,80 & 1,10 & 0,29 \\
\hline 3,3 & 4,23 & 1,05 & 0,25 \\
\hline 3,4 & 4,32 & 1,16 & 0,27 \\
\hline 3,5 & 3,25 & 1,16 & 0,36 \\
\hline 3,6 & 4,00 & 1,01 & 0,25 \\
\hline 3,7 & 3,68 & 1,00 & 0,27 \\
\hline Grupo 3 & 3,90 & 1,12 & 0,29 \\
\hline \multicolumn{4}{|c|}{$\begin{array}{l}\text { 3.1. Tipo de navegador (Tipo del navegador, sus características y capacidades). } \\
\text { 3.2. Tipo de procesador. } \\
\text { 3.3. Características de la pantalla del dispositivo móvil. } \\
\text { 3.4. Características de la conexión a la red. } \\
\text { 3.5. Características de los sensores del dispositivo (acelerómetro, biométricos, termómetro, } \\
\text { etc.). } \\
\text { 3.6. Método de geolocalización del dispositivo (GPS, aGPS, WiFi, etc.). } \\
\text { 3.7. ¿Una clasificación que permita identificar las características técnicas del dispositivo? } \\
\text { Los dispositivos serían clasificados en un nivel de acuerdo con sus características técnicas. } \\
\text { Pregunta opcional: Por favor siéntase libre de escribir algunos conceptos relacionados con } \\
\text { las características del dispositivo y la red que considere que pueden ser considerados para } \\
\text { la definición del contexto en el dispositivo móvil. }\end{array}$} \\
\hline
\end{tabular}

Tabla 5. Análisis de los resultados obtenidos en el grupo 3 de preguntas: 
Cabe mencionarse que en la pregunta opcional se recibieron 14 participaciones, entre las cuales se recibieron como respuestas conceptos como velocidad del procesador, entorno, fecha y hora, entre otros, los cuales habían sido considerados en las secciones posteriores de la encuesta dentro de otros grupos de conceptos a evaluar.

Se pudo identificar que existe un comportamiento regular en las respuestas recibidas, se obtuvieron resultados similares en la media aritmética y la desviación estándar para todos los ítems y para el grupo en general (Figura 7). En este conjunto de preguntas, los ítems 3.3 (Características de la pantalla del dispositivo móvil) y 3.6 (Método de geolocalización del dispositivo) obtuvieron los mejores resultados, mientras que el ítem 3.5 (Características de los sensores del dispositivo) obtuvo la peor calificación, aunque no con una diferencia significativa. De esta forma, se puede identificar que los participantes en la encuesta consideraron que todas las características del dispositivo y la red son elementos de valor como una posibilidad de ser considerados en la mejora de aplicaciones o servicios en los dispositivos móviles. 
6

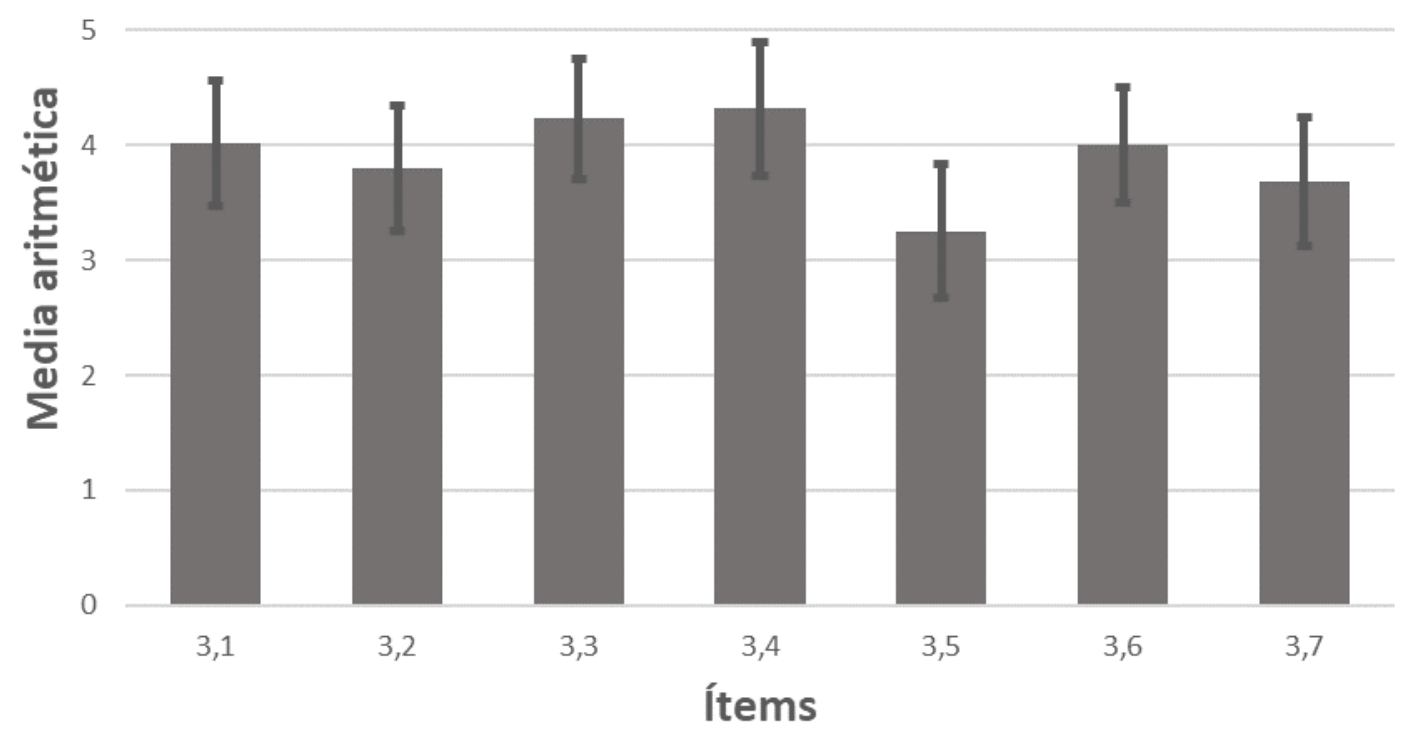

Figura 7. Media aritmética y desviación estándar para el grupo de conceptos: Características del dispositivo y la red

De forma similar, en el grupo 4 de conceptos relacionados con las preferencias del usuario se aplicaron 4 preguntas que incluían una pregunta abierta y en las que se obtuvieron los resultados mostrados en la Tabla 6. 


\begin{tabular}{|c|c|c|c|}
\hline Ítem & $\begin{array}{c}\text { Media } \\
\text { aritmética }\end{array}$ & $\begin{array}{c}\text { Desviación } \\
\text { estándar }\end{array}$ & $\begin{array}{c}\text { Coeficiente de } \\
\text { variación }\end{array}$ \\
\hline 4,1 & 3,97 & 1,09 & 0,27 \\
\hline 4,2 & 3,97 & 1,02 & 0,26 \\
\hline 4,3 & 4,03 & 1,02 & 0,25 \\
\hline Grupo 4 & 3,99 & 1,04 & 0,26 \\
\hline
\end{tabular}

4.1. Direcciones de páginas visitadas frecuentemente.

4.2. Clasificación de los sitios recientemente visitados.

4.3. Resultados preferidos de búsquedas previas.

Pregunta opcional: Por favor siéntase libre de escribir algunos conceptos relacionados con las preferencias del usuario que considere que pueden ser considerados para la definición del contexto en el dispositivo móvil.

Tabla 6. Análisis de los resultados obtenidos en el grupo 4 de preguntas:

Preferencias del usuario.

Para el caso de este grupo de conceptos y en la pregunta abierta opcional se recibieron de igual forma, como en el grupo anterior, algunas respuestas que indicaban conceptos que ya son considerados en otros grupos de conceptos, por ejemplo, la ubicación, fecha y hora, entre otros.

Para este grupo el comportamiento de los resultados finalmente fue similar al grupo anterior, aunque con un poco de mayor uniformidad entre los propios elementos del grupo (Figura 8). La pregunta 4.3 (Resultados preferidos de 
búsquedas previas) obtuvo la mejor calificación, aunque por una diferencia poco significativa. Cabe mencionarse que este grupo obtuvo los mejores puntajes de todos los grupos de conceptos evaluados, por lo que se puede identificar que los encuestados consideran las preferencias del usuario como un factor importante para la mejora de aplicaciones o servicios que consideren el contexto.

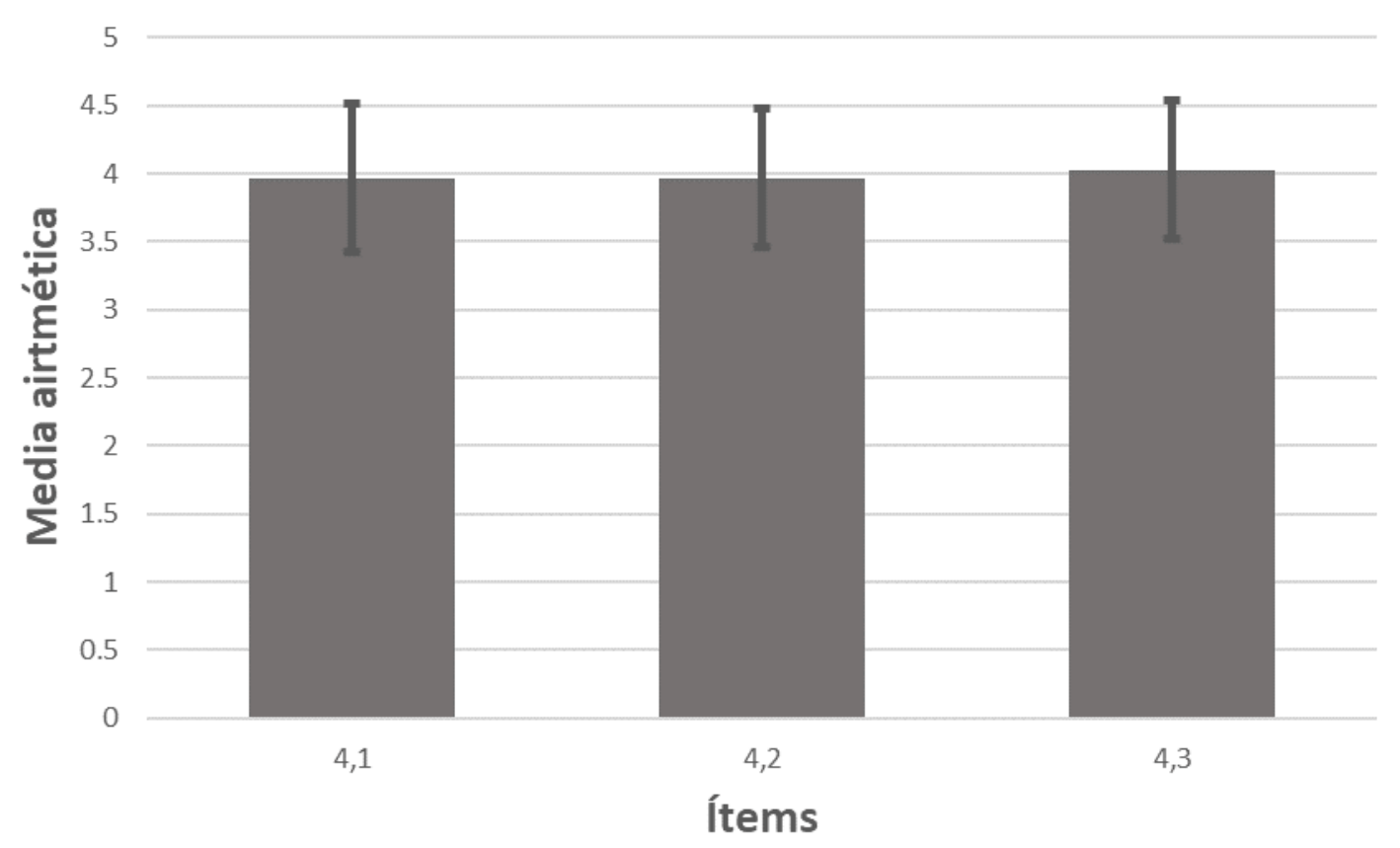

Figura 8. Media aritmética y desviación estándar para el grupo de conceptos: Preferencias del usuario 
En el caso del grupo 5 de preguntas, referentes a los conceptos relacionados con la situación física, se realizaron un total de 5 preguntas, entre las que se incluía la pregunta abierta opcional que previamente se ha mencionado. En este grupo los resultados fueron similares, los cuales puede ser visualizados en la Tabla 7.

\begin{tabular}{|c|c|c|c|}
\hline Ítem & $\begin{array}{c}\text { Media } \\
\text { aritmética }\end{array}$ & $\begin{array}{c}\text { Desviación } \\
\text { estándar }\end{array}$ & $\begin{array}{l}\text { Coeficiente de } \\
\text { variación }\end{array}$ \\
\hline 5,1 & 3,98 & 1,10 & 0,28 \\
\hline 5,2 & 4,02 & 1,11 & 0,28 \\
\hline 5,3 & 3,93 & 1,21 & 0,31 \\
\hline 5,4 & 3,97 & 1,04 & 0,26 \\
\hline Grupo 5 & 3,98 & 1,11 & 0,28 \\
\hline \multicolumn{4}{|c|}{$\begin{array}{l}\text { 5.1. Ubicación geográfica (coordenadas). } \\
\text { 5.2. Ubicación geopolítica (país, ciudad, calle, etc.). } \\
\text { 5.3. Tipo de lugar (aeropuerto, ciudad, playa, montaña, etc.). } \\
\text { 5.4. Tipo de situación (negocios, ocio, etc.). } \\
\text { Pregunta opcional: Por favor siéntase libre de escribir algunos conceptos } \\
\text { relacionados con la situación física que considere que pueden ser } \\
\text { considerados para la definición del contexto en el dispositivo móvil. }\end{array}$} \\
\hline
\end{tabular}

Tabla 7. Análisis de los resultados obtenidos en el grupo 5 de preguntas: 
Se destaca que en la pregunta opcional se recibieron sólo 4 respuestas sobre conceptos que los usuarios consideraron como posibilidades de considerar como contexto para este grupo: Velocidad, situación médica de emergencia, situación de emergencia civil e independencia geográfica.

Como ya se mencionó, el grupo en cuestión obtuvo resultados aproximados a los previamente analizados (Figura 9), la media aritmética obtuvo valores similares para todos los ítems del grupo, pero se destaca que la pregunta 5,3 (Tipo de lugar (aeropuerto, ciudad, playa, montaña, etc.)) alcanzó la calificación más diferenciada al haber alcanzado una desviación estándar de 1,21 y un coeficiente de variación de 0,31 , lo que implica que es un término en el que hubo menor acuerdo entre los encuestados sobre su valor para el contexto de un dispositivo móvil.

En contraparte, la pregunta 5,4 (Tipo de situación (negocios, ocio, etc.)) obtuvo los mejores resultados de este grupo. Los resultados generales del grupo y los particulares de cada ítem del mismo, nos permiten identificar que los participantes en la encuesta le brindaron una significancia importante a la 
ubicación como aporte de contexto para las aplicaciones y servicios móviles, pero esencialmente al tipo de situación en contra del tipo de lugar.

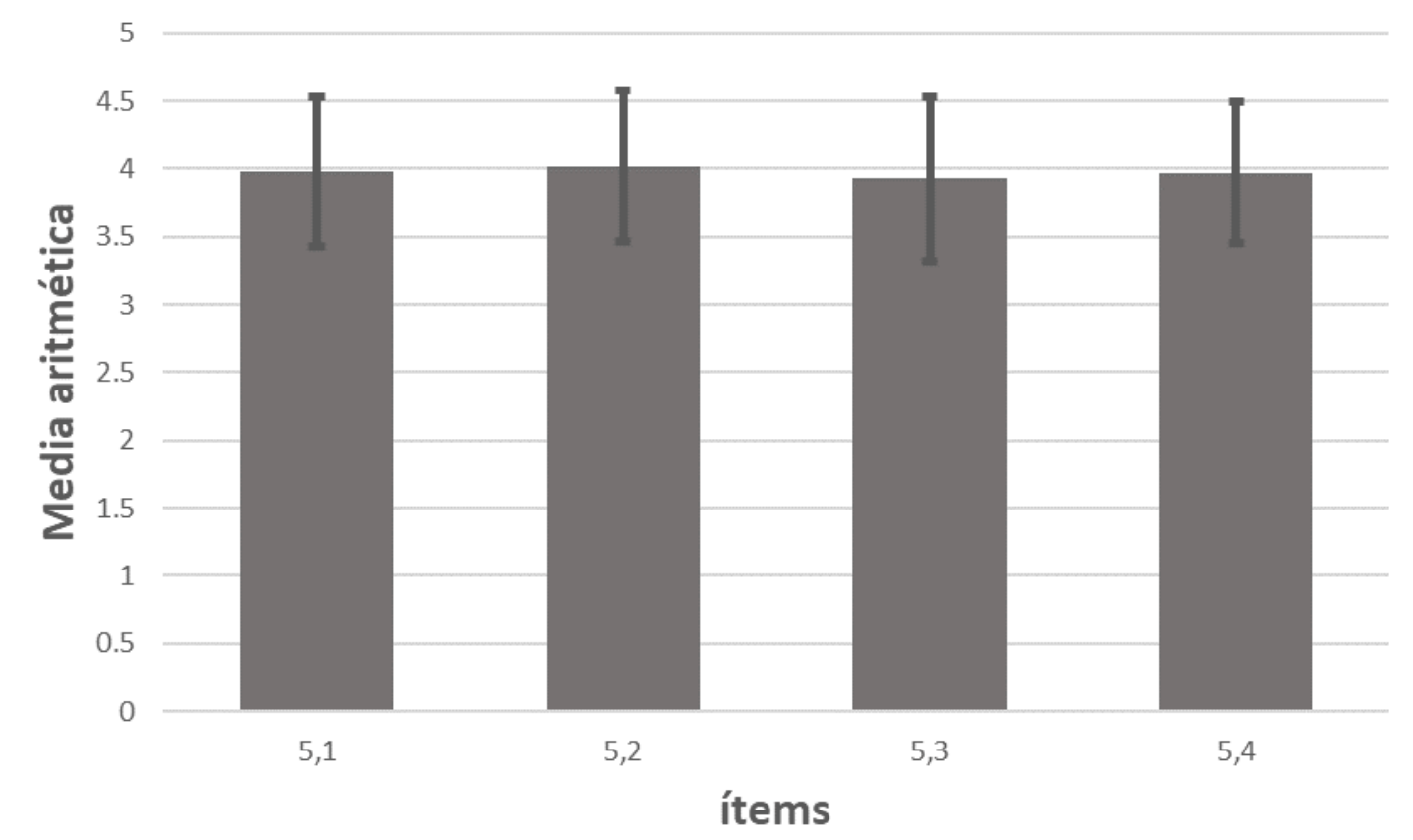

Figura 9. Media aritmética y desviación estándar para el grupo de conceptos: Situación física.

Continuando con el grupo de preguntas número 6, dedicado a evaluar los conceptos relacionados con las condiciones y circunstancias temporales, también constó de 5 preguntas que incluían la pregunta opcional abierta de las que se obtuvieron los resultados mostrados en la Tabla 8. 


\begin{tabular}{|c|c|c|c|}
\hline Ítem & $\begin{array}{c}\text { Media } \\
\text { aritmética }\end{array}$ & $\begin{array}{l}\text { Desviación } \\
\text { estándar }\end{array}$ & $\begin{array}{l}\text { Coeficiente de } \\
\text { variación }\end{array}$ \\
\hline 6,1 & 4,23 & 1,09 & 0,26 \\
\hline 6,2 & 3,77 & 1,16 & 0,31 \\
\hline 6,3 & 3,85 & 1,02 & 0,27 \\
\hline 6,4 & 3,68 & 1,14 & 0,31 \\
\hline Grupo 6 & 3,88 & 1,12 & 0,29 \\
\hline \multicolumn{4}{|c|}{$\begin{array}{l}\text { 6.1. Fecha y hora actuales. } \\
\text { 6.2. Temporada o estación del año. } \\
\text { 6.3. Tiempo relativo actual (madrugada, por la noche, mediodía, etc.). } \\
\text { 6.4. Fecha relativa (fin de semana, inicio del mes, mitad del año, etc.). } \\
\text { Pregunta opcional: Por favor siéntase libre de escribir algunos conceptos } \\
\text { relacionados con las condiciones y circunstancias temporales que considere } \\
\text { que pueden ser considerados para la definición del contexto en el dispositivo } \\
\text { móvil. }\end{array}$} \\
\hline
\end{tabular}

Tabla 8. Análisis de los resultados obtenidos en el grupo 6 de preguntas:

Condiciones y circunstancias temporales.

Para la pregunta abierta opcional se recibieron respuestas de dos encuestados con elementos como el sexo, los intereses del usuario y la información del clima como elementos a considerar.

En el análisis de los resultados de este grupo de conceptos (Figura 10), se pudo identificar que la pregunta 6,1 (Fecha y hora actuales) obtuvo la mejor 
valoración por parte de los encuestados, mientras que la pregunta 6.4 (Fecha relativa) consiguió el puntaje más bajo del grupo. De esta forma se puede identificar que los participantes consideraron al concepto de la fecha y hora actuales como el de mayor representatividad para la definición del contexto móvil dentro de los conceptos referentes a las condiciones temporales.

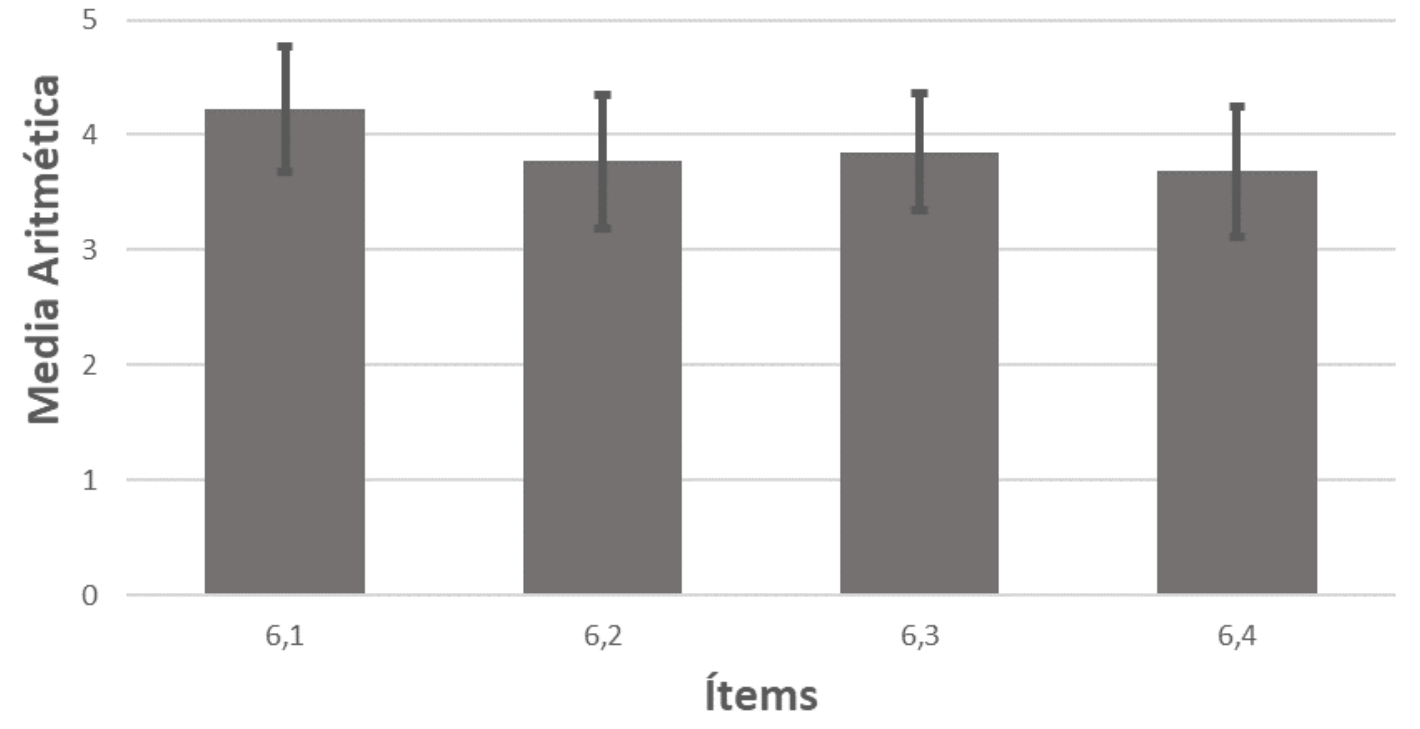

Figura 10. Media aritmética y desviación estándar para el grupo de conceptos: Condiciones temporales. 
Siguiendo con el grupo 7 de preguntas de valoración de conceptos, concerniente a los conceptos relacionados con las condiciones y circunstancias del entorno, se destaca que se efectuaron 4 preguntas que incluyen la pregunta abierta opcional, de las que se pueden analizar los resultados que se muestra en la Tabla 9.

\begin{tabular}{|c|c|c|c|}
\hline Ítem & $\begin{array}{c}\text { Media } \\
\text { aritmética }\end{array}$ & $\begin{array}{l}\text { Desviación } \\
\text { estándar }\end{array}$ & $\begin{array}{l}\text { Coeficiente de } \\
\text { variación }\end{array}$ \\
\hline 7,1 & 3,87 & 1,10 & 0,28 \\
\hline 7,2 & 3,90 & 1,13 & 0,29 \\
\hline 7,3 & 3,40 & 1,15 & 0,34 \\
\hline Grupo 7 & 3,72 & 1,14 & 0,31 \\
\hline \multicolumn{4}{|c|}{$\begin{array}{l}\text { 7.1. Situación del clima actual. } \\
\text { 7.2. Pronóstico del clima. } \\
\text { 7.3. Hora de la salida y puesta del sol. } \\
\text { Pregunta opcional: Por favor siéntase libre de escribir algunos conceptos } \\
\text { relacionados con las condiciones y circunstancias del entorno que considere } \\
\text { que pueden ser considerados para la definición del contexto en el dispositivo } \\
\text { móvil. }\end{array}$} \\
\hline
\end{tabular}

Tabla 9. Análisis de los resultados obtenidos en el grupo 7 de preguntas: 
Para este grupo en la pregunta abierta opcional se recibieron respuestas de dos participantes, las que incluían conceptos de tipo de transporte e índice de rayos ultravioleta.

Para el grupo de preguntas en análisis, el valor más notorio obtenido es el referente a la pregunta 7,3 (Hora de la salida y puesta del sol), que obtuvo el valor más bajo del grupo y unos de los más bajos en general. El resto de los elementos mostraron un comportamiento dentro de los demás términos en lo general (Figura 11). El grupo en general nos permitió que efectivamente los usuarios tienen el factor de las condiciones y circunstancias del entorno como un elemento a considerar en el contexto. 


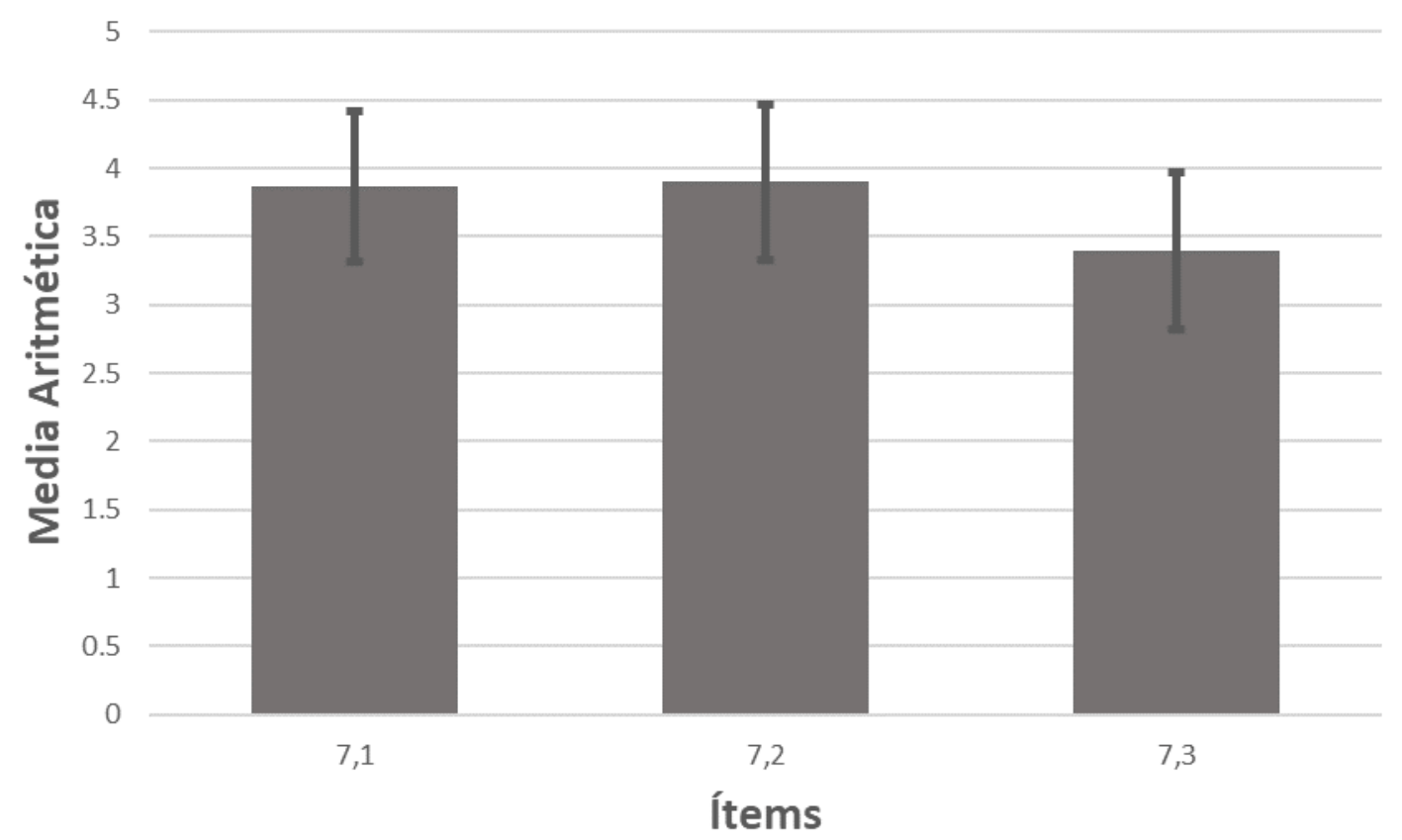

Figura 11. Media aritmética y desviación estándar para el grupo de conceptos: Condiciones y circunstancias del entorno.

El grupo 8 de preguntas, final de la encuesta aplicada y relativo a los conceptos relacionados con las características del movimiento también fue conformado por 4 preguntas que incluyen la pregunta abierta opcional. Los resultados obtenidos por este grupo son mostrados en la Tabla 10. 


\begin{tabular}{|c|c|c|c|}
\hline Ítem & $\begin{array}{c}\text { Media } \\
\text { aritmética }\end{array}$ & $\begin{array}{c}\text { Desviación } \\
\text { estándar }\end{array}$ & $\begin{array}{c}\text { Coeficiente de } \\
\text { variación }\end{array}$ \\
\hline 8,1 & 3,43 & 1,05 & 0,32 \\
\hline 8,2 & 3,58 & 0,98 & 0,27 \\
\hline 8,3 & 3,62 & 1,01 &, 028 \\
\hline Grupo 8 & 3,54 & 1,01 & 0,28 \\
\hline
\end{tabular}

8.1. Velocidad de movimiento del usuario.

8.2. Tipo de movimiento (Dentro de la ciudad, entre ciudades, etc.).

8.3. Tipo de transportación (a pie, bicicleta, tren, etc.).

Pregunta opcional: Por favor siéntase libre de escribir algunos conceptos relacionados con las características del movimiento que considere que pueden ser considerados para la definición del contexto en el dispositivo móvil.

Tabla 10. Análisis de los resultados obtenidos en el grupo 8 de preguntas:

Características del movimiento.

En este grupo de preguntas se recibió solamente una respuesta a la pregunta opcional abierta que consideró el concepto de distancia recorrida.

En el caso del grupo octavo y último de preguntas se presentó un comportamiento regular y consistente entra las preguntas del grupo (Figura 12) pero obteniendo los resultados más bajos de toda la encuesta de acuerdo al promedio aritmético, pero mostrando una similitud en la desviación estándar y el coeficiente de variación. De igual forma, el ítem 8,1 (velocidad de movimiento del usuario) obtuvo la calificación más baja de toda la encuesta, lo que en 
general hace suponer que este concepto supone para los encuestados el factor menos relevante para considerarse como contexto móvil para aplicaciones y servicios.

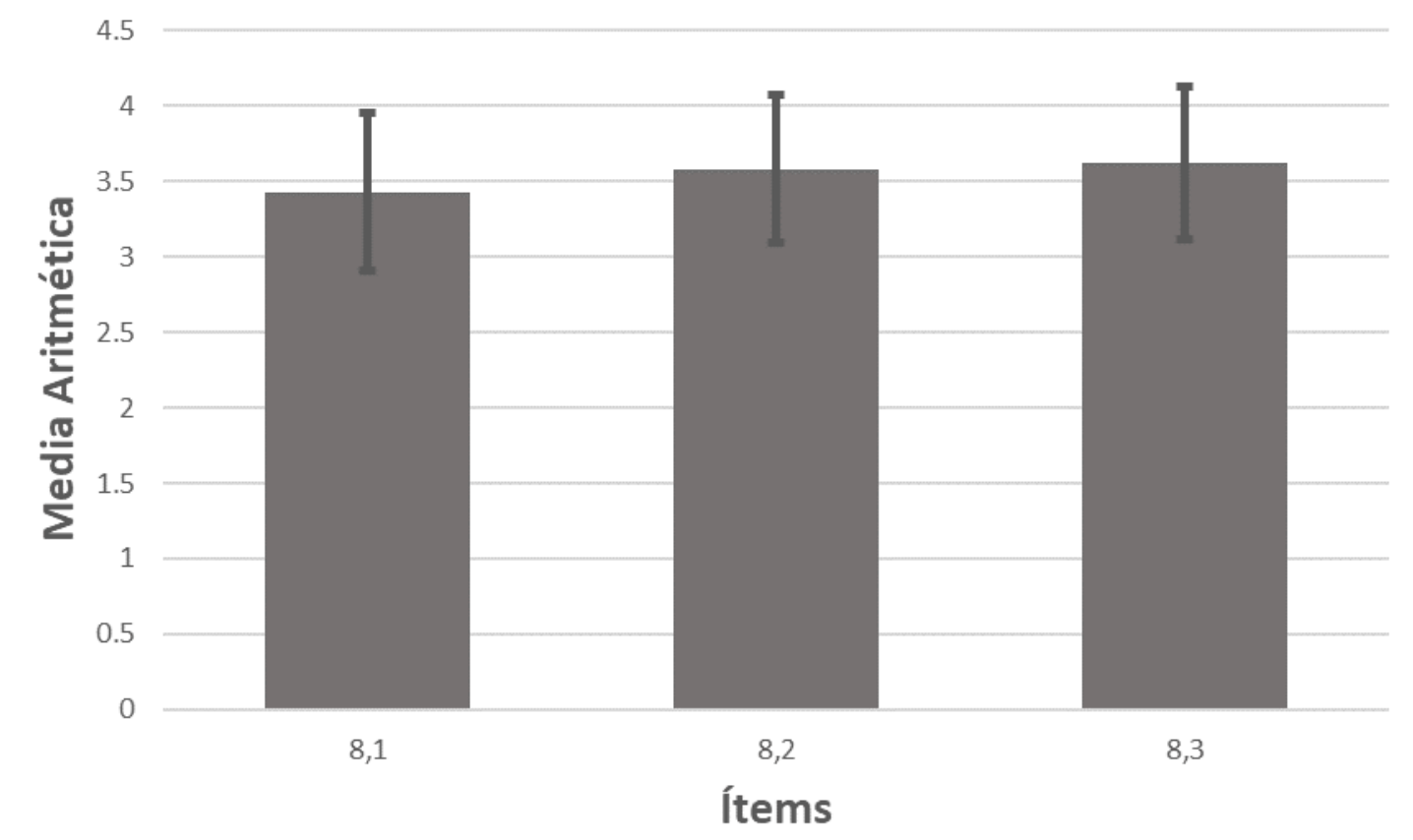

Figura 12. Media aritmética y desviación estándar para el grupo de conceptos: Características del movimiento.

En términos generales, se puede identificar que el comportamiento de los datos obtenidos por la encuesta es uniforme, básicamente al identificarse que no existen grandes variaciones entre ellos, además que las variaciones entre las 
respuestas permiten identificar que existe una cierta concordancia entre las opiniones de los participantes. Aun así, existen algunos que vale la pena destacar sobre los resultados de la encuesta.

Como un análisis individual de las respuestas, se puede identificar que los ítems 3,3 (Características de la pantalla del dispositivo móvil), 3,6 (Método de obtención de la localización) y 4,3 (Resultados preferidos) obtuvieron los mejores resultados de todos con un coeficiente de variación de 0,25. Mientras que el ítem 3,5 (características de los sensores del dispositivo) obtuvo el peor resultado con un coeficiente de variación de 0,36, seguido por el ítem 7,3 (Hora de la salida y puesta del sol) con un valor obtenido en el coeficiente de variación de 0,34 .

En el análisis general (Tabla 11) se obtiene que el grupo 4 de conceptos relacionados con las preferencias del usuario obtuvieron las mejores calificaciones, con un coeficiente de variación del 0,26, en contraparte al grupo 7 de conceptos relacionados con las condiciones y circunstancias del entorno que obtuvo el peor coeficiente de variación con un valor de 0,31. Esto refleja que los usuarios valoraron las preferencias del usuario como el concepto más 
valioso a considerar al utilizar el contexto como soporte en los dispositivos móviles, igualmente las condiciones y circunstancias del entorno como las menos relevantes.

\begin{tabular}{|c|c|c|c|}
\hline Grupo de & Media & Desviación & Coeficiente de \\
conceptos & aritmética & estándar & variación \\
\hline Grupo 3 & 3,90 & 1,12 & 0,29 \\
\hline Grupo 4 & 3,99 & 1,04 & 0,26 \\
\hline Grupo 5 & 3,98 & 1,11 & 0,28 \\
\hline Grupo 6 & 3,88 & 1,12 & 0,29 \\
\hline Grupo 7 & 3,72 & 1,14 & 0,31 \\
\hline Grupo 8 & 3,54 & 1,01 & 0,28 \\
\hline
\end{tabular}

Tabla 11. Análisis de los resultados obtenidos en los grupos de preguntas del

$$
3 \text { al } 8 .
$$

Igualmente representativo es que las desviaciones estándar obtenidas muestran una tendencia entre las respuestas de los usuarios muy uniforme en todos los grupos de preguntas (Figura 13), lo que nos indica que las 
calificaciones obtenidas por los distintos grupos son de similar concordancia en cuanto a la opinión de los encuestados.

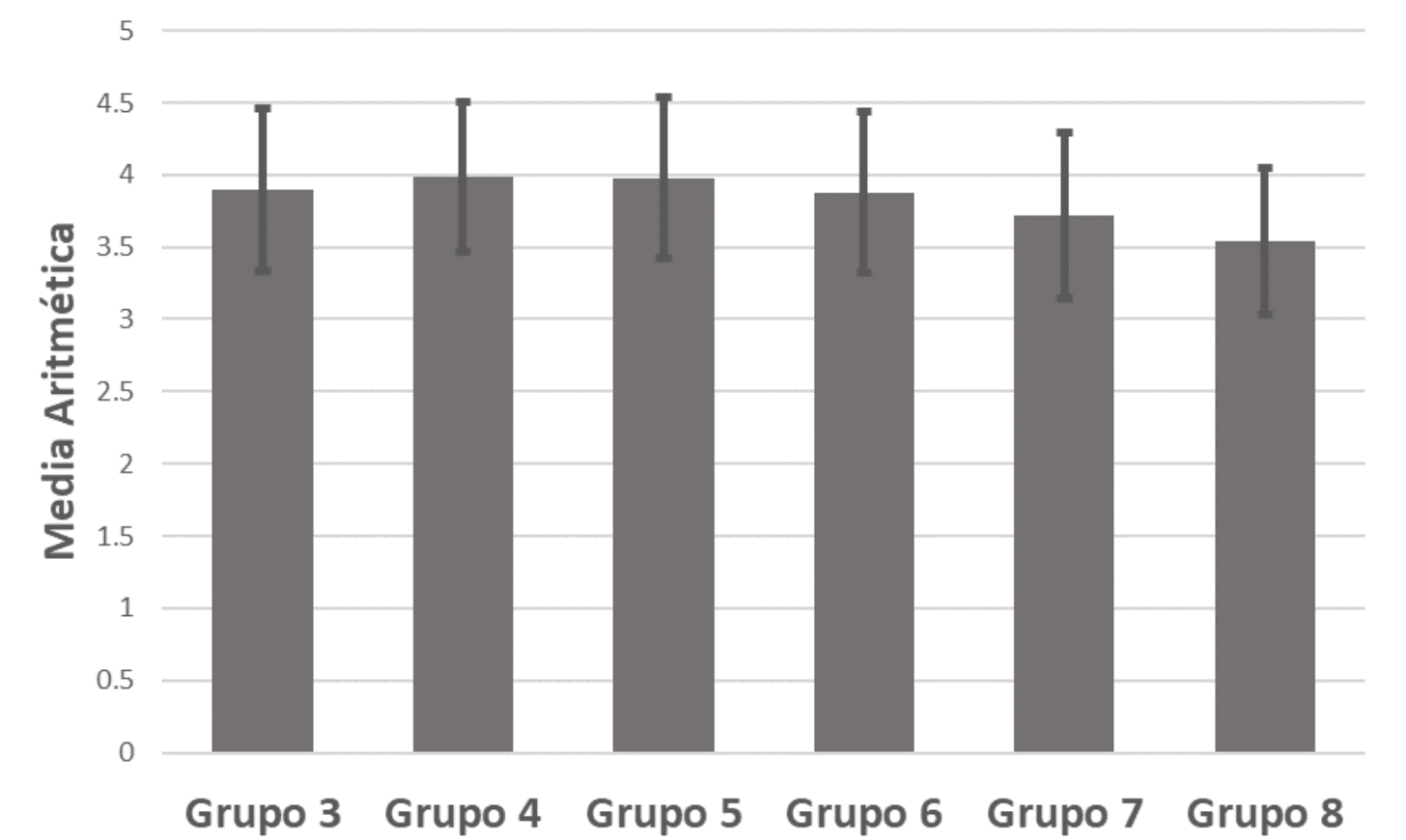

Figura 13. Media aritmética y desviación estándar por grupo de conceptos.

La encuesta nos permitió identificar los conceptos o grupos de conceptos que pueden ser considerados como parte de un contexto definido en el entorno de los dispositivos móviles, validando la utilidad que los encuestados consideraron para cada uno de los ítem y grupos presentados. 
Como ya se mencionó, el grupo de conceptos relacionados con las preferencias de los usuarios resultó el mejor valorado, demostrando que los participantes en la encuesta lo consideraron como el más valioso o preponderante sobre los demás conceptos a considerar. De igual forma, algunos de los elementos mejor valorados individualmente se encuentran relacionados con las características propias del dispositivo móvil, lo que podría interpretarse como que los encuestados también creen que las características del propio dispositivo móvil pueden ser un factor preponderante a ser considerado.

El grupo de conceptos relacionados con las condiciones del entorno (grupo 7) obtuvo la peor calificación en general, pero es debido esencialmente a que el ítem 7,3 (Hora de la salida y puesta del sol) obtuvo la peor calificación de todas, arrastrando hacia la parte inferior la calificación como grupo, ya que los demás elementos del grupo tuvieron un comportamiento regular. Una situación similar ocurrió con el elemento 3,5 (características de los sensores del dispositivo) que obtuvo el segundo peor resultado general, pero el resto de los ítems del grupo obtuvieron un rendimiento o puntajes promedio. Es de considerarse que estos dos elementos sean considerados de forma menos relevante o en su caso y con un posterior análisis particular, considerar su eliminación. 


\subsubsection{Conclusiones de la encuesta}

A pesar de que existen diversas propuestas relacionadas con la creación de ontologías para la definición del contexto móvil, hemos planteado la posibilidad de crear una ontología de definición del contexto móvil que pueda ser utilizada como soporte para la mejora de aplicaciones o servicios móviles, mediante el aprovechamiento del contexto que la ontología pueda proporcionar.

En base a las ontologías previamente analizadas, propusimos una evaluación por parte de usuarios a través de una encuesta para determinar si los conceptos generales propuestos pudieran ser considerados como la base para la creación de la ontología de definición de contexto móvil. La evaluación nos brindó información valiosa acerca de las consideraciones de los usuarios, así como ideas claras sobre lo que los usuarios están esperando sobre el contexto definido en la ontología para dar soporte a las aplicaciones y servicios que hagan uso de esta herramienta

El resultado principal de la encuesta aplicada es la posibilidad de identificar los elementos que los usuarios consideran como de mayor valía, dándonos herramientas para dar mayor soporte a la creación de la ontología. Finalmente 
se consiguió identificar los conceptos generales que darán soporte a la ontología COMoDE (Figura 14), que se encuentras agrupados en los siguientes:

- Características del dispositivo y la red

- Preferencias del usuario

- Situación física

- Circunstancias temporales

- Circunstancias del entorno

- Características del movimiento

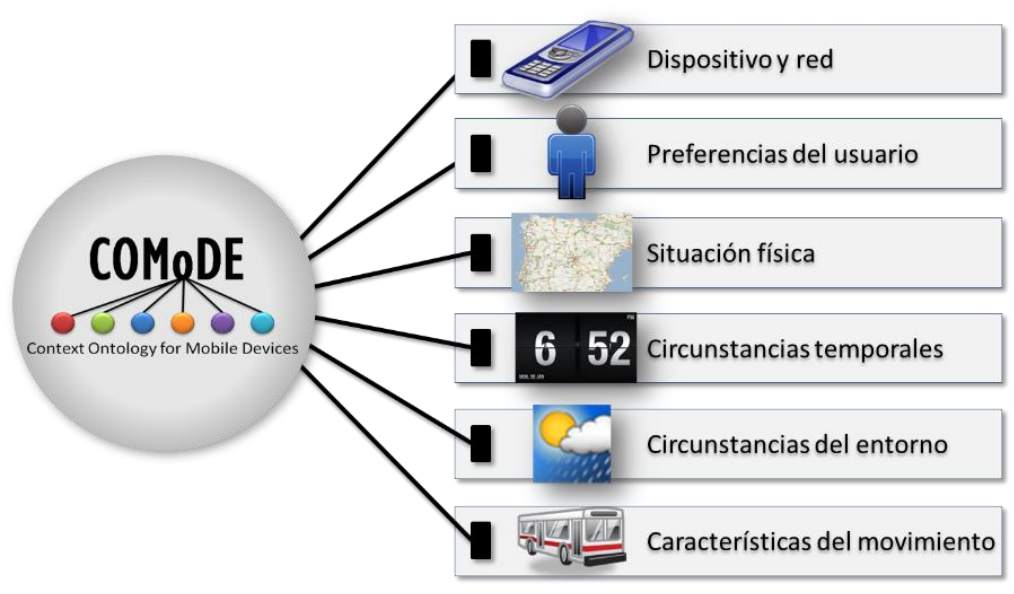

Figura 14. Subdominios generales de la ontología COMODE para la definición del contexto móvil. 


\subsubsection{Paso tres: Identificación de los términos del área de competencia}

Para este paso se requiere la identificación de la mayoría de los conceptos que puedan ser plasmados relacionados con el área de competencia de la ontología que se desea crear, ya que estos serán la base sobre la que serán cimentados los siguientes pasos de la creación, donde se definen las clases y propiedades, principalmente.

Para la identificación de los términos del área de competencia fue necesario crear una lista general basada en los conceptos obtenidos por medio del análisis de los elementos generales de ontologías similares, que a su vez fueron validados en el paso anterior por medio de una encuesta entre usuarios para identificar si era posible considerar dichos elementos como la base para la ontología.

Se llevó a cabo una revisión de conceptos del tesauro WordNet (Princeton University, 2011), complementada con la estructura obtenida a partir de las categorías que ofrece Yahoo (Yahoo, 2011). Cabe mencionar que las categorías de Yahoo ya han sido utilizadas de forma efectiva como herramienta para crear 
estructuras de categorías, tal como fuera demostrado por Labrou (Labrou, 1999).

Como resultado de esta revisión y análisis se obtuvo una primera estructura de conceptos, la cual se detalla en la Tabla 12, agrupada por cada uno de los grupos de conceptos mostrados en el paso anterior y jerarquizados utilizando WordNet y Yahoo, los conceptos fueron descritos utilizando el idioma inglés:

1) The Device and Network Characteristics

a) Kind of Browser

i) browserType

ii) browserversion

iii) browserJava

iv) browserFlash

v) browserWAP

vi) browserWEB

vii) browserCookie

viii) browserPDF

b) Kind of Processor

i) $\mathrm{CPU}$

ii) CPUSpeed

c) Screen

i) screenSize

ii) screenType

iii) screenResolution

iv) screenlmages

v) screenColor

d) Network Connection
2) The User Preferences

a) User Identification

i) userlD

b) Preferred web sites

i) pageURL

ii) pageType

iii) pageNoOfVisits

iv) pageTypePreferred

c) Preferred results

i) pageFormatPreferred

ii) pageDistancePreferred

d) Birthday -> age

e) Language

f) Health

i) Allergies

(1) alimentary

(2) pharmacological

(3) environmental

ii) heartCondition

g) Activities preferences 


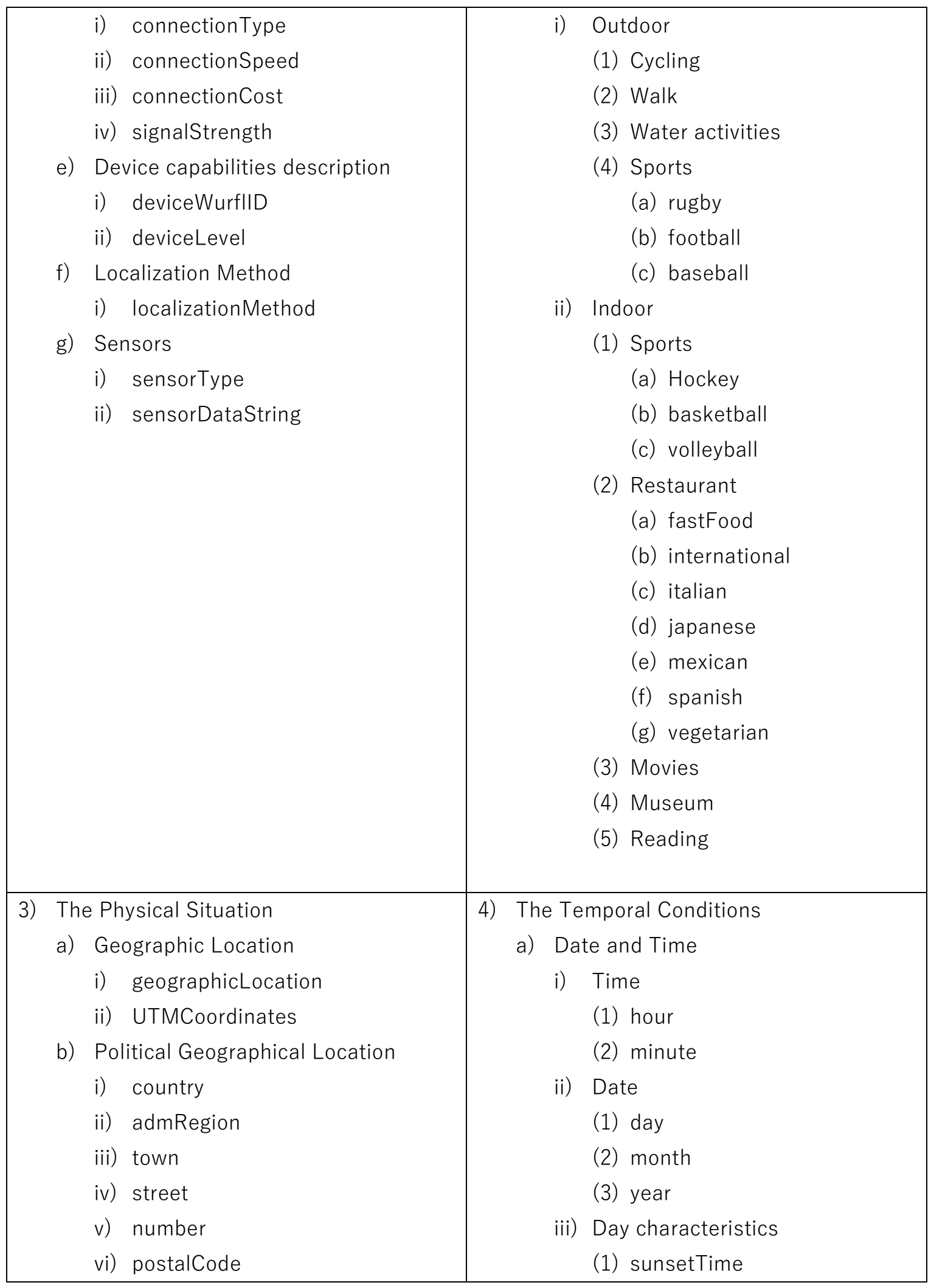




\begin{tabular}{|c|c|c|c|c|c|c|}
\hline & $\begin{array}{l}\text { Kind of } F \\
\text { i) type } \\
\text { User's L } \\
\text { i) type } \\
\text { ii) type }\end{array}$ & $\begin{array}{l}\text { n Characteristics } \\
\text { ation } \\
\text { ation }\end{array}$ & & 列 & $\begin{array}{l}\text { (2) sunriseTime } \\
\text { iv) Season } \\
\text { (1) spring } \\
\text { (2) summer } \\
\text { (3) autumn } \\
\text { (4) winter } \\
\text { v) timeZone } \\
\text { vi) daylightSavingTime } \\
\text { Relative Time } \\
\text { i) morning } \\
\text { ii) afternoon } \\
\text { iii) nigth } \\
\text { Relative Date } \\
\text { i) dayOfWeek } \\
\text { ii) dayOfMonth } \\
\text { iii) dayOfYear }\end{array}$ \\
\hline 5) & $\begin{array}{l}\text { The } \\
\text { a) }\end{array}$ & $\begin{array}{l}\text { Environr } \\
\text { Weather } \\
\text { i) Wea } \\
\text { (1) } \mathrm{t} \\
\text { (2) } \mathrm{t} \\
\text { (3) } \mathrm{t} \\
\text { (4) } \mathrm{c} \\
\text { (5) } \mathrm{s} \\
\text { (6) } \mathrm{s} \\
\text { (7) } \mathrm{r} \\
\text { (8) } \mathrm{r} \\
\text { (9) } \mathrm{f} \\
\text { (10) } \\
(11) \\
\text { (12) } \\
(13) \\
\text { (14) } \\
\text { Wea } \\
\text { (1) } \mathrm{t}\end{array}$ & $\begin{array}{l}\text { Conditions } \\
\text { orecast } \\
\text { ctual } \\
\text { rature24hMaximum } \\
\text { rature24hMinimum } \\
\text { ratureCurrent } \\
\text { tornado } \\
\text { sandstorm } \\
\text { wind } \\
\text { allergieAlert } \\
\text { uvlndex } \\
\text { recast } \\
\text { ratureMaximum }\end{array}$ & & $\begin{array}{l}\text { The } \\
\text { a) } \\
\text { b) } \\
\text { c) }\end{array}$ & $\begin{array}{l}\text { User Movement Characteristics } \\
\text { Kind of Movement } \\
\text { i) MoveSpeed } \\
\text { (1) movementSlow } \\
\text { (2) movementFast } \\
\text { (3) movementStatic } \\
\text { Relative Distance } \\
\text { i) MoveType } \\
\text { (1) intraCity } \\
\text { (2) interCity } \\
\text { (3) intraCountry } \\
\text { (4) interCountry } \\
\text { Type of Transport } \\
\text { i) TransportType } \\
\text { (1) train } \\
\text { (2) airplane } \\
\text { (3) car } \\
\text { (4) bus } \\
\text { (5) bicycle }\end{array}$ \\
\hline
\end{tabular}




\begin{tabular}{|c|c|c|}
\hline iii) & $\begin{array}{l}\text { (2) temperatureMinimum } \\
\text { (3) cloud } \\
\text { (4) sun } \\
\text { (5) snow } \\
\text { (6) rain } \\
\text { (7) hail } \\
\text { (8) fog } \\
\text { (9) wind } \\
\text { (10) } \quad \text { tornado } \\
\text { (11) andstorm } \\
\text { (12) ullergieAlert } \\
\text { (13) } \quad \text { uvdex } \\
\text { TemperatureMeasurement } \\
\text { (1) celsius } \\
\text { (2) fahrenheit }\end{array}$ & (6) walk \\
\hline $\begin{array}{l}\text { Descripción } \\
\text { 5) } \\
\text { a) } \\
\text { i) } \\
\text { (1) }\end{array}$ & $\begin{array}{l}\text { de la estructura de conceptos: } \\
\text { Grupo de conceptos } \\
\text { Categoría de conceptos } \\
\text { Elementos específicos } \\
\text { palabras clave relacionadas }\end{array}$ & \\
\hline
\end{tabular}

Tabla 12. Primera estructura de conceptos agrupados y jerarquizados mediante el uso de WordNet y Yahoo

\subsubsection{Paso cuatro: Jerarquización de las clases}

Utilizando como base los conceptos validados en el segundo paso y complementados en el tercer paso, se generó la estructura de clases, la que 
contempla clases principales y las subclases de segundo, tercer y hasta cuarto nivel.

En este caso se llevó a cabo la tarea de acuerdo al proceso descrito por Uschold y Grüninger (Uschold \& King, Towards a Methodology for Building Ontologies, 1995) y mencionado en el capítulo 2, en el que se refieren 3 formas básicas de llevarlo a cabo. En este caso en particular se utilizó el procedimiento arribaabajo, en el que se comienza por identificar a los elementos candidatos a ser clases de mayor nivel y se continua en escala descendente.

Los términos de la etapa anterior fueron reestructurados creando una estructura en forma de árbol fundamentada en la inclusividad de los términos, mientras mayor sea el término deberá estar ubicado en un lugar más alto de la estructura (Figura 15). Como un ejemplo, el término "temperatureMeasurement" está incluido en el término de mayor nivel denominado "environmentalCondition". 


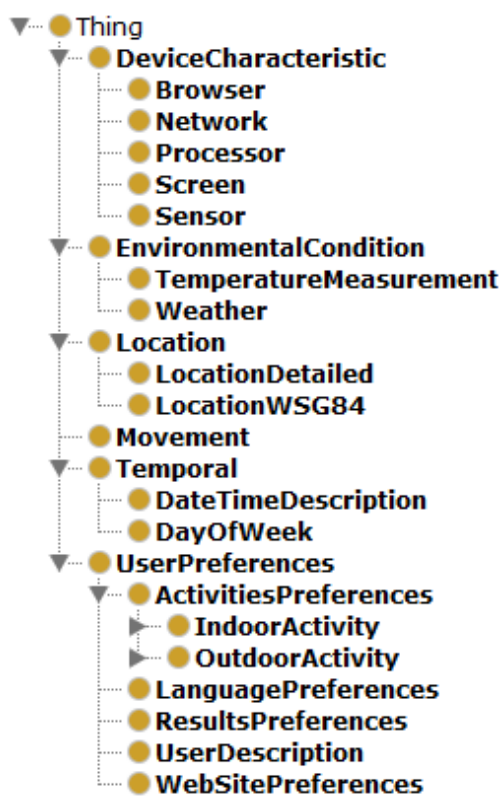

Figura 15. Ejemplo de la estructura inicial para las clases de la ontología COMODE.

A su vez, todos los términos definidos como clases se encuentran relacionados entre sí, dando soporte al significado de la estructura de toda la ontología (Figura 16). 


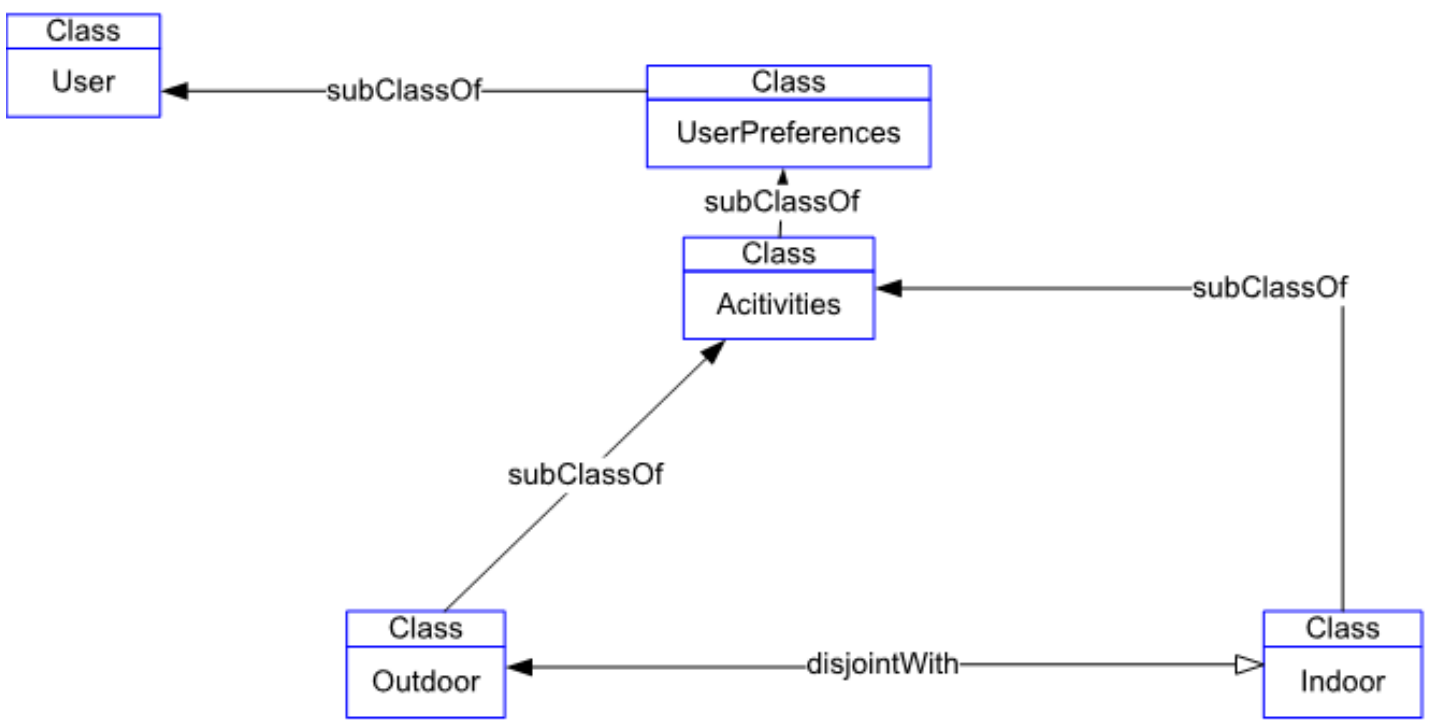

Figura 16. Ejemplo de relaciones entre clase en la ontologia COMoDE.

\subsubsection{Paso cinco: Identificación de las propiedades}

Para el paso de identificación de las propiedades de la ontología, se observaron aquellos términos que no tienen suficiente relevancia para ser considerados como una clase o que permiten representar características de las clases ya identificadas, recordando lo mencionado en el capítulo 2, donde se describe que las propiedades se encuentran ligadas a las clases identificando sus propiedades. 
Como un ejemplo, el término "celsius" ha sido enlazado como una propiedad para el término "temperatureMeasurement" que finalmente quedó implementado en la ontología como una clase.

\subsubsection{Paso seis: Definición de características de las propiedades}

Posterior a la definición de las propiedades de las clases, se cuenta con una estructura que detalla de forma más completa la ontología que se está creando, en el siguiente paso se requiere llevar a cabo la caracterización de las propiedades. Las características de la propiedades detallan los posibles valores que puede una propiedad asumir, creando las restricciones y límites en los que se deberá basar el proceso de instanciación de la ontología.

Como un ejemplo, la clase "locationWGS84" que ha sido creada para establecer la posibilidad de utilizar ubicaciones utilizando el World Geodetic System 84 ${ }^{10}$, que es un estándar utilizado en cartografía y navegación GPS, donde las coordenadas tienen propiedades como latitud, longitud, altitud y que hace uso de números de punto flotante para representar estos valores. De esta forma,

${ }^{10}$ https://en.wikipedia.org/wiki/World_Geodetic_System\#WGS84 
hemos definido tres propiedades como valores de punto flotante para permitir la instanciación de las coordenadas utilizando el sistema mencionado (Figura 17).

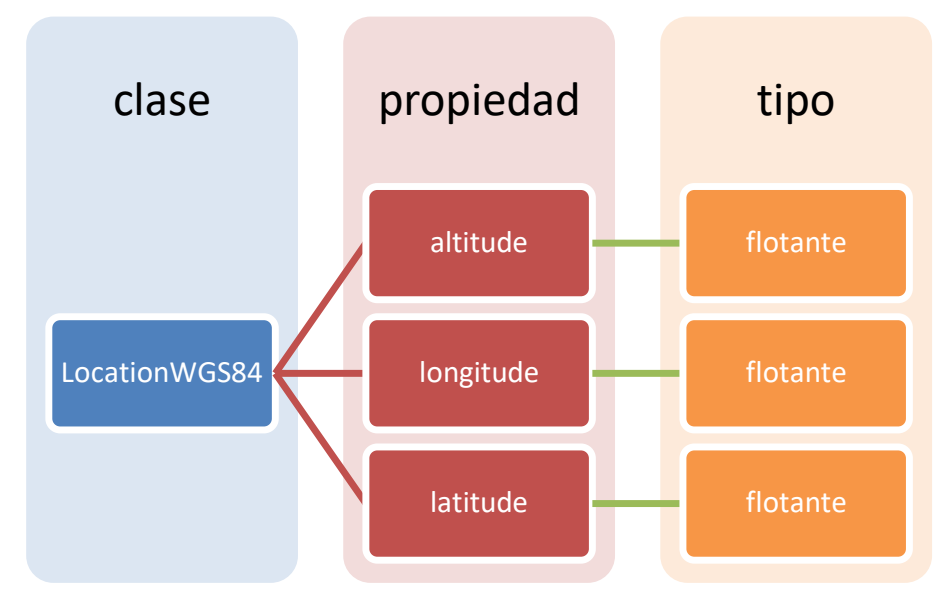

Figura 17. Ejemplo de definición de características de propiedades en la ontología COMODE.

\subsubsection{Paso siete: Creación de las instancias}

El paso final en la creación de una ontología, de acuerdo a los pasos descritos en el capítulo 2 y descritos inicialmente por Noy (Noy \& Mcguinness, 2001), Grüninger (Grüninger \& Fox, 1995) y Uschold (Uschold \& King, Towards a Methodology for Building Ontologies, 1995), es el proceso de instanciación de la ontología. 
La instanciación ocurre cuando la ontología, que es una estructura de conceptos, toma vida mediante la asignación de valores de la vida real mediante la utilización de aplicaciones que hacen el uso y aprovechamiento de la ontología.

Para la ontología COMoDE se han llevado a cabo algunas pruebas en las que se ha realizado el proceso de instanciación, las que serán descritas en el capítulo 5, dedicado a la evaluación de la ontología en tareas específicas que allí mismo se describen. 


\section{Capítulo 5}

\section{Uso de la ontología COMoDE}

Este capítulo discute sobre la utilización experimental de la ontología COMoDE que fuera creada como se describió en el capítulo 4, buscando que funcionara como una mejora para dos actividades que usualmente se llevan a cabo en dispositivos móviles, como es la escritura de texto y la recepción de mensajes o notificaciones.

La aplicación experimental de la ontología como mejora de actividades propias de dispositivos móviles se llevó a cabo por medio de la utilización de esquemas de evaluación de ontologías discutidos en el capítulo 2.

Posterior al análisis de las aproximaciones en los métodos de evaluación o prueba de ontologías, que fueran discutidos inicialmente por Brank (Brank, Grobelnik, \& Mladenic, 2005), complementados por Gangemi (Gangemi, Catenacci, Ciaramita, \& Lehmann, 2006) y descritos en el capítulo 2 del 
presente documento, se eligió la utilización del método de evaluación por medio de aplicación para la ontología COMoDE, porque su razón fundamental es la de proveer de soporte o apoyo para las aplicaciones o servicios móviles donde la efectividad en la utilización de la ontología puede ser una tarea subjetiva, que dependa esencialmente del punto de vista de los usuarios. De esta forma la evaluación basada en una aplicación permite obtener las expectativas y percepciones del usuario acerca de la eficiencia que la ontología provea como soporte para una tarea en particular.

La evaluación basada en una aplicación o tarea en particular a la que se ha hecho referencia, se enfoca a la medición de la aptitud de la ontología para el cumplimiento de algunos objetivos, precondiciones, postcondiciones, restricciones, opciones, entre otros, como lo describiera Gangemi.

Considerando los diversos enfoques y aproximaciones en la evaluación de ontologías, las consideraciones hechas por Porzel y Green descritas en el capítulo 2, así como el objetivo de la creación de la ontología COMoDE, que es la de brindar soporte para aplicaciones y servicios en dispositivos móviles por medio de la consideración del contexto como un factor de mejora en sus 
funcionalidades, se puso a prueba la mejora de un par de actividades que son llevadas a cabo en los dispositivos móviles, utilizando las técnicas de evaluación basada en una tarea o aplicación, de forma tal que se identifique el resultado de utilizar la ontología en dichas actividades.

Para el diseño de los experimentos se eligió una variación del modelo de experimentación controlada propuesto por Christensen (Christensen, 2007), que es un modelo que mejor se adapta para los requerimientos propios de la valoración buscada, ya que se busca determinar si la ontología provee de una mejora en una situación en particular. Experimentos controlados usualmente comparan los resultados obtenidos entre dos muestras, una muestra es utilizada como muestra de control, mientras que otra muestra es la prueba del experimento que se desea probar, ambas son prácticamente idénticas excepto por la variable, condición o aspecto independiente que desea ser comparado, que es el propósito del experimento.

Trasladando estos conceptos a la prueba basada en una tarea o aplicación, el experimento debe incluir la comparación de los resultados obtenidos entre la utilización o no utilización de la ontología en una aplicación o tarea específica, 
para de esta forma realizar alguna medición de la diferencia que implica la utilización de la ontología.

Con estas consideraciones, se hizo el diseño de dos experimentos para probar la funcionalidad o efectividad de aplicar la ontología como soporte para dos tareas diferentes, ambos experimentos se llevaron a cabo utilizando como recurso la valoración por medio de una aplicación o tarea específica, método de evaluación de ontologías previamente descrito. El primero de ellos se llevó a cabo mediante la utilización de la ontología en un servicio de recomendación de palabras, el segundo de ellos en una aplicación de envío de mensajes a teléfonos móviles. Ambos experimentos son explicados y detallados en las secciones 5.1 y 5.2, mientras que en el siguiente capítulo se verá un análisis de los resultados obtenidos.

\subsection{Mejora en la recomendación de palabras en dispositivos móviles} mediante la aplicación de la ontología de contexto COMoDE.

Para este experimento de prueba de mejora por medio de la ontología COMoDE, relacionado con la recomendación de palabras, se propone la creación de un experimento en línea que evalúa la utilización de la ontología en un sistema de 
recomendación de palabras, similar a la forma en que se hace una búsqueda desde sitios web de búsquedas como Bing (Bing, 2017), Yahoo (Yahoo search, 2017) y Google (Google, 2017), donde se requiere que el usuario haga la introducción de un texto que servirá como la cadena de búsqueda. Este proceso en particular ha sido claramente identificado por diversos autores, como Hattori y colegas (Hattori, Tezuka, \& Tanaka, 2006) (Hattori, Tezuka, \& Tanaka, 2007) que señalan que el proceso de introducción de texto para las búsquedas es crítico y que puede ser mejorado mediante la utilización del contexto.

En este experimento se consideró el trabajo de Arias y colegas (Arias, y otros, 2008) que mostraba una propuesta de generación de recomendaciones de texto para búsquedas web, en las que era considerado el contexto.

De igual forma Adomavicius y Tuzhilin (Adomavicius \& Tuzhilin, 2015) mencionaron que el principal valor de un sistema de recomendaciones en términos generales se centra en que debe ser capaz de predecircuál es el ítem que vale la pena recomendar, así como que las recomendaciones muestran mayor relevancia cuando toman en cuenta el contexto como factor en la elección de la recomendación a considerar. Así como Costa y colegas (Costa \& 
Filho, 2007) mencionaban sobre la sinergia que debe existir entre los sistemas de recomendaciones y la computación sensible al contexto.

A pesar de que la ontología de contexto y el sistema de recomendación de palabras fueron desarrollados para entornos móviles, el experimento fue creado como una aplicación en línea abierta, donde abierta implica que cualquier tipo de dispositivo podría participar, ya sea dispositivo móvil o un equipo de escritorio. Las razones principales para la toma de estas decisiones van relacionadas con la cobertura y el control.

- Cobertura. Buscamos contar con la mayor cantidad de usuarios para colaborar en el experimento. Un experimento en línea nos permite buscar la cobertura de un mayor número de usuarios en contra de una aplicación instalada en equipos locales. Esta cobertura también nos permite tener un grupo más heterogéneo de usuarios, ya que cualquier persona que cuente con un equipo con conexión a Internet podría participar. De acuerdo con Kamvar (Kamvar \& Baluja, 2008) con 30 usuarios se considera como un número representativo de participantes para experimentos similares. Para este experimento en particular consideramos que podríamos obtener entre 30 y 40 participaciones, las que resultarían adecuadas de acuerdo a lo previamente mencionado. 
- Control. La utilización de la aplicación en línea del instrumento de evaluación nos permite contar con cierto nivel de control, ya que la interfaz del experimento se desarrolla para diversos tipos de dispositivos, ya sean móviles o equipos de escritorio, buscando que independientemente del dispositivo la experiencia de participación en el experimento sea equivalente.

\subsubsection{Diseño del experimento}

Para llevar a cabo el experimento de utilización de la ontología de contexto como mejora para un sistema de recomendación de palabras, hemos diseñado y desarrollado una aplicación web considerando los siguientes elementos:

- La creación de contextos simulados en la ontología para ser utilizados como base para el experimento.

- La creación de reglas y un tesauro para dar soporte al sistema de recomendación de palabras.

- El desarrollo de una evaluación por parte del usuario sobre el sistema de recomendación de palabras soportado a través de la ontología de contexto. 
El experimento fue llevado a cabo por medio de Internet a través de una aplicación en línea con la idea de cubrir tantos usuarios como fuera posible, buscando contar con un mínimo de 30 usuarios como fuera propuesto por Kamvar y previamente descrito. La participación fue mediante invitación principalmente entre usuarios ubicados en México, España y Estados Unidos de Norteamérica.

Para evaluar la efectividad de la ontología creamos un experimento por medio de doce ítems que correspondían a doce elementos que representaban diferentes escenarios imaginarios, los cuales se presentaban al usuario divididos en tres distintas clasificaciones, además de la utilización de dos variables independientes para identificar la utilidad de la ontología desde la apreciación de los usuarios participantes.

Los ítems se mostraron uno a uno a cada usuario, en los que se les proponía una situación hipotética y en la que debían de realizar la escritura de una cadena de texto simulando una búsqueda de información de acuerdo al contexto imaginario propio del elemento que correspondía. La cadena de texto podría o no contar con algún nivel de ayuda por medio de la sugerencia de 
palabras para ser completada, de acuerdo a las tres clasificaciones o grupos de items que se especifican a continuación, tal como fueran usadas en experimentos similares Ilevados a cabo por Paek (Paek, Lee, \& Thiesson, 2009) y que se describen a continuación:

- Ítems sin recomendación de palabras (No Word Recommendation, NWR). Son ítems que son utilizados como grupo de control, no cuentan con ninguna recomendación o sugerencia de palabras y en las que los usuarios requerían escribir todo el texto que se les pedía de acuerdo al elemento o escenario imaginario.

- Ítems con recomendación de palabra simple (Simple Word Recommendation, SWR). Ítems de este grupo cuentan con recomendación de palabras o términos mientras el usuario comienza la escritura de los conceptos, pero los términos mostrados provienen directamente de un tesauro sin ningún tratamiento especial, por lo que las sugerencias de términos son un simple listado alfabético de textos filtrados que concuerdan con lo que el usuario haya escrito hasta el momento.

- Ítems con recomendación de palabras basada en contexto (Context Based Word Recommendation, CBWR). Para estos items la recomendación de palabras o términos se hace mientras el usuario 
escribe, pero a diferencia de los del tipo SWR, los términos son obtenidos por medio de la utilización de la ontología para identificar si dicho término es más adecuado de acuerdo al contexto definido para el elemento del contexto imaginario de prueba, por lo que la lista además de coincidir con el filtrado de acuerdo al texto escrito por el usuario, cumple también con condiciones propias aplicadas por las reglas para el contexto simulado.

Los ítems del tipo NWR y SWR actúan como una referencia sobre los ítems que utilizan la recomendación de palabras o términos basada en contexto (CBWR), como fuera utilizado en los experimentos de Paek previamente mencionados.

Las variables independientes que se utilizaron para la evaluación de los ítems nos permitieron identificar las diferencias entre los grupos o clasificaciones de items y de elementos con escenarios imaginarios, obteniendo de esta forma la valoración sobre el impacto de la utilización de la ontología en esta tarea.

Las variables definidas para la medición de los resultados obtenidos en este proceso se determinaron como se describe a continuación: 
- Keystrokes Per Query (KSPQ). KSPQ es la definición de teclas pulsadas para la obtención de la consulta, es decir, es un valor obtenido por medio de la contabilidad de las teclas requeridas para completar la consulta o texto que se propone para cada ítem, este valor es calculado por el conteo de las teclas presionadas ( $k p)$ y el tamaño del texto que se deseaba escribir (ql), dicho valor es computado de la siguiente forma:

$$
K S P Q=\left(\frac{k p}{q l}\right)
$$

En un teclado QWERTY (que es la distribución de teclas más común) sin cometer ningún error en la captura del texto propuesto y sin la utilización de ningún sistema de sugerencia de palabras, el valor de KSPQ debería ser de 1, es decir, el valor del conteo de las teclas presionadas es igual al valor de los caracteres que se deben de capturar. Mientras el valor de KSPQ tienda a cero será mejor valor obtenido para esta variable, ya que implica que se requiere un menor número de presiones de teclas para obtener la cadena de texto buscada. Si la variable es mayor a 1 indica que se tuvieron que hacer correcciones en la escritura y por lo tanto hubo una mayor cantidad de teclas presionadas que los caracteres que se requería introducir de acuerdo al elemento del escenario imaginario. 
- Workload (WL). La variable WL se refiere a la carga de trabajo subjetiva que se requiere para llevar a cabo una tarea. Para esta variable se utilizó una variante denominada $A_{\text {SWAT }}$ (Adapted Subjective Workload Assessment Technique (ASWAT), 2012) de la Técnica Subjetiva de Evaluación de la Carga de Trabajo, identificada como SWAT por sus siglas en inglés y que fuera inicialmente propuesta por Reid (Reid \& Nygren, 1988) y que fuera utilizada por Luximon (Luximon \& Goonetilleke, 20 February 2001) en un experimento similar. La escala NASA-TLX (Hart \& Staveland, 1988) es otra escala muy similar a la $\mathrm{A}_{\text {SwAT }}$ y de igual forma fue utilizada por Kamvar (Kamvar \& Baluja, 2008) en un experimento que requería que los usuarios escribieran un texto utilizando la recomendación de palabras. Ambas escalas han sido ampliamente utilizadas cuando se trata de la evaluación de la carga de trabajo subjetiva, como lo identificó Hendy (Hendy, Hamilton, \& Landry, December 1993). En nuestro experimento la variable WL plantea la medición de la evaluación subjetiva de parte del usuario respecto a la utilización o no utilización de la ontología como apoyo para la recomendación de palabras. La técnica $A_{\text {Swat }}$ permite obtener sus resultados por medio de la utilización de tres conceptos independientes que son evaluados por medio de una escala continua, estos elementos 
miden tres diferentes aspectos de la carga de trabajo (WL). Los conceptos utilizados para el presente experimento son los siguientes:

- ¿Qué sentimiento tiene sobre el tiempo requerido para introducir el texto requerido?

- ¿Qué tan difícil resultó introducir el texto solicitado?

- ¿Qué implicación de estrés sintió cuando tuvo que introducir el texto requerido?

Cada uno de estos conceptos fue mostrado por medio de la utilización de un control del tipo slider (Figura 18) que permitía al usuario seleccionar en una escala continua desde "muy poco" hasta "extenso", que representaba un valor oculto que variaba desde cero (para "muy poco") hasta 100 puntos (para "extensivo").

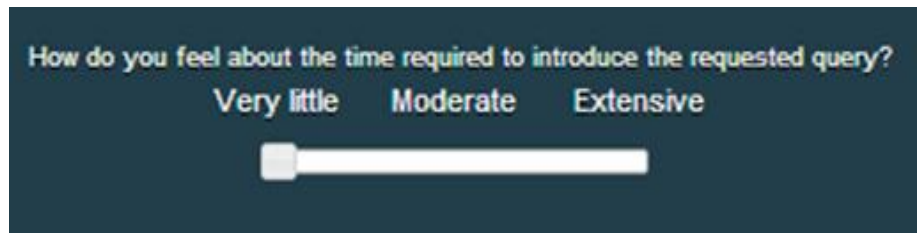

Figura 18. Muestra de la medición de la carga de trabajo. 
Para la creación del software requerido para llevar a cabo el experimento se hizo manejo del lenguaje de programación Java ${ }^{11}$, complementado con la utilización de NetBeans ${ }^{12}$ como entorno de desarrollo integrado para el desarrollo, la fase de pruebas y finalmente la implementación. Se utilizó este lenguaje debido a su habilidad en la manipulación de ontologías por medio de la utilización de la estructura proporcionada por Jena ${ }^{13}$, además de la posibilidad de utilizar estas herramientas en una aplicación en línea por medio de la utilización de Java Servlets ${ }^{14}$, y con la utilización de un servidor Tomcat ${ }^{15}$ para la publicación y puesta en funcionamiento de la aplicación del experimento como una aplicación en línea. Toda la aplicación fue montada en un servidor que contenía una distribución de Linux como sistema operativo. El código fuente del experimento está disponible en Internet a través de un repositorio de GitHub ${ }^{16}$.

\footnotetext{
${ }^{11}$ https:// www.java.com/

12 https://netbeans.org/

${ }^{13}$ https://jena.apache.org/

${ }^{14}$ https://en.wikipedia.org/wiki/Java_servlet

${ }^{15}$ https://tomcat.apache.org/

${ }^{16}$ https://github.com/proyecto-comode/Experimento1
} 
Al inicio del experimento se tiene una pantalla de bienvenida (Figura 19), la que explicaba los detalles del experimento y como se debe participar en él, la página fue diseñada con parámetros para hacerla responsiva, por lo que podía ser utilizada desde un equipo de escritorio, una tableta o un teléfono inteligente. 
COMQDE

Co.

Context Ontology for Mobile Devices

\section{Experiment description \\ Please read all the instructions carefully}

This experiment consists in 12 items which will be showed one by one. Each item will show you an imaginary situation where you should be required to introduce a query search string, this query string must be introduced in the text box, once completed, you should press the "Continue" button:

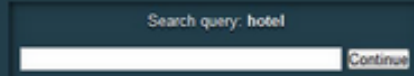

There are three type of items, they are described as follows:

- No Word Fecommendation: You must enter all the asked query text in the box, no helper text will be shown.

- Simple Word Recommendation: When start typing the asked query text in the box, a list of word recommendations will be shown.

- Context Based Word Fecommendation: When start typing the asked query in the box, a list of word recommendations will be shown, but those words are generated based in the imaginary context.

You will always be able to know what type of item are you receiving, in the top-right an indicator will be showed:

Word Recommendation Type

No WR Simple WR Context based WR

After you completed the text in the box and push the "continue" button, an item evaluation section will appear at the bottom part of the page. three slider buttons are shown and you should move it to any side where you consider as a best answer for the related question.
Very little
Moderate
Extensive

\section{Initial Information}

In order to control this experiment session we need you to introduce your email address, this information will be used solely to control this session, you will not receive any comunication from us.

If you want to receive information about the experiment results, please email to vdanielacusur.udg.mx.

Please introduce your email address*

Submit

Figura 19. Página de bienvenida para el experimento, vista desde un

ordenador de escritorio. 
Posterior a la pantalla explicativa y de bienvenida aparecian al usuario doce ítems a los que el usuario debería de evaluar, cada uno de ellos en su página independiente y distribuidos como lo explica la Tabla 13.

\begin{tabular}{|c|c|}
\hline Cantidad & Tipo \\
\hline 4 & NWR \\
\hline 4 & SWR \\
\hline 4 & CBWR \\
\hline
\end{tabular}

\begin{tabular}{|c|c|c|c|c|c|c|c|c|c|c|c|c|}
\hline \multicolumn{13}{|c|}{ Distribución } \\
\hline ह & 1 & 2 & 3 & 4 & 5 & 6 & 7 & 8 & 9 & 10 & 11 & 12 \\
\hline$\stackrel{1}{1}$ & NWR & SWR & CBWR & NWR & NWR & NWR & SWR & SWR & SWR & CBWR & CBWR & CBWR \\
\hline
\end{tabular}

Tabla 13. Cantidad, tipo y secuencia de los ítems de evaluación en el experimento. 
Los ítems que no contenían ningún tipo de recomendación o sugerencia de palabras (NWR) y los que contenian una recomendación simple de palabras (SWR) funcionaron como referencia sobre los ítems que contenían la recomendación de palabras basada en la ontología de contexto (CBWR), tal como se describió previamente que fuera utilizado en experimentos llevados a cabo por Paek (Paek, Lee, \& Thiesson, 2009).

Todos los usuarios recibieron los primeros tres ítems con una secuencia que iniciaba con un elemento de tipo NWR, posteriormente otro del tipo SWR y finalmente uno del tipo CBWR; estos tres ítems funcionaban como una curva de aprendizaje para entender en la práctica el funcionamiento del experimento y sus características de funcionamiento e interacción. El resto de los ítems fueron distribuidos en el mismo orden de tipo de elemento, pero recibiendo el usuario tres de cada uno de ellos, para completar los 12 ítems con los que participaría (Tabla 13).

Para funcionar, cada ítem mostraba alguno de los elementos con escenarios imaginarios que se diseñaron para el experimento, de los que fueron creados doce diferentes y que eran entregados a los usuarios de forma aleatoria 
(Apéndice C). Esto quiere decir que en el ítem uno podría aparecer cualquiera de los doce elementos imaginarios, para el ítem dos aparecería cualquier de los elementos imaginarios restantes y así sucesivamente, hasta completar los doce items de la evaluación, con los doce elementos de escenarios imaginarios. De esta forma se buscó que cualquiera de los elementos con escenarios imaginarios fuera evaluado en cualquiera de los tipos de ítems del experimento (NWR, SWR y CBWR).

Todos los ítems independientemente del tipo que se trate, estaban divididos en tres secciones:

- Una primera sección que detalla al usuario el escenario imaginario sobre el que se haría el experimento y que define el contexto simulado sobre el que se basa el ítem.

- Una segunda sección que contiene una caja de texto donde el usuario debe de introducir la cadena de texto que se le solicita, en la que no podrá avanzar hasta no completar la captura del texto indicado. Es en esta sección donde existe una diferencia entre los diversos tipos de ítems del experimento, ya que en el caso de los ítems del tipo NWR el usuario deberá introducir todo el texto utilizando el teclado de su dispositivo, en el caso de los ítems del tipo SWR conforme el usuario comienza con la 
escritura del texto solicitado le aparecerán sugerencias de palabras, las que podrá ir seleccionando para evitar la escritura completa del texto, finalmente en el caso de los ítems del tipo CBWR también aparecerán sugerencias pero que en este caso serán generadas de acuerdo al contexto imaginario del elemento que corresponde, en las que también podrá seleccionar entre las alternativas disponibles de forma que les permite ahorrar en la escritura del texto requerido.

- Una sección final que consiste en la evaluación de la experiencia relacionada con el trabajo realizado para el ítem y la utilización de las recomendaciones de términos en el caso de los ítems SWR y CBWR, desde el punto de vista del participante en el experimento. Cabe mencionar que esta sección permanece oculta hasta que el usuario completa el texto que debe introducir en la caja de texto, para posteriormente aparecer y permitir al usuario evaluar su experiencia en el ítem.

Como se mencionó previamente, para la creación de los elementos se han definido escenarios imaginarios en los que el usuario debería de introducir unos términos en una caja de texto y en los que en algunos casos el sistema le mostraría sugerencias de términos como una forma de optimización para la 
captura del texto. Cada elemento contaba además con una definición de contexto precargada en la ontología (Figura 20) de forma que permitiera al sistema ofrecer las sugerencias de palabras que se requerían y que se encontraban ligadas a cada uno de los escenarios imaginarios de los elementos, por lo que también se generaron los contextos imaginarios ligados a cada escenario. Para la construcción de estos requerimientos se utilizó la herramienta para edición de ontologías creada por la Universidad de Stanford (Stanford University, 2017) denominada Protégé, la que ofrece diversas funcionalidades para la creación y edición de ontologías.

Cada escenario imaginario se asignaba a los usuarios de forma aleatoria buscando uniformidad en la aplicación del instrumento, por lo que cada ítem era diferente entre los usuarios y también era mostrado en orden diferente entre usuarios. 


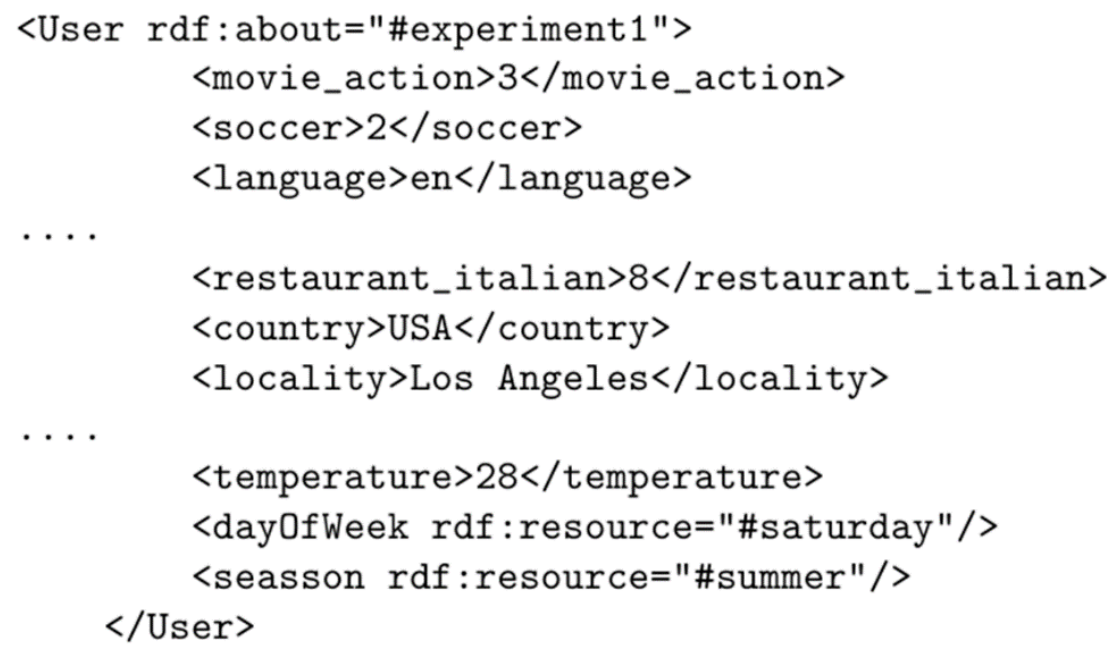

Figura 20 Ejemplo de instanciación en la ontología COMoDE utilizada en un contexto simulado.

De igual forma se crearon un conjunto de reglas (Figura 21) que permitían obtener las características del contexto simulado para cada ítem y que servían de apoyo para el sistema de recomendación de palabras utilizado en el experimento, ya que estas reglas permitían identificar las palabras que eran adecuadas de acuerdo al contexto simulado y las condiciones que indicaban las reglas definidas para ello. 


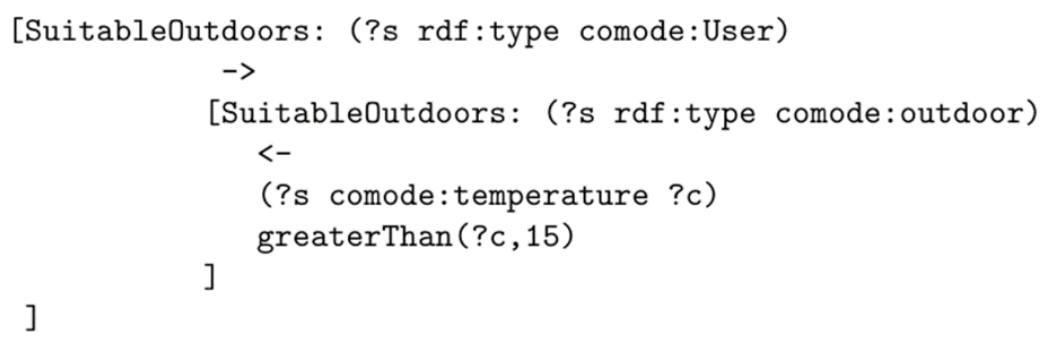

Figura 21 Ejemplo de una regla aplicada a la ontología COMODE.

Finalmente se hizo utilización de un tesauro para dar soporte y proveer de los contenidos requeridos para el sistema de recomendación de palabras utilizado en el experimento.

Construir un tesauro requiere de un trabajo arduo de llevar a cabo para la identificación, organización y la captura de los términos que lo componen, pero es una tarea de una sola vez, tal como lo considera Hunemark (Hunemark, 2010). Para el caso del tesauro utilizado en el experimento se incluyeron solamente términos relacionados con el ocio con la finalidad de establecer solamente términos que podrían ser de utilidad en esta tarea, considerando que el ocio es uno de los principales tipos de actividades que se llevan a cabo en los teléfonos móviles de acuerdo a Lepp (Lepp, Andrew, 2014). 


\subsection{Mejora de un sistema de envío de mensajes mediante la aplicación de} la ontología de contexto COMoDE.

En el segundo experimento elaborado para llevar a cabo la mejora de una funcionalidad o servicio de los dispositivos móviles mediante la utilización de la ontología de contexto, al igual que en el experimento previo, se llevó a cabo una prueba basada las características de evaluación en una aplicación o tarea, de acuerdo a las clasificaciones de tipos de evaluación de ontologías previamente descritas.

Para este experimento se propone la utilización de un sistema de distribución y envío de mensajes a una aplicación móvil, que a su vez permita una retroalimentación manual por parte del usuario móvil, una variante del que fuera mostrado por Jeng (Jeng, Shu, Huang, Huang, \& Chen, 2015) que utiliza la retroalimentación para la toma de decisiones, en este caso la información de retroalimentación es la valoración del usuario respecto al mensaje recibido, valorando la oportunidad del mensaje recibido.

Se siguió el mismo esquema en la valoración del experimento que en el caso del experimento anteriormente mostrado en el presente capítulo, donde se 
utilizó el modelo de experimentación controlada propuesto por Christensen (Christensen, 2007) y que previamente fue mencionado, en el que se establecen dos muestras, una de control y otra que es utilizada como la prueba del experimento, en el caso de esta prueba la muestra de control consiste en el envío de mensajes sin la utilización de la ontología contra la muestra de prueba que es el grupo de mensajes enviados mediante la utilización de la ontología.

En este experimento se busca que se tenga una interacción más cercana a lo esperado en la utilización real de la ontología, por lo que se decidió implementar la utilización del contexto definido por la ontología en una aplicación especialmente diseñada para ello, bajo las siguientes características:

- Interacción con el usuario. Se buscó que el experimento representara una interacción con el usuario lo más cercana posible a la forma en que los usuarios hacen uso de los dispositivos móviles en la actualidad, generalmente por medio de aplicaciones instaladas en el propio dispositivo.

- Control. En el caso particular de este experimento el control se aseguró por medio de la utilización de una aplicación móvil especialmente diseñada para el experimento, en la que se invitó a participar a un grupo particular de usuarios. 


\subsubsection{Diseño del experimento}

A grandes rasgos, se trata de la creación de un prototipo que valide la funcionalidad de la ontología que define el contexto para dispositivos móviles a través de una prueba experimental mediante un servicio de envío de mensajes masivos y personalizados desde un servidor y hacia una aplicación para dispositivos móviles instalada en equipos de los usuarios participantes en el experimento, en la que los usuarios validen la pertinencia o no del mensaje recibido.

La idea fundamental es que exista un servidor con la función de enviar mensajes informativos a una aplicación móvil, los que se distribuyen de acuerdo a si corresponden al grupo de mensajes de control o al grupo de mensajes de prueba. Los mensajes utilizados como grupo de control serían enviados sin la utilización de la ontología por lo que no tendrían en cuenta el contexto ni las preferencias del usuario, para el caso de los mensajes de la prueba se utilizaría la ontología que define el contexto y las preferencias, así como las reglas que validan si el mensaje es el indicado para ser enviado a cada uno de los usuarios en particular, es decir, como fuera mencionado por Emmanouilidis y colegas (Emmanouilidis, Koutsiamanis, \& Tasidou, 2013), enviar la información correcta a la persona correcta, en el momento correcto y en el lugar adecuado. 
Todos los mensajes son recibidos por una aplicación móvil desarrollada ex profeso para el experimento y que permite evaluar el mensaje recibido por parte del usuario, para que la retroalimentación obtenida sea almacenada en una base de datos identificando a que grupo de mensajes corresponde. Mehrotra y colegas (Mehrotra, Hendley, \& Musolesi, 2016) Ilevaron a cabo una propuesta similar que filtra los mensajes que le son mostrados al usuario de acuerdo a sus preferencias, la diferencia con nuestra propuesta radica básicamente en el aspecto del filtrado de los mensaje ya que se lleva a cabo sobre los mensajes recibidos, a diferencia de nuestra propuesta que hace el análisis de las preferencias y el contexto del usuario previo al envío de los mensajes, por lo que el usuario recibirá sólo los mensajes que cumplan con las características determinadas por su contexto.

Por ejemplo, se pretende enviar un mensaje sobre un partido de fútbol que se Ilevará a cabo en la cancha principal de un campus universitario, para lo que se debe introducir la información concerniente al evento en la página en el servidor diseñada para la captura de esa información, se introduce la información del mensaje que incluye un título y el texto mensaje, si el mensaje es del grupo de prueba se elige la clasificación del tipo o características del mensaje (evento deportivo, futbol). El servidor entonces debe validar si el usuario está 
geolocalizado en la ciudad (ubicación) para no enviarlo a una persona que esté en otra población y si el usuario tiene interés en los deportes y/o en el fútbol en particular (preferencia). Posteriormente, el mensaje es enviado a la aplicación cliente de todos los usuarios que cumplen con las condiciones o reglas determinadas para el mensaje y de acuerdo al contexto y preferencias del usuario. Finalmente, el usuario evalúa la pertinencia del mensaje recibido.

Para el caso de este experimento se llevó el registro de los resultados obtenidos mediante la retroalimentación de los usuarios buscando determinar la utilidad de la ontología en el sistema de envío de mensajes. Para cada mensaje enviado se obtenían los siguientes valores:

- Tipo de mensaje enviado. Identifica si el mensaje correspondía al grupo de control o al grupo de prueba.

- Alcance de usuarios. Determina a cuantos usuarios les fue entregado el mensaje, por lo que cuando el mensaje es del grupo de control será el número total de usuarios registrados en el experimento, mientras que para el grupo de prueba el valor obtenido será variable, de acuerdo al número de usuarios que cumplan con las condiciones establecidas por el mensaje en particular. Se identifica mediante el término Al. 
- Oportuno. Valor de sumatoria de todos los usuarios que valoraron el mensaje como un mensaje oportuno, se identifica por medio del valor Op

- Inoportuno. Valor de sumatoria de todos los usuarios que valoraron el mensaje es inoportuno y se identifica por medio del valor In.

Cabe mencionar que el valor de sumatoria obtenido por los mensajes calificados como oportuno e inoportuno pueden no coincidir con el total de usuarios a los que les fue enviado el mensaje y que se identificaron mediante el valor definido como alcance, ya que puede haber usuarios que simplemente cierren la notificación y no provean de respuesta alguna. En estos casos sólo se consideran los datos obtenidos mediante retroalimentación de los usuarios.

Todos estos datos nos permiten identificar las diferencias respecto a los resultados conseguidos entre el grupo de control y el grupo de prueba, valorando el impacto que el uso de la ontología implica en el envío de este tipo de mensajes, obtenido mediante los siguientes cálculos:

- Alcance real. Ya que existe la posibilidad de que algún usuario no proporcione respuesta sobre el mensaje que se le proporciona, por desinterés, imposibilidad de atender o cualquier otro asunto, se 
considera que el valor del alcance real de cada mensaje enviado se debe de calcular mediante la suma de los valores de oportuno e inoportuno obtenidos por el mensaje, descartando el resto de los usuarios que no proporcionaron respuesta alguna.

$$
A_{R}=O p+I n
$$

- Oportunidad del mensaje. La oportunidad del mensaje mide la evaluación de los usuarios respecto a la recepción de los mensajes en la aplicación móvil, este valor será el que fundamentalmente nos podrá mostrar el impacto positivo que implica la utilización de la ontología como validación para el envío de los mensajes, se calcula determinando el valor porcentual de la calificación de oportunidad obtenida por el mensaje a valorar:

$$
T_{M}=O p / A_{R}
$$

En este valor se busca obtener un valor mayor entre los mensajes del grupo de prueba en los que su envío está basado en la ontología, respecto a los mensajes del grupo de control, que son enviados sin la utilización de la ontología. 
- Inoportunidad del mensaje. Es la medición del impacto negativo obtenido por el mensaje, sirve como complemento para el resultado obtenido por el indicador previo, ya que permite identificar el valor relacionado con la consideración negativa que los usuarios otorgan al mensaje recibido, es calculada de la siguiente forma:

$$
I_{M}=\operatorname{In} / A_{R}
$$

De esta forma los valores de $T_{M}$ e $I_{M}$ son complementarios, por lo que la suma de ambos debe resultar con el valor de 1, que representa al 100\% de los participantes que completaron la retroalimentación para la pregunta en cuestión.

$$
1=T_{M}+I_{M}
$$

- Efectividad de respuesta. Este valor nos permite identificar en qué grado los datos obtenidos como respuestas representan a la totalidad de los usuarios que debían de responder de acuerdo al tamaño de muestra que corresponde para la población en la que se está validando el instrumento, considerando a la población de cada ítem como a la totalidad de los usuarios que cumplen con los parámetros de grupo de control o grupo de prueba $\left(A_{R}\right)$, es decir, los usuarios que deben recibir el mensaje. La 
efectividad de la respuesta es entonces la forma en que se identifica que la cantidad de usuarios que proporcionaron retroalimentación para cada ítem se puede considerar como una muestra válida.

La fórmula general para la determinación del grado de confianza es la siguiente:

$$
n=\frac{N \sigma^{2} Z_{\alpha}^{2}}{e^{2}(N-1)+\sigma^{2} Z_{\alpha}^{2}}
$$

En la que las variables se describen como sigue:

$\sigma=$ Es la desviación estándar de la población, en la que en caso de no contar con dicho valor se utiliza la constante de 0,5 , que será el valor utilizado en este ejercicio.

$Z_{\alpha}=$ Es el valor del nivel de confianza, el cual se obtiene de la tabla de distribución normal de acuerdo al nivel de confianza buscado para el análisis de la muestra, en el caso de este experimento se buscó obtener un nivel de confianza del 95\%, lo que equivale al valor de 1,64.

$e=$ Es el límite aceptable de error muestral, para que el que se utilizó el valor intermedio de 0,05 que equivale a un $5 \%$ de límite aceptable. $N=$ Es el valor del tamaño de la población, que para el experimento equivale al valor de $A_{R}$. 
Utilizando como base la fórmula en cuestión se puede identificar los ítems en los que la cantidad de participación de los usuarios no puede ser considerada dentro del nivel de confianza buscado, mediante el siguiente cálculo:

$$
E_{R}=\frac{A_{R}}{n}
$$

En el que el valor obtenido debe ser mayor o igual a 1 para considerar que la participación es válida.

Para llevar a cabo el experimento se desarrollaron tres diversos componentes que permitieron efectuar la difusión y puesta en funcionamiento del experimento, así como dar seguimiento a su desarrollo y la obtención de los resultados,

- Sitio web informativo y para la descarga de la aplicación cliente.

- Aplicación de servidor.

- Aplicación cliente para dispositivos móviles.

Sitio web del experimento

Para el experimento se implementó un sitio web informativo temporal diseñado (Figura 22) mediante la utilización de tecnología responsiva con la finalidad de 
que pudiera ser accedido desde cualquier dispositivo móvil sin detrimento en la calidad de la visualización del contenido.
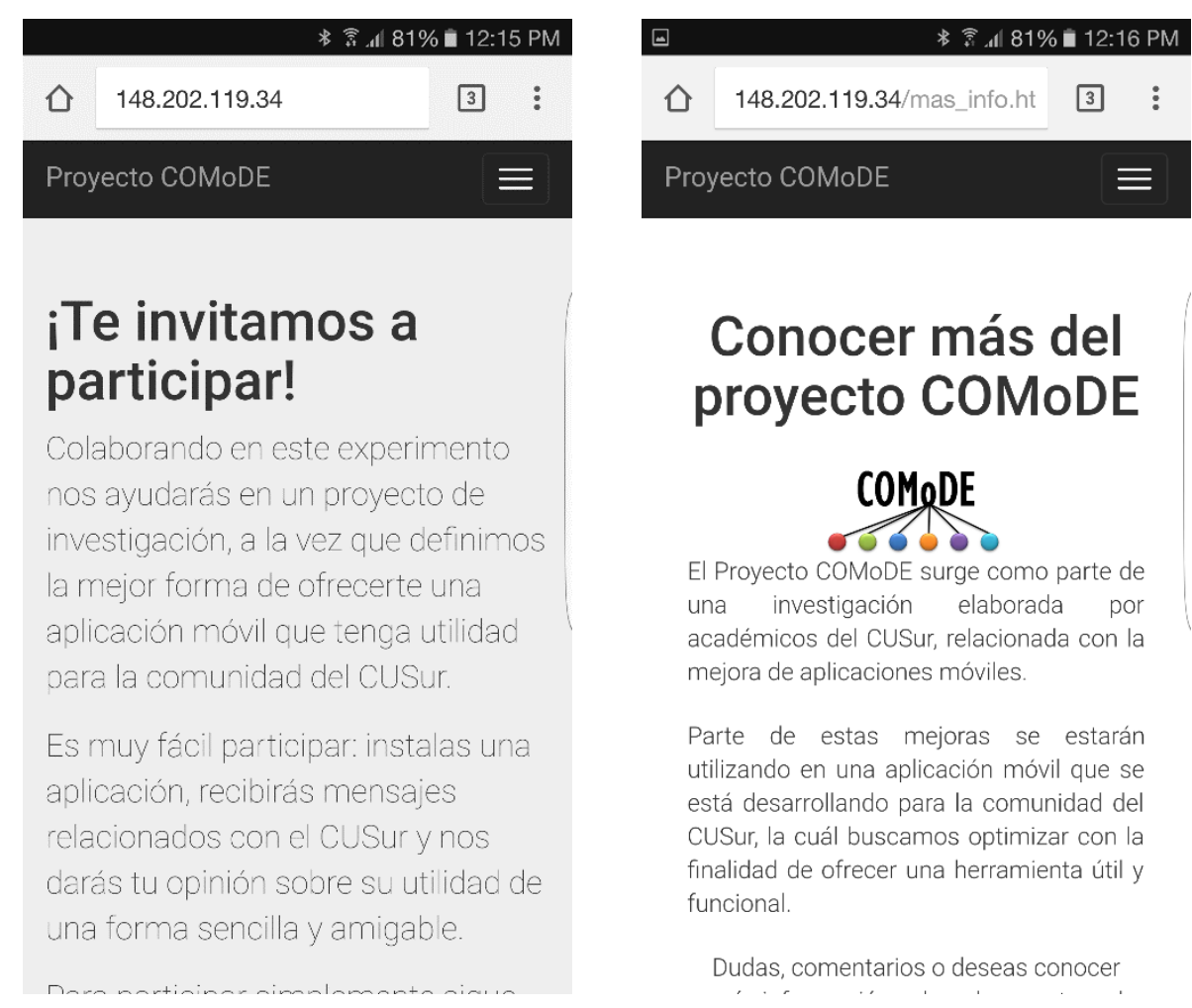

\title{
Conocer más del proyecto COMoDE
}

COMgDE

\section{obsos}

El Proyecto COMoDE surge como parte de una investigación elaborada por académicos del CUSur, relacionada con la mejora de aplicaciones móviles.

\begin{abstract}
Parte de estas mejoras se estarán utilizando en una aplicación móvil que se está desarrollando para la comunidad del CUSur, la cuál buscamos optimizar con la finalidad de ofrecer una herramienta útil y funcional.
\end{abstract}

Dudas, comentarios o deseas conocer

Figura 22. Captura de pantalla del sitio web destinado a la información sobre el experimento y descarga de la aplicación.

En el sitio se podía encontrar una explicación de los objetivos y la finalidad del experimento, así como el enlace para la descarga del archivo APK para dispositivos con el sistema operativo de Android de la aplicación necesaria para 
participar, las indicaciones para su instalación, configuración y finalmente las instrucciones sobre cómo se llevaría a cabo la colaboración con el experimento.

En la página de inicio del sitio web se describía paso a paso la forma en que los usuarios podrían participar, así como otro enlace que detallaba las intenciones del proyecto en general y el porqué del experimento (Figura 23).

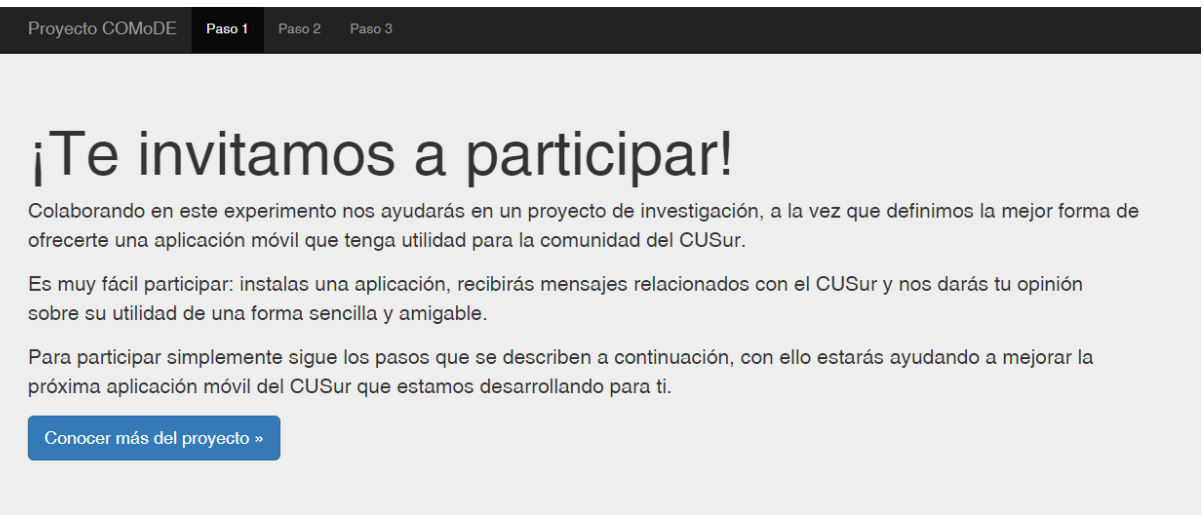

Paso 1: Descarga la aplicación

Se requiere de la instalación de un aplicación, la cuál
estará reoibiendo meneajes que forman parte del experimento. Una vez concluido el experimento puedes desinstalarla ein problema.

Ver más información "
Paso 2: Configura las preferencias

Deberás configurar tus preterencias de la aplicación del
experimento.

Ver más información "
Paso 3: Participa activamente

La aplicación instalada y configurada te permitiré recibir
moneajos do interés para la comunidad universitaria, tu funoión será calficicar si el mensaje recibido fue apropiado ○ no. Éeta valoración dependerá de si el meneajo es de tu interés, te llega en el tiempo o lugar adecuades.

Figura 23. Captura de pantalla (versión escritorio) del sitio web destinado a la información del experimento. 
La página que especificaba el proceso requerido para la instalación de la aplicación móvil del experimento era accedida a través de la sección de "Descarga de la aplicación" y en ella se podía tener acceso al enlace para la descarga del archivo COMoDE.apk (Figura 24). El archivo se debía descargar y posteriormente abrir en cualquier sistema operativo Android, aunque para su funcionamiento correcto se debían seguir los pasos de instalación de acuerdo a las configuraciones de seguridad de aplicaciones propias de cada dispositivo, además de realizar la configuración inicial que requiere que el usuario elija de entre las preferencias que le mostrará en pantalla. 


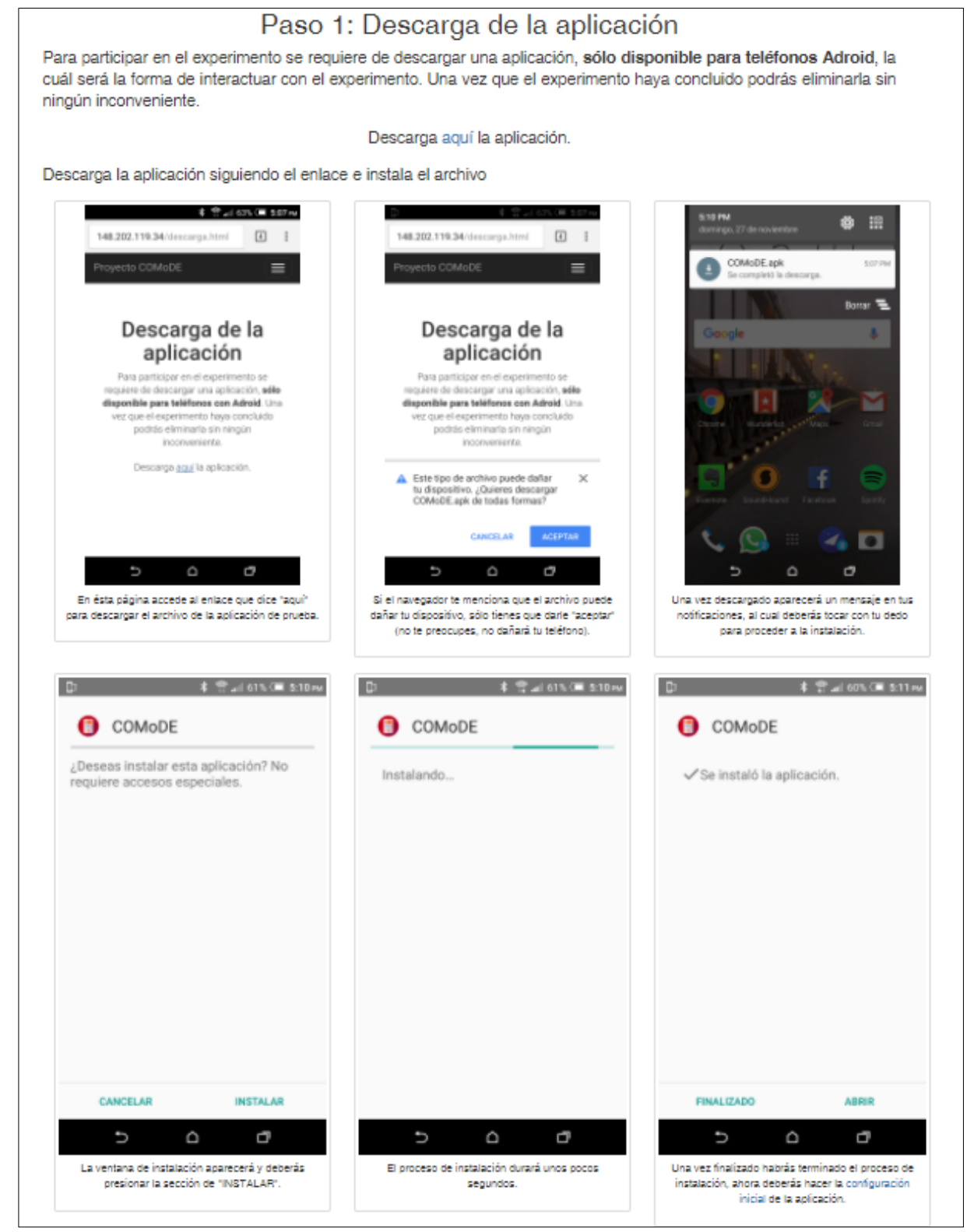

Figura 24. Captura de pantalla (versión escritorio) del sitio web destinado a la información sobre la descarga e instalación de la aplicación móvil del 
Posterior a la instalación de la aplicación móvil era requerido que se llevará a cabo un pequeño paso para la configuración de las preferencias, el cual también era detallado en el sitio web. Finalmente, también se describía la forma en que el usuario estaría interactuando con el experimento mediante la recepción de notificaciones en la aplicación, a las cuales les debería de dar una respuesta para completar la actividad correspondiente (Figura 25).

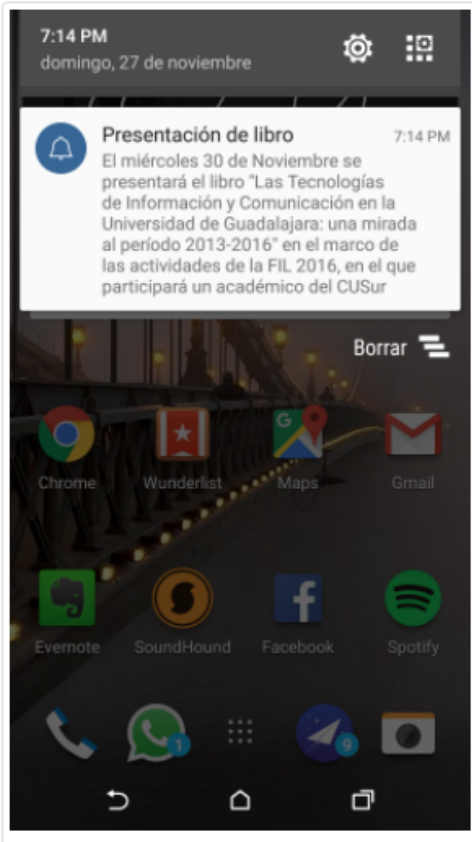

Esporádicamente recibirás notificaciones referentes a actividades y avisos del CUSur, simplemente ábrelas para revisar los detalles.

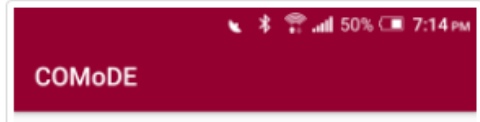

Presentación de libro

El miércoles 30 de Noviembre se presentará el libro "Las Tecnologías de Información y Comunicación en la Universidad de Guadalajara: una mirada al período 2013-2016" en el marco de las actividades de la FIL 2016, en el que participará un académico del CUSur

La notificacion fue

OPORTUNO INOPORTUNO

Figura 25. Captura de pantalla del detalle donde se explica la interacción con la aplicación para los usuarios del experimento. 
Para el diseño del sitio web se utilizó fundamentalmente la herramienta Bootstrap $^{17}$ que es una estructura que hace utilización de HTML, CSS y JavaScript para la creación de sitios web responsivos de una forma amigable.

El sitio web y la aplicación servidor utilizada para el experimento se montaron en un equipo de cómputo que tenía una IP pública con permisos específicos en el firewall para poder ser accedida desde cualquier equipo con conexión a Internet. Para su funcionamiento y al no tener grandes necesidades se utilizó una herramienta WAMP ${ }^{18}$ que permitiera establecer el servicio de forma rápida, siendo la popular XAMPP ${ }^{19}$ en su versión 3.2.2 la que se instaló en el equipo que funcionó como servidor, montado sobre Microsoft Windows en su versión 10 como sistema operativo base. Cabe mencionarse también que en este equipo también se llevó cabo toda la programación requerida para el experimento.

\footnotetext{
${ }^{17}$ http://getbootstrap.com/

${ }^{18}$ https://es.wikipedia.org/wiki/WAMP

${ }^{19}$ https://www.apachefriends.org/es/index.html
} 


\section{Aplicación del Servidor}

La aplicación del servidor tiene tres objetivos primordiales (Figura 26),

1. Llevar el registro de los dispositivos de los usuarios que acceden al experimento y determinar los datos de contexto y preferencias propios de cada usuario;

2. El envío de mensajes a los dispositivos de los usuarios identificando si el mensaje corresponde al grupo de control o al grupo de prueba (a elección del usuario que envía el mensaje) y en el caso de los mensajes de prueba deberá elegir si es adecuado o no de acuerdo al contexto de cada usuario;

3. Recuperar la retroalimentación de cada usuario respecto a la oportunidad (o no) existente en los mensajes de acuerdo a los criterios de cada usuario participante y del grupo de mensaje que corresponde, ya sea de control o de prueba. 

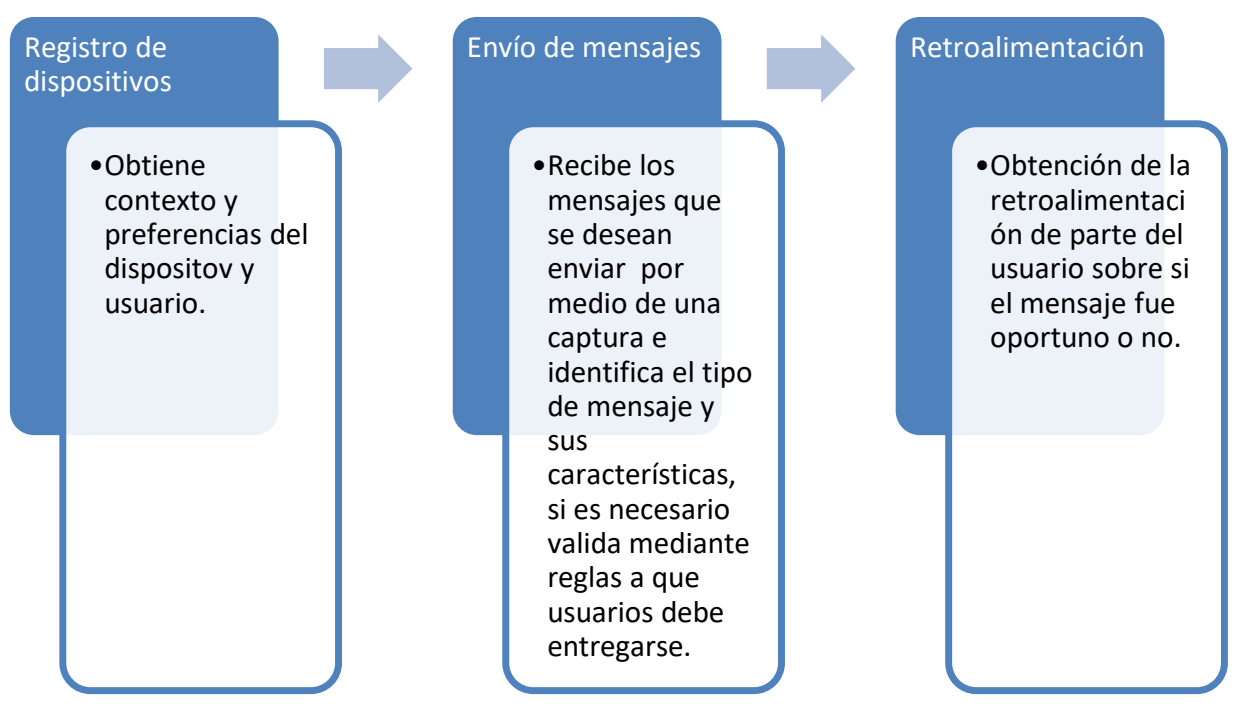

Figura 26. Vista general del proceso realizado en el servidor de envío de mensajes.

Para el sistema de envío de mensajes para este experimento se llevó a cabo la utilización del servicio Firebase Cloud Messaging ${ }^{20}$ (FCM), que es una arquitectura proporcionada por Google para envío de mensajes multiplataforma de uso libre que sustituye a la anterior arquitectura de Google Cloud Messaging, y que funciona mediante el esquema de:

- Un origen para las notificaciones, ya sea mediante la Consola que proporciona Firebase o por medio de un servidor denominado entorno de

${ }^{20}$ https://firebase.google.com/docs/cloud-messaging/ 
confianza basado en HTTP o XMPP, en este caso se utilizó el servidor HTTP por su simpleza de uso y ya que no se requería de mayores funcionalidades.

- El servicio de Firebase Cloud Messaging, que es el que se encargar de encauzar las peticiones que se hacen desde el entorno de confianza.

- Una aplicación cliente que recibe las notificaciones, que puede ser una aplicación para Android, iOS o Web. En el caso del presente experimento la aplicación cliente se desarrolló solamente para la plataforma Android.

En primer término, para el registro de los dispositivos en la aplicación del servidor se requiere que el usuario instale y configure la aplicación especialmente diseñada para el experimento, obteniendo de esta forma la ontología que define el contexto y preferencias propias de cada usuario, los que son almacenados en el servidor para su posterior utilización.

Este registro se hace al momento de instalar la aplicación y realizar la configuración de las preferencias de usuario (Figura 27) y consiste en la identificación del dispositivo por medio de un token generado por el servicio de notificaciones Firebase Cloud Messaging y al que se le enlazan los datos 
obtenidos del contexto del dispositivo y las preferencias que el usuario haya registrado. Todos estos datos son almacenados en una ontología mediante la utilización de una interfaz de Jena.

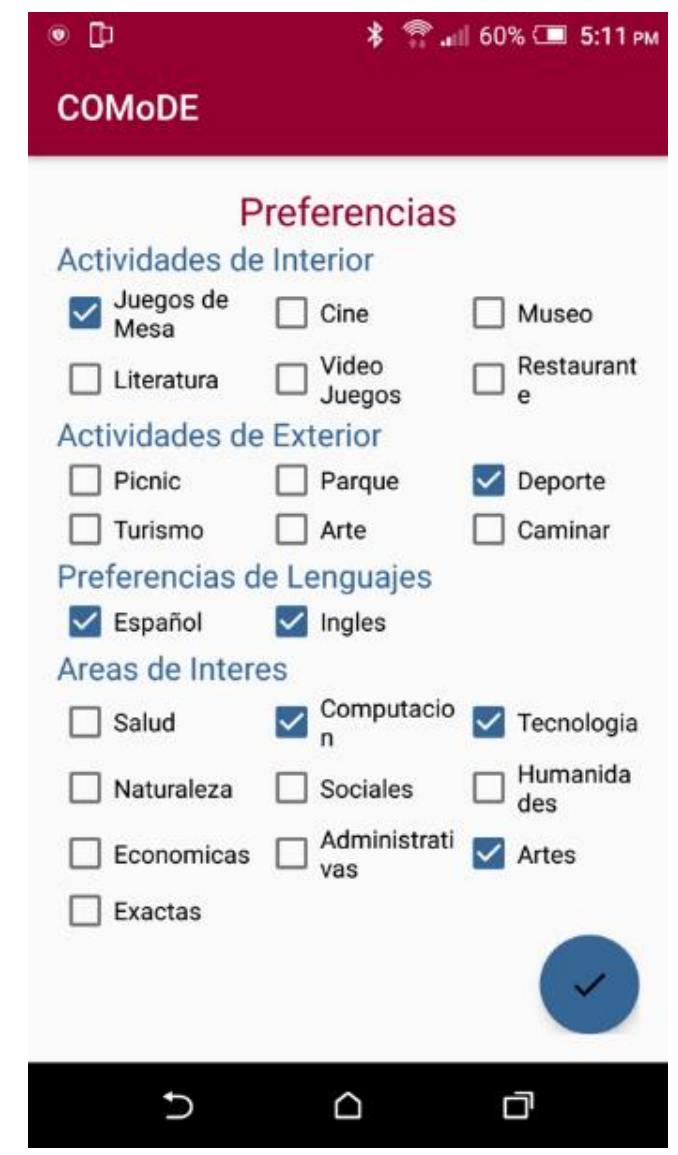

Figura 27. Captura de preferencias en la aplicación móvil, para su registro en el servidor. 
En segundo momento, la aplicación del servidor cuenta con una interfaz vía web para la entrada de los mensajes que se van a enviar a los usuarios (Figura 28), la que permite recibirlos, procesarlos e identificar a que usuarios se debe de enviar, para finalmente hacer el envío.

En esta interfaz también se muestra la opción de enviar el mensaje de forma general para el grupo de mensajes que será considerado como de control o por medio del uso de la ontología que define el contexto y preferencias de cada uno de los usuarios para el grupo de mensajes que corresponde al grupo de prueba del experimento. 


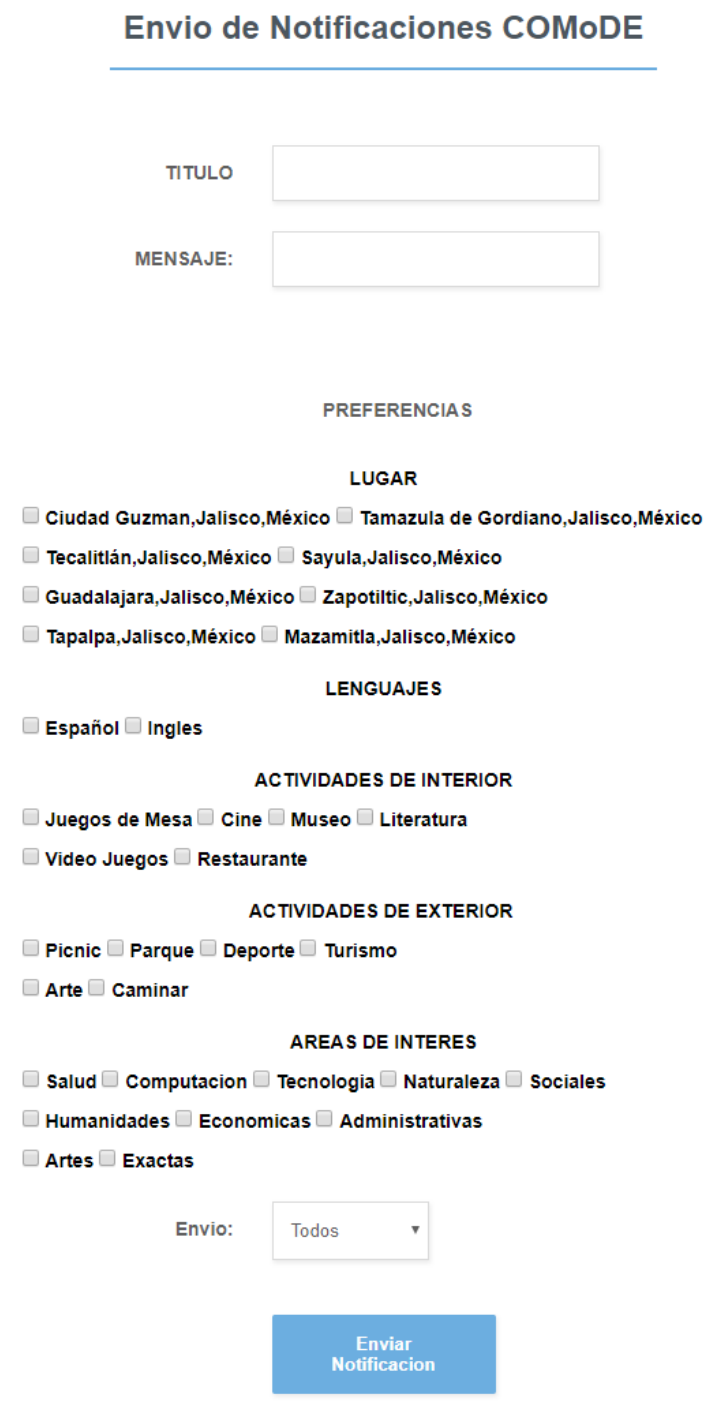

Figura 28. Página de captura de mensajes de la aplicación servidor.

Una vez escritos los datos propios del mensaje y seleccionadas las opciones de envío, se selecciona si será un mensaje del tipo general (grupo de control) o mediante la utilización de la ontología (grupo de prueba), siendo esta última la 
que obliga a que sea seleccionada al menos alguna de las opciones disponibles para personalizar las características del envío del mensaje.

Cuando se determina que el envío del mensaje está listo para ser llevado a cabo, se presiona el botón del "Enviar Notificación" que ejecuta el proceso de envío del mensaje por medio del servicio de notificaciones de Google, el FCM previamente descrito; en el caso del grupo de control de forma inmediata y para todos los tokens registrados, en el caso de los mensajes de grupo de prueba se realiza la validación mediante la utilización de la ontología y las reglas que indican para que usuarios es válido hacer el envío del mensaje, para entonces enviarlos a los tokens que corresponden a los usuarios que cumplen con las condiciones de la entrega.

La aplicación del servidor cuenta también con un componente que permite recibir la retroalimentación de parte de los usuarios para cada mensaje que es enviado, independientemente si fuera enviado como parte de los mensajes del grupo de control o de los mensajes del grupo de prueba del experimento, almacenando la información obtenida en una base de datos. 
Para el desarrollo de la aplicación del servidor se utilizó como entorno integrado de desarrollo la plataforma de NetBeans en su versión 8.2, en el cual se llevó a cabo la programación, depuración, prueba y puesta en funcionamiento mediante la utilización de nueva cuenta del lenguaje de programación Java, la interfaz con la ontología por medio de Jena y el manejo de JavaServlets, utilizando para este experimento la plataforma de GlassFish ${ }^{21}$ para su publicación en línea e interfaces requeridas para generar todo el proyecto. El código fuente se encuentra disponible en GiHub²2.

Cliente móvil

En términos generales el cliente que se generó para el experimento se encarga de identificar el contexto en el que se encuentra el usuario y su dispositivo, así como sus preferencias personales, los cuales se almacenan en la ontología y son compartidos con el servidor que administra los mensajes. De igual forma se encarga de recibir los mensajes y mostrarlos al usuario, para que finalmente sea el propio usuario quien califique si el mensaje fue oportuno o no.

\footnotetext{
${ }^{21}$ https://es.wikipedia.org/wiki/GlassFish

${ }^{22}$ https://github.com/proyecto-comode/Experimento2-WebService
} 
Esta aplicación se desarrolló a través de la utilización de la plataforma de diseño para Android denominada Android Studio, con la que se generó el archivo .APK ${ }^{23}$ correspondiente a la aplicación para dispositivos móviles. El código fuente se encuentra disponible en GitHub ${ }^{24}$.

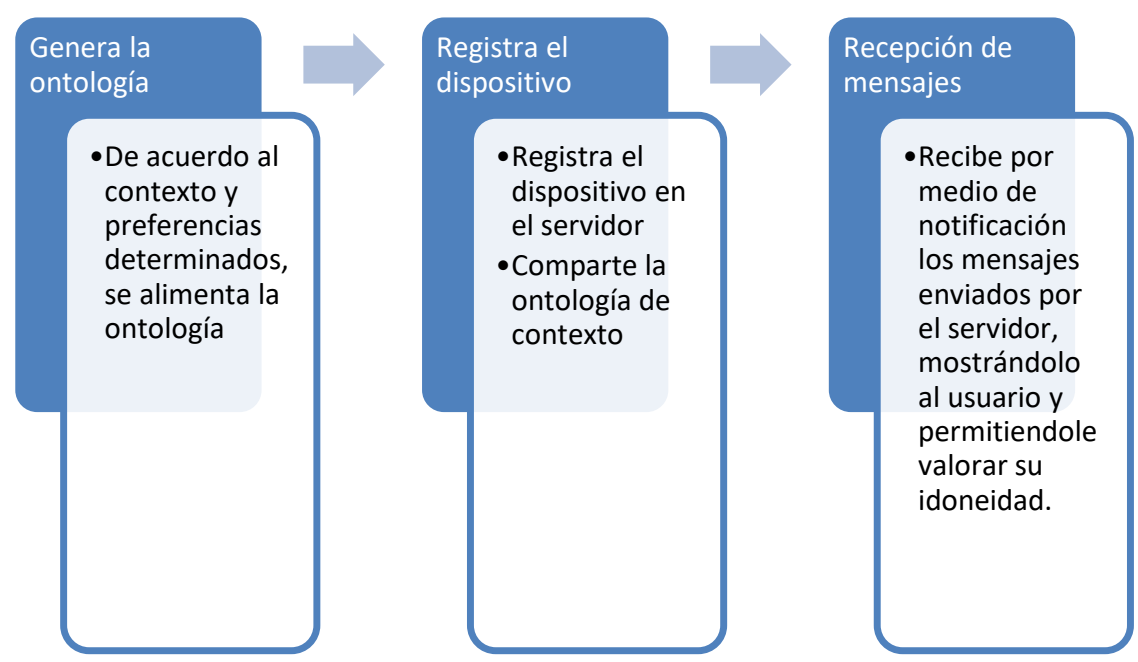

Figura 29. Vista general del proceso que se lleva a cabo en la aplicación móvil del experimento.

\footnotetext{
${ }^{23}$ https://es.wikipedia.org/wiki/APK_(formato)

${ }^{24}$ https://github.com/proyecto-comode/Experimento2-app
} 
En la aplicación móvil generada para el experimento se cuenta con un par de funciones solamente, una de ellas es la configuración preferencias y la otra es la recepción y calificación de los mensajes que forman parte del experimento.

La definición de preferencias se hace a través de la selección de diversas opciones, las cuales al ser seleccionadas por el usuario son almacenadas en la ontología de definición del contexto móvil para cada uno de los usuarios de la aplicación. Las preferencias pueden ser modificadas a voluntad por el usuario e implica que cada que se realice un cambio se actualizan las preferencias en la instancia de la ontología de contexto correspondiente al usuario.

Una vez que las preferencias han sido definidas y guardadas, se comienza a recibir mensajes a través de notificaciones en el dispositivo, las cuales deben ser evaluadas por el usuario en cuanto a su oportunidad, es decir, que el mensaje llegó correcta o incorrectamente de acuerdo a las características en las que este ha sido recibido, ya sea por las preferencias que el usuario había plasmado en la aplicación, la ubicación geográfica, la fecha y hora, entre otros. 


\section{Capítulo 6}

\section{Análisis de los resultados obtenidos}

En el presente capítulo se discuten los resultados obtenidos de los experimentos para la evaluación de la aplicación de la ontología como mejora de dos servicios propios de los dispositivos móviles, detallados en el capítulo 5, que a su vez se soportaron en los contenidos sobre evaluación de ontologías mencionados en el capítulo 2.

Como se mostró previamente, la valoración se llevó a cabo por medio de dos experimentos que permitieron identificar si desde el punto de vista de los usuarios la utilización de la ontología que define el contexto significó una mejora en dos tareas o aplicaciones muy específicas, la recomendación de palabras como soporte para la introducción de un texto, así como en el envío de mensajes a través de un servicio de mensajería para dispositivos móviles. 
Al igual que en el capítulo anterior donde se mostraron los experimentos realizados, en este capítulo se discutirán los resultados de forma separada para ambos experimentos.

\subsection{Resultados en un experimento de recomendación de palabras}

La participación para el experimento estuvo abierta por medio de invitación para personas de diversos lugares geográficos y de diversas actividades profesionales, con la intención de obtener un grupo de usuarios lo más heterogéneo posible, buscando que los resultados tuvieran una mayor relevancia y significado para el proyecto.

Finalmente se pudo contar con la participación de 38 usuarios, que es un valor dentro de lo esperado para este experimento y que resulta un poco superior a lo mostrado por Kamvar (Kamvar \& Baluja, 2008) en un experimento similar, en el que intervinieron un total de 30 personas.

Los resultados obtenidos se obtuvieron mediante la concentración de información relacionada con dos variables independientes, la variable Keystrokes Per Query (KSPQ) y la variable Workload (WL), ambas explicadas 
referente a su significado y el valor funcional que representan para los fines del experimento en el capítulo 5 en la sección del diseño del experimento.

Como primer análisis de los resultados se llevó a cabo la revisión de los datos obtenidos para la variable KSPQ. Se pudo identificar las diferencias de los resultados obtenidos en esta variable de acuerdo a diversos de los puntos de vista posibles.

Primeramente, se pudo identificar que el promedio del valor de KSPQ mostró diferencias significativas de acuerdo al tipo de ítem, considerando si el ítem no contaba con recomendación de palabras (NWR), si tenía una recomendación simple de palabras (SWR) o si por el contrario se existía la recomendación de palabras basada en el contexto (CBWR). Para el caso de los ítems del tipo NWR el valor promedio de KSPQ resultó en 1,072, lo que indica que existe un pequeño factor de error en la captura de los textos; por el contrario, el valor de KSQP para los ítems del tipo SWR resultó con un promedio de 0,842 , indicando que la recomendación de palabras simple efectivamente resulta en una mejora respecto al valor de inicio de la variable $\mathrm{KSPQ}$ que en una situación normal debería ser de uno. Finalmente se pudo comprobar que para los ítems del tipo 
CBWR que tenían como soporte para la recomendación de palabras el valor de KSPQ disminuyó en promedio casi a la mitad respecto a los del tipo NWR, ya que se obtuvo un valor de 0,597 (Figura 30), lo que implica una mejora del $45 \%$ en el número de teclas requeridas para introducir el texto en promedio

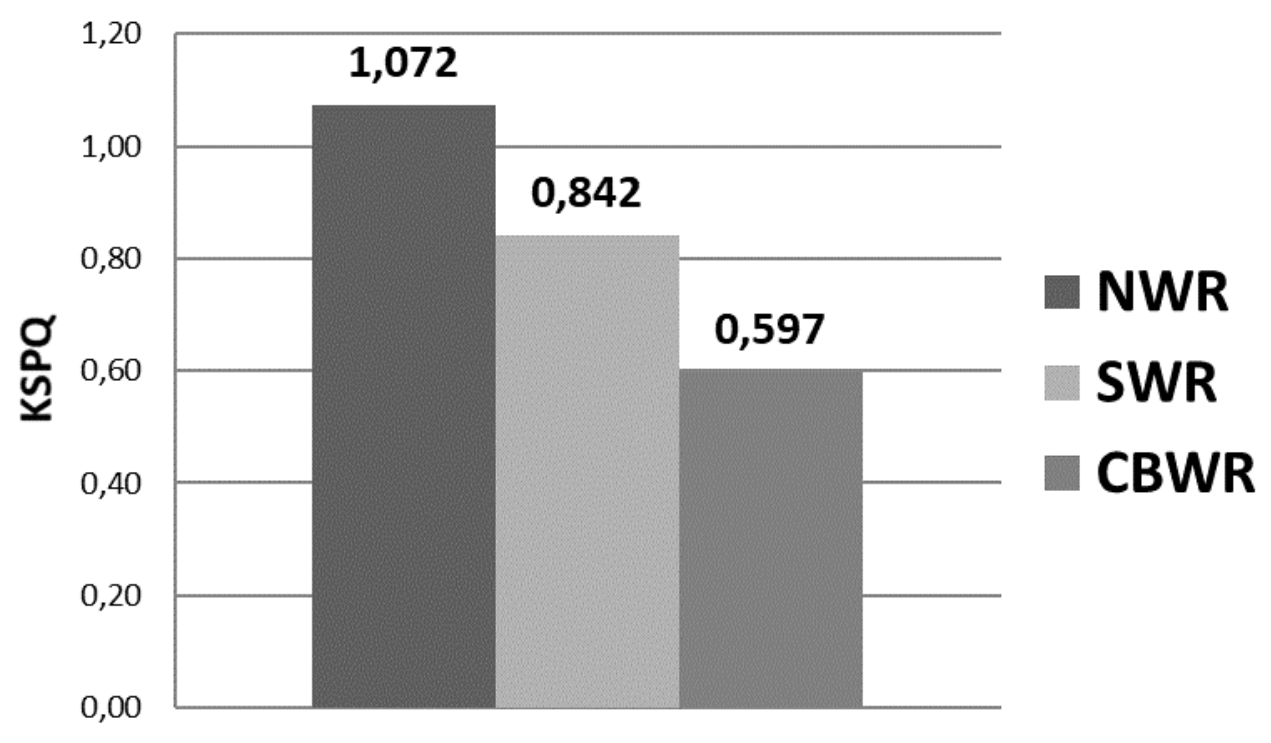

Figura 30. Promedio de los resultados obtenidos para la variable KSPQ por tipo de item.

Aunque en la medida que las palabras son más largas este valor tiende a mejorar a favor de la recomendación basada en la ontología, ya que en el caso del texto cuya extensión es de 18 caracteres (Figura 31) se pudo apreciar que la mejora fue de un $72 \%$ en promedio cuando se hace la utilización de la 
recomendación de palabras mediante la utilización de la ontología, destacándose aún más que la mejora para el caso de los dispositivos móviles se elevó a un $87 \%$.

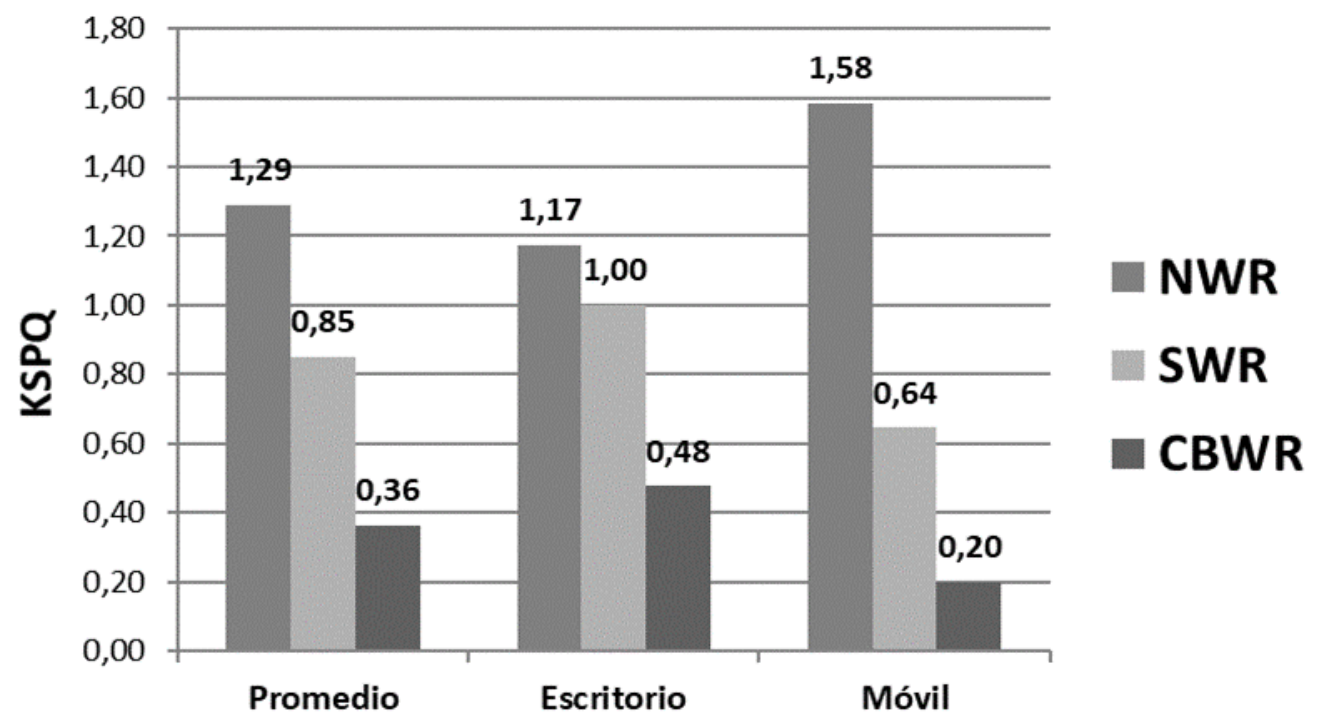

Figura 31. Promedio de teclas pulsadas para obtener el texto solicitado en un texto de 18 caracteres de longitud.

Como primera interpretación de los resultados, es posible determinar con certeza que la utilización de un sistema de recomendación de palabras mejora el rendimiento en lo referente a las teclas necesarias para introducir un texto determinado, en el caso de los dispositivos móviles el impacto es mayor por las propias características de los teclados propios de estos dispositivos. 
Es aún más notorio que la mejora se incrementa si la recomendación de palabras se hace mediante la utilización de la ontología de contexto que permite recomendar palabras más acordes a la situación o características del entorno en el que van a ser escritas, que como ya se mencionó, reflejó una mejora promedio de un $45 \%$ respecto a la no utilización de la recomendación de palabras.

\subsection{Resultados en un experimento de envío de mensajes a dispositivos} móviles

En el caso del experimento de envío de mensajes, la participación fue abierta por medio de invitación llevada a cabo en redes sociales entre la comunidad estudiantil de un centro universitario en el que se cuentan con diversos perfiles profesionales, entre las áreas de la salud, tecnológicas, de las sociales y humanidades, a los que posterior a la invitación se les dio una charla sobre el propósito del experimento y la forma de participar.

Aunque hubo una buena cantidad de consultas en el sitio web y descargas de la aplicación para el experimento, finalmente se contó con la participación de 42 usuarios que concluyeron el experimento. 
El envío de mensajes del experimento estuvo disponible desde octubre de 2016 hasta febrero de 2017, periodo en el que se enviaron un total de 50 mensajes a los usuarios, donde se buscó que 25 mensajes fueran enviados a la totalidad de los usuarios como parte del grupo de mensajes de la muestra de control, mientras que los restantes 25 mensajes fueron enviados mediante la utilización de la ontología para definir las preferencias de los usuarios y que representan los mensajes del grupo de prueba.

Como se describió en el capítulo anterior, las variables que nos permiten identificar la valoración de los usuarios respecto a los mensajes recibidos es la oportunidad del mensaje, representada por $T_{M}$, mientras que la efectividad de la respuesta nos permite identificar la validez estadística de las respuestas obtenidas, representada por $E_{R}$.

Es necesario destacar que la participación fue de una forma muy regular, aunque por la duración del experimento se pudo identificar que conforme avanzaba en el tiempo se fue reduciendo, aunque no de forma significativa que llegara a propiciar que alguno de los ítems a evaluar no se pudiera considerar dentro del rango de efectividad que se buscaba. Este factor 
identificado por el valor de $E_{R}$ fue decrementando conforme avanzó el experimento, no de forma significativa ni que afectara en la validación de los resultados obtenidos, ya que todos los ítems se encontraron dentro del parámetro de nivel de confianza elegido para el experimento, del 95\% ( Figura 32).

\subsection{0}

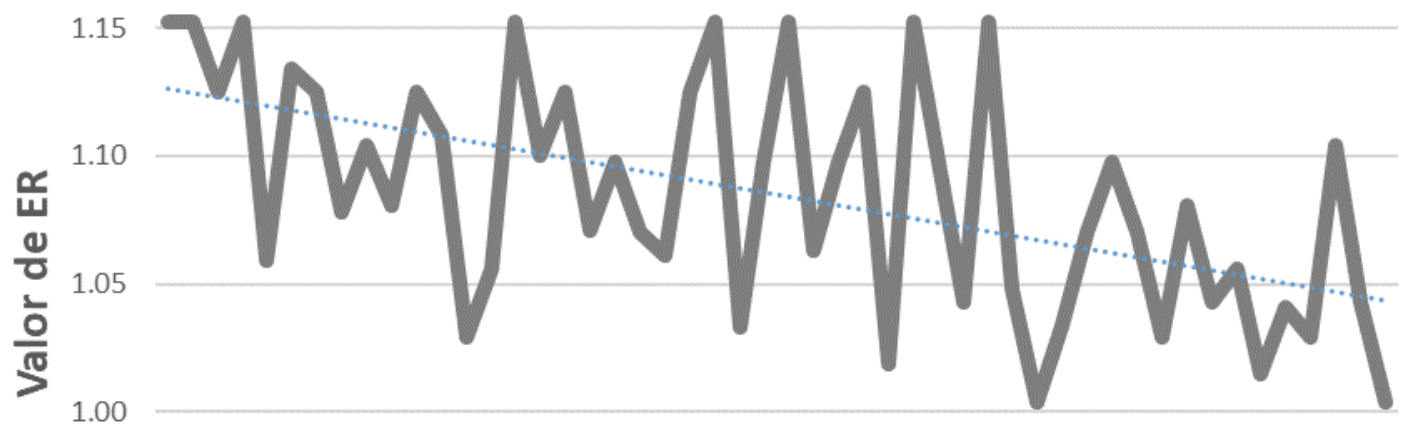

0.95

0.90

$\begin{array}{lllllllllllllllllllllllll}1 & 3 & 5 & 7 & 9 & 11 & 13 & 15 & 17 & 19 & 21 & 23 & 25 & 27 & 29 & 31 & 33 & 35 & 37 & 39 & 41 & 43 & 45 & 47 & 49\end{array}$ Número de pregunta

Figura 32. Valor de $E_{R}$ durante el transcurso del experimento y línea de tendencia. 
Aunque el experimento terminó dentro de los tiempos que se habían considerado, que consistía en evaluar 50 elementos conformados por 25 del grupo de control y 25 del grupo de prueba, es notorio que de haberse extendido y con la tendencia marcada por esta variable los siguientes ítems podrían entrar de los elementos fuera del nivel de confianza establecido, lo que nos puede hacer considerar como acertado el número de ítems a evaluar en el experimento.

De esta forma, en el análisis de los resultados obtenidos se pudo constatar las diferencias entre los dos grupos de mensajes enviados, en los que el valor promedio de $T_{M}$ resultó en 0,73 considerando a todos los ítems. Analizando los datos por separado en los dos grupos de mensaje se puede identificar que para el caso de los mensajes enviados para el grupo de control y que fueron enviados sin la utilización de la ontología, el promedio de $T_{M}$ resultó en 0,56; mientras que los mensajes enviados para el grupo que hacía uso de la ontología para el envío de los mensajes, el promedio del valor de $T_{M}$ resultó en 0,89 , lo que significa una diferencia de 0,32 en puntos porcentuales obtenidos entre ambos grupos, o una mejora respecto a los mensajes del grupo de control del $58 \%$ respecto a la no utilización de la ontología (Figura 33). 


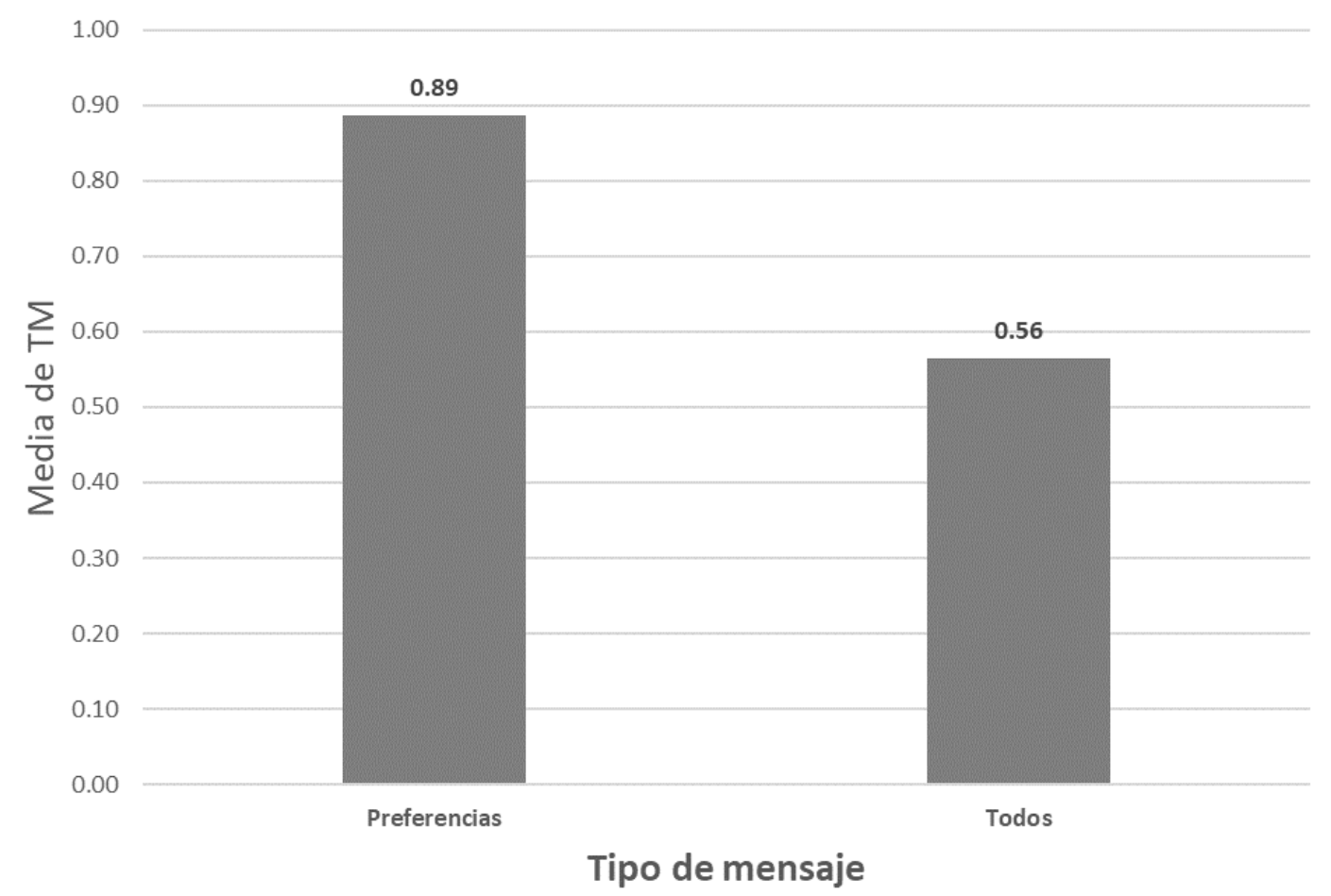

Figura 33. Media de los valores obtenidos en $T_{M}$ por tipo de mensaje.

En un análisis un poco más detallado de los resultados, se puede destacar que las diferencias entre los resultados obtenidos por el grupo de control y el grupo de prueba resultaron significativas. Además de la diferencia de 0,32 puntos porcentuales en los resultados obtenidos en promedio para $T_{M}$ entre el grupo de control y el de prueba, también se pudo identificar que fueron más consistentes los resultados del grupo de prueba, ya que el valor de la desviación 
estándar fue de apenas 0,09 , mientras que para el grupo de control se obtuvo un valor de 0,20 en este mismo apartado.

En este mismo sentido, se identifica que en el grupo de control el valor mínimo obtenido para $T_{M}$ fue de 0,26 y el máximo de 0,98 , reflejado por la desviación estándar mencionada, mientras que para el grupo de prueba el mínimo resultó en 0,66 y el máximo en un valor de 1,00.

Estos datos muestran que, mientras en el grupo de control existía mucha diversidad de opiniones referente a la oportunidad de los mensajes recibidos, en el grupo de prueba se obtuvieron resultados más consistentes que permiten avalar que el uso del contexto por medio de la ontología ha establecido una mejora desde el punto de vista de los usuarios. 


\section{Capítulo 7}

\section{Conclusiones y trabajo futuro}

La construcción de una ontología resulta una tarea ardua que puede considerarse como una labor subjetiva, ya que las ontologías son representaciones de una realidad en un dominio de interés en particular, por lo que desde su creación pueden tener enfoques muy particulares de acuerdo a la utilización que se espera de la propia ontología, además de los propios sesgos que se pueden originar por la percepción, intereses o inclusive habilidades de quien la crea.

En el caso de la creación de una ontología para la definición del contexto para dispositivos móviles, como es el caso de este trabajo, entra también en juego el entendimiento o lo que se debe considerar como contexto de acuerdo a la aplicación o servicio en particular del que se trate, tomando también en consideración el entorno para el que se desea considerar, como es el relacionado a los dispositivos móviles. 
El presente trabajo propone la creación de una ontología de definición del contexto en dispositivos móviles para que pueda ser utilizada en servicios o aplicaciones como herramienta para soportar una mejora en tareas específicas, buscando proporcionar finalmente algún beneficio directo o indirecto a los usuarios de estos dispositivos en las aplicaciones o servicios.

En el caso de la ontología COMoDE, la definición del contexto en dispositivos móviles funciona de forma independiente del servicio o aplicación que hace uso de la misma, lo que permite que sea de utilidad en diversas situaciones, brindando la ventaja que a través de una sola estructura y una sola definición del contexto se pueden hacer mejoras sin importar el servicio o aplicación del que se trate, ya que se convierten en clientes de la estructura e información que proporciona la ontología.

Se llevaron a cabo dos experimentos diferentes para probar la funcionalidad de la ontología, en ambos casos con la consideración del usuario como un factor importante de validación, ya que al final de cuentas se busca que el impacto que ofrece la utilización de la ontología sea un valor agregado que el propio usuario pueda reconocer o valorar. 
Se pudo comprobar que la utilización de definición del contexto a través de la ontología representa una mejora, la que puede variar de acuerdo con la situación particular de uso de la misma, por lo que en algunos casos el impacto resulta de mayor relevancia que en otros casos de uso. En los experimentos llevados a cabo se encontraron diferencias reveladoras respecto a la no utilización de la ontología, con valores que nos hacen creer que la utilización del contexto aporta un valor significativo a los posibles servicios o aplicaciones que hagan uso de esta herramienta.

En el primer experimento de utilización del contexto a través de la ontología en un sistema de recomendación de palabras se pudo encontrar que respecto a la no utilización de la ontología en promedio indicaba una mejora del $45 \%$, siendo en uno de los casos extremos explorados de un $87 \%$, ambos valores de un impacto relevante y que muestran que existen casos donde la consideración del contexto proporcionado por la ontología implica una diferencia sustancial.

Resaltar que es una ontología que brinda el soporte para la definición del contexto en dispositivos móviles que funciona de forma independiente del servicio o aplicación que hace uso de esta, lo que permite que sea de utilidad 
para diversos servicios y aplicaciones, brindando la ventaja que a través de una sola estructura y una sola definición del contexto se pueden hacer mejoras sin importar el servicio o aplicación del que se trate.

De forma similar, en el segundo experimento enfocado a soportar un sistema de envío de mensajes de interés a dispositivos móviles se obtuvieron resultados que mostraron la utilidad de la ontología que define el contexto en una situación diferente, en la que la utilización del contexto representa un valor de apoyo importante.

En este segundo experimento el impacto de la utilización de la ontología se vio reflejado mediante la obtención de una mejora de un $58 \%$ en la efectividad de los mensajes enviados respecto a los mensajes que no hicieron utilización de la ontología desde el punto de vista de los propios usuarios. Estos resultados son consistentes con los obtenidos por Yang y colegas (Yang, Lu, Gupta, \& Cao, 2012), donde se pudo identificar que los usuarios de dispositivos móviles tienen una tendencia mayor a utilizar los servicios de su dispositivo móvil si estos consideran el contexto como soporte. 
Como trabajo futuro se tiene previsto la utilización de la ontología de definición del contexto en una aplicación móvil de uso generalizado que será desarrollada para la Universidad de Guadalajara en la que se brindará acceso a información propia de la situación del estudiante, pero que hará la utilización de una versión adaptada y mejorada del sistema de envío de notificaciones similar al utilizado en el segundo experimento, donde la ontología permitirá mejorar la experiencia de usuario al brindarle información relevante de acuerdo al contexto.

De los trabajos que a lo largo de la duración de este proyecto se llevaron a cabo, se obtuvieron los siguientes los siguientes resultados de difusión:

- Aréchiga, D., Vegas, J., \& De la Fuente Redondo, P. (2009). Ontology supported personalized search for mobile devices. Proceedings of the ONTOSE. (Aréchiga, Vegas, \& De la Fuente Redondo, 2009). En esta difusión se presentó la propuesta de utilización de una ontología como una herramienta de apoyo para realizar una personalización mediante la utilización del contexto en servicios o aplicaciones en dispositivos móviles, se mostró en particular el caso de las búsquedas web, está relacionado con lo mostrado en el Capítulo 3 y con el experimento que se presenta en el capítulo 5 que hace uso de la recomendación de palabras. 
- Vegas, J., \& Aréchiga, D. (2010). Ontologies for Context Definition on Mobile Devices: Improving the Mobile Web Search. Mobile Web 2.0: Developing and Delivering Services to Mobile Devices, 211. (Vegas \& Aréchiga, 2010). En esta publicación se presenta principalmente la temática de la utilización de las ontologías como un medio para representar el contexto, para ser utilizado en los dispositivos móviles. De igual forma se encuentra relacionado con lo expuesto en los Capítulos 3 y 5.

- Aréchiga, D., Crestani, F., \& Vegas, J. (2014). Ontology-driven word recommendation for mobile Web search. The Knowledge Engineering Review, 29(02), 186-200. (Aréchiga, Crestani, \& Vegas, Ontology driven word recommendation for mobile web search, 2013). Este documento presenta una propuesta referente a la recomendación de palabras apoyada en una ontología, como parte del proceso de búsquedas web, temáticas abordadas de igual forma en los Capítulos 3 y 5. 


\section{Referencias}

5G Americas. (2017, Jul). Retrieved from http://www.5gamericas.org/

Abowd, G. D., Dey, A. K., Brown, P. J., Davies, N., Smith, M., \& Steggles, P. (1999). Towards a Better Understanding of Context and ContextAwareness. En H.-W. Gellersen, Handheld and Ubiquitous Computing (págs. 304-307). Springer Berlin Heidelberg.

Adapted Subjective Workload Assessment Technique (ASWAT). (Oct de 2012).

Adomavicius, G., \& Tuzhilin, A. (2015). Context-Aware Recommender Systems.

En F. Ricci, L. Rokach, \& B. Shapira, Recommender Systems Handbook (págs. 191-226). Springer US.

Aréchiga, D., Crestani, F., \& Vegas, J. (September de 2013). Ontology driven word recommendation for mobile web search. 28(3).

Aréchiga, D., Vegas, J., \& De la Fuente Redondo, P. (June de 2009). Ontology Supported Personalized Search for Mobile Devices. En C. Kop, M.-A. Sicilia, \& F. Sartori (Ed.), Ontology, Conceptualization and Epistemology for Information Systems, Software Engineering and Service Science. Amsterdam, The Netherlands: CEUR. 
Arias, M., Cantera, J. M., Vegas, J., de la Fuente, P., Alonso, J. C., Bernardo, G. G., .. Zubizarreta, A. (2008). Context-Based Personalization for Mobile Web Search. PersDB, (págs. 33-39).

Bellavista, P., Corradi, A., Fanelli, M., \& Foschini, L. (2012). A survey of context data distribution for mobile ubiquitous systems. ACM Computing Surveys.

Berneras, A. (1996). Building and reusing ontologies for electrical network applications. Procceedings of ECAl, (págs. 298-302).

Berners-Lee, T., Hendler, J., \& Lassila, O. (2001). The semantic web. Scientific american, 284(5), 28-31.

Biancalana, Claudio, Gasparetti, F., Micarelli, A., \& Sansonetti, G. (January de 2013). An Approach to Social Recommendation for Context-aware Mobile Services. ACM transactions on intelligent systems and technology, 4(1). doi:10.1145/2414425.2414435

Bing. (November de 2017). Obtenido de http://bing.com

Bouidghaghen, O., Tamine, L., \& Boughanem, M. (2011). Context-aware user's interests for personalizing mobile search. En IEEE (Ed.), Mobile Data Management (MDM), 2011 12th IEEE International Conference, 1, págs. 129-134. 
Bouneffouf, D., Bouzeghoub, A., \& Gancarski, A. L. (2012). Following the user's interests in mobile context-aware recommender systems: The hybrid-egreedy algorithm. Advanced Information Networking and Applications Workshops (WAINA), 2012 26th International Conference (págs. 657662). IEEE.

Brank, J., Grobelnik, M., \& Mladenic, D. (2005). A survey of ontology evaluation techniques. ConferenceProceedings of the Conference on Data Mining and Data Warehouses SiKDD.

Brewster, C., Alani, H., Dasmahapatra, S., \& Wilks, Y. (2004). Data Driven Ontology Evaluation. ConferenceProceedings of International Conference on Language Resources and Evaluation. Lisbon, Portugal.

Cantera Fonseca, J. M., Guido García, B., \& Vegas Hernández, J. (2008). An Automatic Page Classification Method to Improve User Experience on the MobileWeb. UBICOMM 2008 (págs. 171-177). IEEE Press.

Cantera Fonseca, J., \& Lewis, R. (2010). W3C Delivery Context Ontology. Retrieved from http://www.w3.org/TR/dcontology/

Chen, G., \& Kotz, D. (2000). A survey of context-aware mobile computing research. 
Chen, H., Finin, T., \& Joshi, A. (2003). An ontology for context-aware pervasive computing environments. 18(3), 197-207.

Christensen, L. B. (2007). Experimental Methodology (10th ed.). Pearson.

Church, K., Smyth, B., Cotter, P., \& Bradley, K. (2007). Mobile Information Access: A Study of Emerging Search Behavior on the Mobile Internet. ACM Transactions on the Web, 1(1).

Costa, A., \& Filho, G. P. (2007). COReS: Contextaware, Ontology-based Recommender system for Service recommendation. Proc. CAISE'07 Workshop on Ubiquitous Mobile Information and Collaboration Systems.

Delivery Context Ontology. (Marzo de 2017). Obtenido de https://www.w3.org/TR/dcontology/

Desmet, B., Vallejos, J., \& Costanza, P. (2007). Layered design approach for context-aware systems. VaMoS 2007.

Dey, A. K. (2000). Providing architectural support for building context-aware applications. Atlanta, GA, USA.

Emmanouilidis, C., Koutsiamanis, R.-A., \& Tasidou, A. (2013). Mobile guides: Taxonomy of architectures, context awareness, technologies and applications. Journal of Network and Computer Applications. 
Falbo, R. d., Nardi, J. C., Almeida, J. P., Guizzardi, G., Pires, L. F., Van Sinderen, M. J., \& Guarino, N. (2013). Towards a Commitment-based Reference Ontology for Services. Enterprise Distribuited Object Computing Conference (EDOC) 2013 17th IEEE International (págs. 175--184). IEEE.

Fensel, D. (2001). Ontologies. En Ontologies: A Silver Bullet for Knowledge Management and Electronic Commerce (págs. 11-18). Springer Berlin Heidelberg.

Fernández-López, M. (1999). Overview of methodologies for building ontologies. Workshop Ontologies and Problem-Solving Methods: Lessons Learned and Future Trends de la conferencia International Joint Conference for Artificial Intelligence (IJCAl'99). Stockholm.

Ferreira, D., Kostakos, V., Dey, \& K., A. (2015). AWARE: mobile context instrumentation framework. Frontiers in ICT.

Gangemi, A., Catenacci, C., Ciaramita, M., \& Lehmann, J. (2006). Modelling ontology evaluation and validation. ConferenceProceedings of the 3rd European Semantic Web Conference (ESWC2006), number 4011 in LNCS, Budva. Springer.

Gartner Press Release. (Enero de 2014). Obtenido de http://www.gartner.com/newsroom/id/2645115 
Gauch, S., Chaffee, J., \& Pretschner, A. (January de 2003). Ontology-based personalized search and browsing. 1 (3), 219-234.

Göker, A., \& Myrhaug, H. I. (2002). User context and personalisation. Workshop proceedings for the 6th European Conference on Case Based Reasoning.

Gómez-Pérez, A. (1995). Some ideas and examples to evaluate ontologies. CAIA '95: ConferenceProceedings of the 11th Conference on Artificial Intelligence for Applications (pág. 299). Washington, DC, USA: IEEE Computer Society.

Gómez-Pérez, A. (2001). Evaluation of ontologies. 16 (3), 391-409.

Google. (January de 2017). Obtenido de http://google.com

Green, P. (2004). Applying Ontologies to Business and Systems Modelling Techniques and Perspectives: Lessons Learned. 15 (2), 105-117.

Gruber, T. (1993). A Translation Approach to Portable Ontology Specifications.

Gruber, T. (1995). Toward Principles of the Design of Ontologies Used for Knowledge Sharing. International Journal of Human-Computer Studies.

Gruber, T. (2001). What is an Ontology? Recuperado el 04 de 2012, de wwwksl.stanford.edu/kst/what-is-an-ontology.html 
Grüninger, M., \& Fox, M. (1995). Methodology for the Design and Evaluation of Ontologies. IJCAl'95, Workshop on Basic Ontological Issues in Knowledge Sharing, April 13, 1995.

Guarino, N., \& Welty, C. (2002). Evaluating ontological decisions with OntoClean. $45(2), 61-65$.

Guarino, N., \& Welty, C. (2004). An Overview of OntoClean. Handbook on Ontologies (págs. 151-159). Germany: Springer Verlag.

Hart, S. G., \& Staveland, L. E. (1988). En P. A. Hancock, \& N. Meshkati (Edits.). North Holland Press.

Hartmann, J., Spyns, P., Giboin, A., Maynard, D., Cuel, R., Suarez-Figueroa, M. C., \& Sure, Y. (2005). D1.2.3 Methods for ontology evaluation. Knowledge Web Consortium.

Hattori, S., Tezuka, T., \& Tanaka, K. (2006). Query modification based on realworld contexts for mobile and ubiquitous computing environments. 7th International Conference on Mobile Data Management (pág. 77). IEEE.

Hattori, S., Tezuka, T., \& Tanaka, K. (2007). Context-aware query refinement for mobile web search. International Symposium on Applications and the Internet Workshops (pág. 15). IEEE. 
Hendy, K. C., Hamilton, K. M., \& Landry, L. N. (December 1993). Measuring Subjective Workload: When Is One Scale Better than Many? 35, 579-601.

Hoehndorf, R. (2010). What is an upper level ontology? Ontogenesis.

Hunemark, L. (2010). Query expansion using search logs and WordNet.

Janse, M. (2008). AMIGO: Ambient intelligence for the networked home environment. Philips Research.

Jeng, Y.-L., Shu, Y., Huang, T.-C., Huang, Y.-M., \& Chen, C.-C. (2015). Developing a Mobile Instant Messaging System for Problem-based Learning Activity. En IEEE (Ed.), Proceedings of International Conference on Interactive Collaborative Learning (ICL).

Jeon, H., Kim, T., \& Choi, J. (2008). Mobile Semantic Search Using Personal Preference Filtering. ConferenceProceedings of the 2008 Fourth International Conference on Networked Computing and Advanced Information Management - Volume 02 (págs. 531-534). Washington, DC, USA: IEEE Computer Society.

Kamvar, M., \& Baluja, S. (2008). Query suggestions for mobile search: understanding usage patterns. $\mathrm{CHI}$ 2008: Proceeding of the twenty-sixth annual SIGCHI conference on Human factors in omputing systems (págs. 1013-1016). New York, NY, USA: ACM. 
Khushraj, D., \& Lassila, O. (2005). Ontological Approach to Generating Personalized User Interfaces for Web Services. The Semantic Web ISWC 2005, (págs. 916-927).

Labrou, Y. K. (1999). Yahoo as an Ontology - using Yahoo categories to describe documents. Proceedings of the 1999 ACM Conference on Information and Knowledge Management (C/KM'99).

Lathia, N. (2015). The Anatomy of Mobile Location-Based Recommender Systems. En F. Ricci, L. Rokach, B. Shapira, \& P. B. Kantor, Recommender Systems Handbook (págs. 493-510). New York: Springer US.

Lepp, Andrew. (2014). The Intersection of Cell Phone Use and Leisure: A Call for Research. Journal of Leisure Research, 46(2), 218-225.

Leung, K. W.-T., Lee, D. L., \& Lee, W.-C. (2010). Personalized Web search with location preferences. ICDE, (págs. 701-712).

Levenshtein, V. I. (1966). Binary Codes capable of correcting deletions, insertions and reversals. Soviet Physics Doklady, 10, 707.

Lorhard, J. (1606). Ogdoas Scholastica. Straub. Obtenido de https://www.ontology.co/jacob-lorhard.htm

Löwe, R., Mandl, P., \& Weber, M. (2012). Context Directory: A context-aware service for mobile context-aware computing applications by the example 
of Google Android. 2012 IEEE International Conference on Pervasive Computing and Communications Workshops (PERCOM Workshops) (págs. 76-81). IEEE.

Lozano-Tello, A., \& Gómez-Pérez, A. (June de April de 2004). ONTOMETRIC: A Method to Choose the Appropriate Ontology. 15(2).

Luximon, A., \& Goonetilleke, R. S. (20 February 2001). Simplified subjective workload assessment technique. 44, 229-243.

Maedche, A., \& Staab, S. (2002). Measuring Similarity between Ontologies. EKAW '02: ConferenceProceedings of the 13th International Conference on Knowledge Engineering and Knowledge Management. Ontologies and the Semantic Web (págs. 251-263). London, UK: Springer-Verlag.

Mehrotra, A., Hendley, R., \& Musolesi, M. (2016). PrefMiner: Mining User's Preferences for Intelligent Mobile Notification Management. Proceedings of the 2016 ACM International Joint Conference on Pervasive and Ubiquitous Computing (págs. 1223-1234). ACM.

Merriam-Webster OnLine "context". (2018). Retrieved from https://www.merriam-webster.com/dictionary/context 
Missaoiu, S., \& Faiz, R. (2015). A Preferences Based Approach for Better Comprehension of User Information Needs. Transactions on Computational Collective Intelligence XVIII (págs. 67-85). Springer.

Mizoguchi, R., \& Ikeda, M. (1998). Towards ontology engineering. JournalJapanese Society for Artificial Intelligence, 13, 9-10.

Mizoguchi, R., Tijerino, Y., \& Ikeda, M. (1992). Taks ontology and its use in a task analysis interview system. Proceedings of the Second Japaneese Knowledge Acquisition for Knowledge-Based Systems Workshop.

MYMOSE, My Mobile Search Project. (2010).

Noy, N. F., \& Mcguinness, D. (2001). Ontology Development 101: A Guide to creating your first Ontology.

Øhrstrøm, P., Andersen, J., \& Schärfe, H. (2005). What Has Happened to Ontology. En F. Dau, M.-L. Mugnier, \& G. Stumme, Conceptual Structures: Common Semantics for Sharing Knowledge (págs. 425-438). Springer Berlin Heidelberg.

Paek, T., Lee, B., \& Thiesson, B. (2009). Designing phrase builder: a mobile realtime query expansion interface. MobileHCl '09: ConferenceProceedings of the 11th International Conference on Human-Computer Interaction with Mobile Devices and Services (págs. 1-10). New York, NY, USA: ACM. 
Porzel, R., \& Malaka, R. (2004). A Task-based Approach for Ontology Evaluation. ECAl Workshop on Ontology Learning and Population (2004).

Poveda Villalon, M., Suárez-Figueroa, M., García-Castro, R., \& Gómez-Pérez, A. (2010). A Context Ontology for Mobile Environments. Workshop on Context, Information and Ontologies. 626. Lisbon, Portugal: CEUR-WS.

Poveda-Villalón, M., Suárez-Figueroa, M. C., \& Gómez-Pérez, A. (2012). Validating Ontologies with OOPS! International Conference on Knowledge Engineering and Knowledge Management. 7603, págs. 267261. Springer.

Pretschner, A., \& Gauch, S. (1999). Ontology Based Personalized Search. ICTA/ '99: ConferenceProceedings of the 11th IEEE International Conference on Tools with Artificial Intelligence (pág. 391). Washington, DC, USA: IEEE Computer Society.

Princeton University. (March de 2011). WordNet. Obtenido de http://wordnet.princeton.edu/

Reid, G. B., \& Nygren, T. E. (1988). The Subjective Workload Assessment Technique: A Scaling Procedure for Measuring Mental Workload. En P. A. Hancock, \& N. Meshkati (Edits.). North-Holland. 
Rios, D., Costa, P. D., Pires, L. F., Gonçalves, J., Filho, P., \& Sinderen, M. V. (2003). Using ontologies for modeling context-aware service platforms. OOPSLA 2003 Workshop on Ontologies to Complement Software Architectures, Anaheim, CA, USA, (págs. 26-30).

Rodríguez, J., Bravo, M., \& Guzmán, R. (2013). Multidimensional Ontology Model to Support Context-aware Systems. Paper from the AAAl 2013 Workshop. Bellevue, Washington.

Sanagavarapu, L., Gollapudi, S., Chimalakonda, S., Raghu Reddy, Y., \& Choppella, V. (2017). A Lightweight Approach for Evaluating Sufficiency of Ontologies. 29th International Conference on Software Engineering and Knowledge Engineering, (págs. 557-561).

Scherp, A., Saathoff, C., Franz, T., \& Staab, S. (2011). Designing Core Ontologies. Appl. Ontol., 6(3), 177--221.

Schilit, B. N., \& Theimer, M. M. (oct. de sept. de 1994). Disseminating active map information to mobile hosts. 8(5), 22-32.

Shin, C., Hong, J.-H., \& Dey, A. K. (2012). Understanding and Prediction of Mobile Application Usage for Smart Phones. Proceedings of the 2012 ACM Conference on Ubiquitous Computing (págs. 173-182). Pittsburgh: ACM. 
Shin, S., Ko, J., Shin, D.-H., Jung, J., \& Lee, K.-H. (2013). Semantic search for smart mobile devices. Proceedings of the companion publication of the 2013 international conference on Intelligent user interfaces companion (págs. 95-96). ACM.

Sieg, A., Mobasher, B., \& Burke, R. (2007). Ontological User Profiles for Representing Context in Web Search. WI-IATW 2007: ConferenceProceedings of the 2007 IEEE/WIC/ACM International Conferences on Web Intelligence and Intelligent Agent Technology Workshops (págs. 91-94). Washington, DC, USA: IEEE Computer Society.

Singh, M. P., \& Jain, M. K. (2014). Evolution of processor architecture in mobile phones. International Journal of Computer Applications.

Staab, S., \& Studer, R. (2004). Handbook on Ontologies. Springer-Verlag.

Staab, S., Sure, Y., Gomez-Pérez, A., Daelemans, W., Reinberger, M.-L., Guarino, N., \& Noy, N. F. (2004). Why Evaluate Ontology Technologies? Because It Works! 19(4), 74-81.

Stanford University. (2017). Protégé. Retrieved from http://protege.stanford.edu/.

Su, X., Alapnes, S., \& Shiaa, M. M. (2009). Mobile Ontology: Its Creation and Its Usage. En Constructing Ambient Intelligence: Am/ 2008 Workshops, 
Nuremberg, Germany 19-22, 2008. Revised Papers (págs. 75-79). Springer Berlin Heidelberg. doi:10.1007/978-3-642-10607-1_13

Suárez-Figueroa, M., Gómez-Pérez, A., \& Fernández-López, M. (2011). The NeOn Methodology for Ontology Engineering. En M. Suárez-Figueroa, A. Gómez-Pérez, E. Motta, \& A. Gangemi, Ontology Engineering in a Networked World. Berlin: Springer.

Sutterer, M., Droegehorn, O., \& David, K. (2008). UPOS: User Profile Ontology with Situation-Dependent Preferences Support. First International Conference on Advances in Computer-Human Interaction. IEEE.

The State Of The Internet. (2017). Obtenido de Akamai: https://www.akamai.com/us/en/about/our-thinking/state-of-theinternet-report/global-state-of-the-internet-connectivity-reports.jsp

United Nations Organization, Department of Economic and Social Affairs. (Oct de 2015).

Uschold, M., \& Grüninger, M. (1996). Ontologies: principles, methods, and applications. 11, 93-155.

Uschold, M., \& King, M. (1995). Towards a Methodology for Building Ontologies. In Workshop on Basic Ontological Issues in Knowledge Sharing, held in conjunction with IJCAI-95. 
Vanwelkenhuysen, J., \& Riichiro, M. (1994). Maintaining the workplace context in a knowledge level analysis. Proceedings of JAKW, (págs. 33-47).

Vegas, J., \& Aréchiga, D. (2010). Ontologies for Context Definition on Mobile Devices: Improving the Mobile Web Search. En S. A. Ahson, \& M. Ilyas, Mobile Web 2.0: Developing and Delivering Services to Mobile Devices. CRC Press.

Vélez León, P. (2014). Consideraciones historiográficas para una historia de la ontología. XX Congrés Valencià de Filosofia, (págs. 347-362). Valencia.

Villalonga, C., Strohbach, M., Snoeck, N., Sutterer, M., Belaunde, M., Kovacs, E., ... Droegehorn, O. (2009). Mobile Ontology: Towards a Standardized Semantic Model for the Mobile Domain. (págs. 248-257). Berlin, Heidelberg: Springer-Verlag.

Völker, J., Vrandečić, D., \& Sure, Y. (2005). Automatic Evaluation of Ontologies (AEON). En The Semantic Web -- ISWC 2005: 4th International Semantic Web Conference, ISWC 2005, Galway, Ireland, November 6-10, 2005. Proceedings (págs. 716--731). Springer Berlin Heidelberg.

W3C Mobile Web Initiative. (2017). Obtenido de http://www.w3.org/Mobile Weißenberg, N., Voisard, A., \& Gartmann, R. (2004). Using ontologies in personalized mobile applications. GIS 2004: ConferenceProceedings of 
the 12th annual ACM international workshop on Geographic information systems (págs. 2-11). New York, NY, USA: ACM.

Worku Kerie, T. (2015). Context Aware Semantic Search Engine for Smart Phones.

Yahoo. (2011, March). Yahoo Categories. Retrieved from https://answers.yahoo.com/dir/index

Yahoo search. (January de 2017). Obtenido de http://yahoo.com

Yang, S., Lu, Y., Gupta, S., \& Cao, Y. (2012). Does Context Matter? The Impact of Use Context on Mobile Internet Adoption. International Journal of Human-Computer Interaction, 530-541. 


\section{Apéndices}

\section{Apéndice A: Estructura base de la ontología COMoDE}

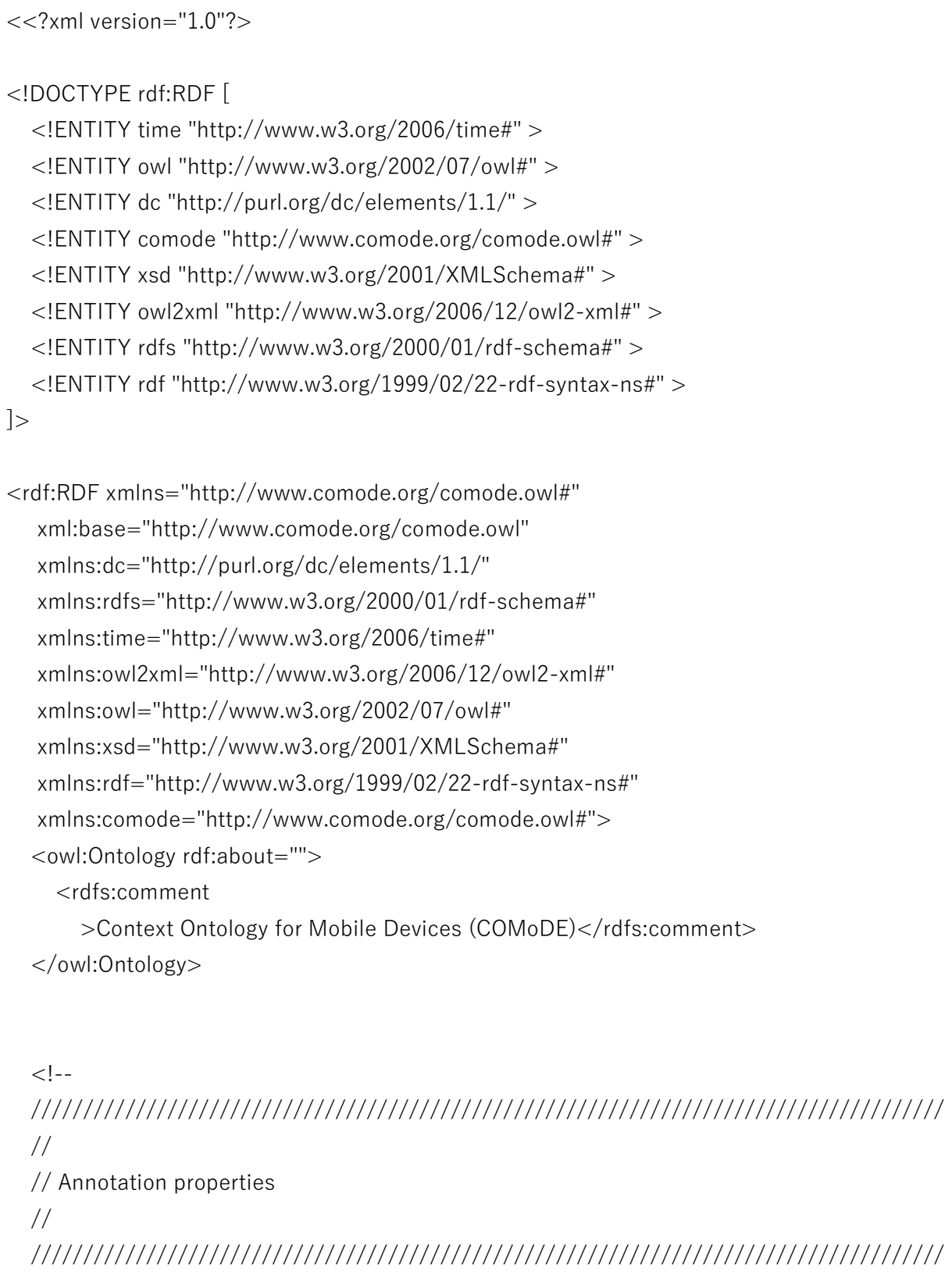




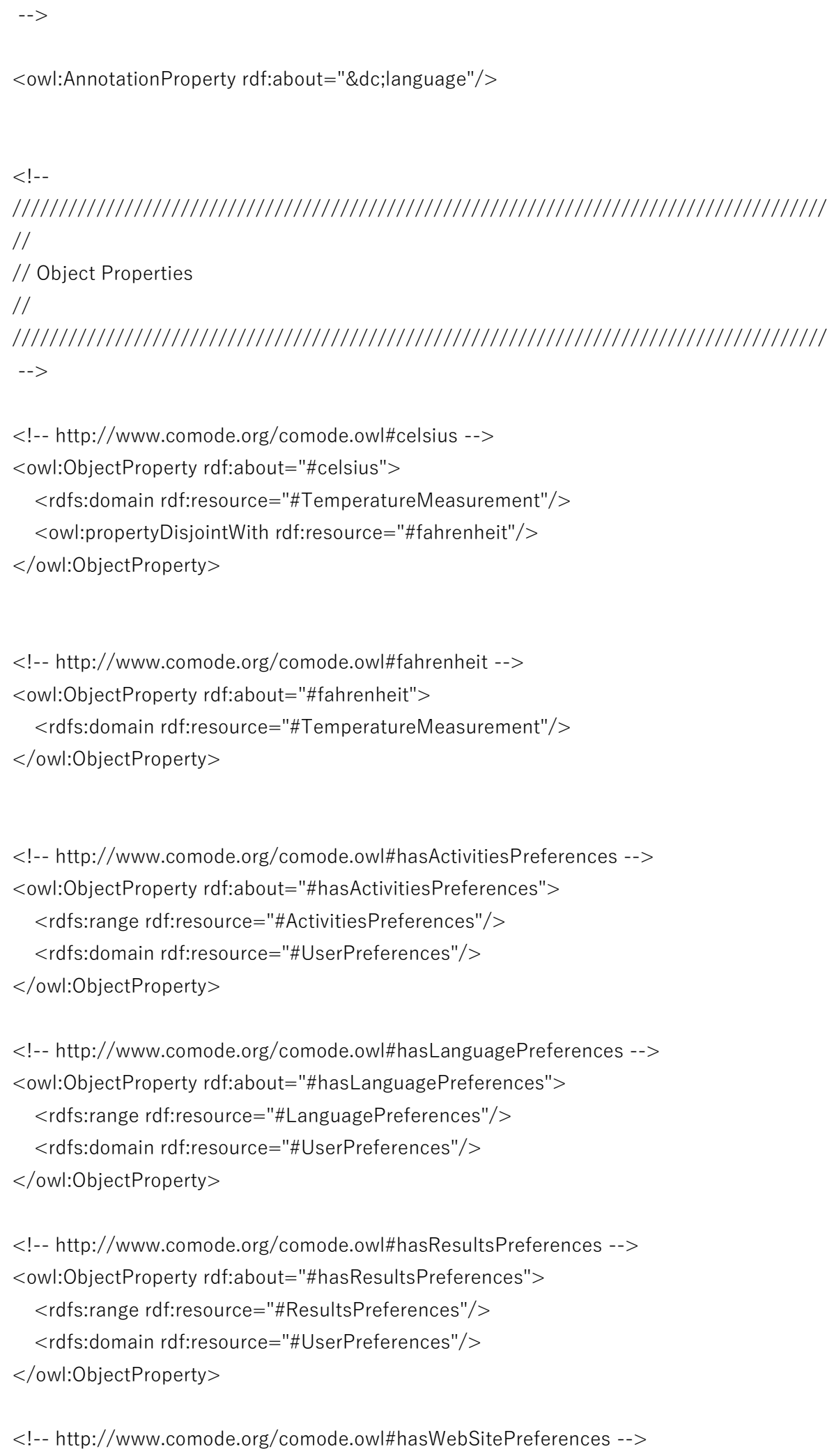




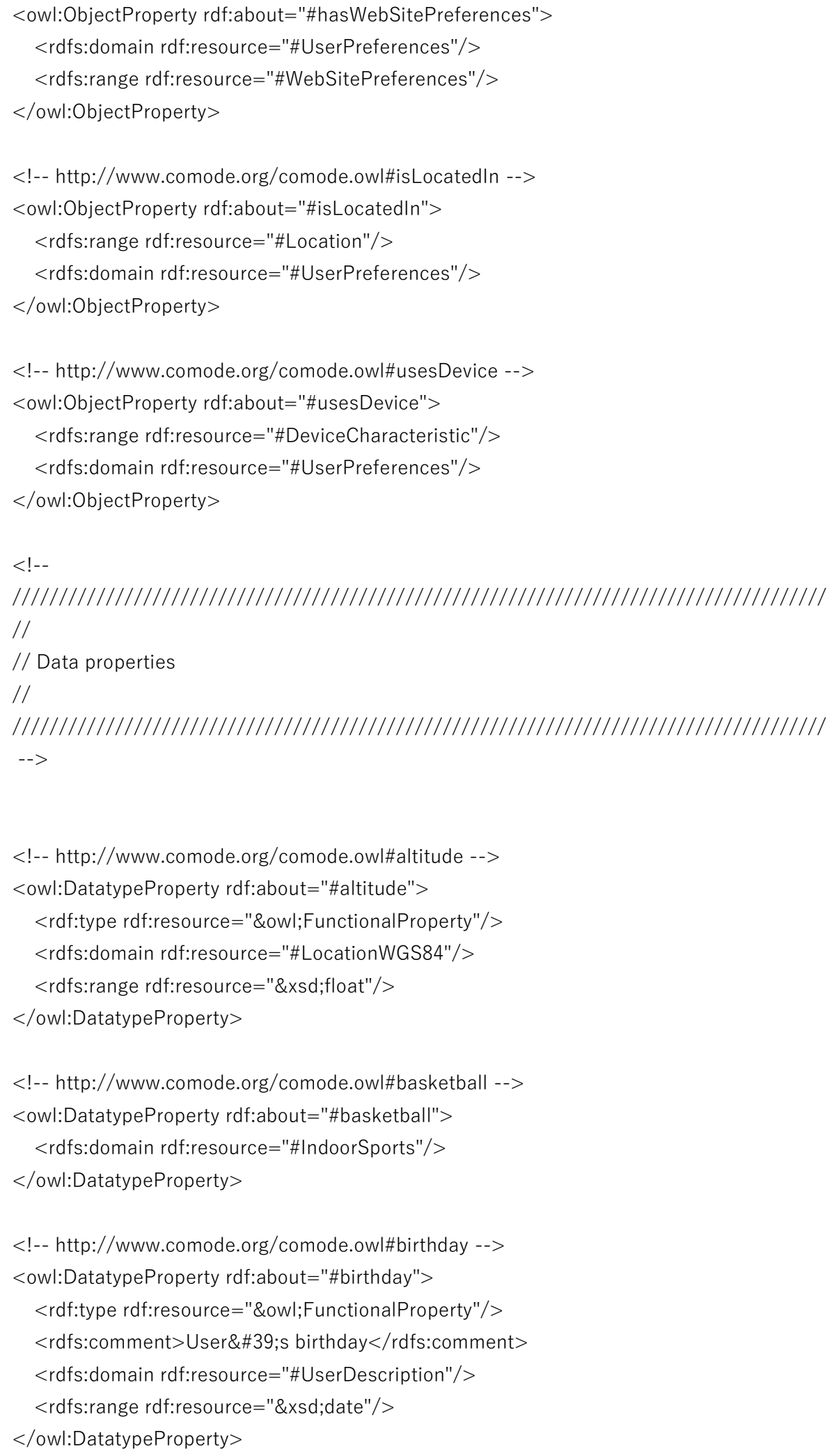




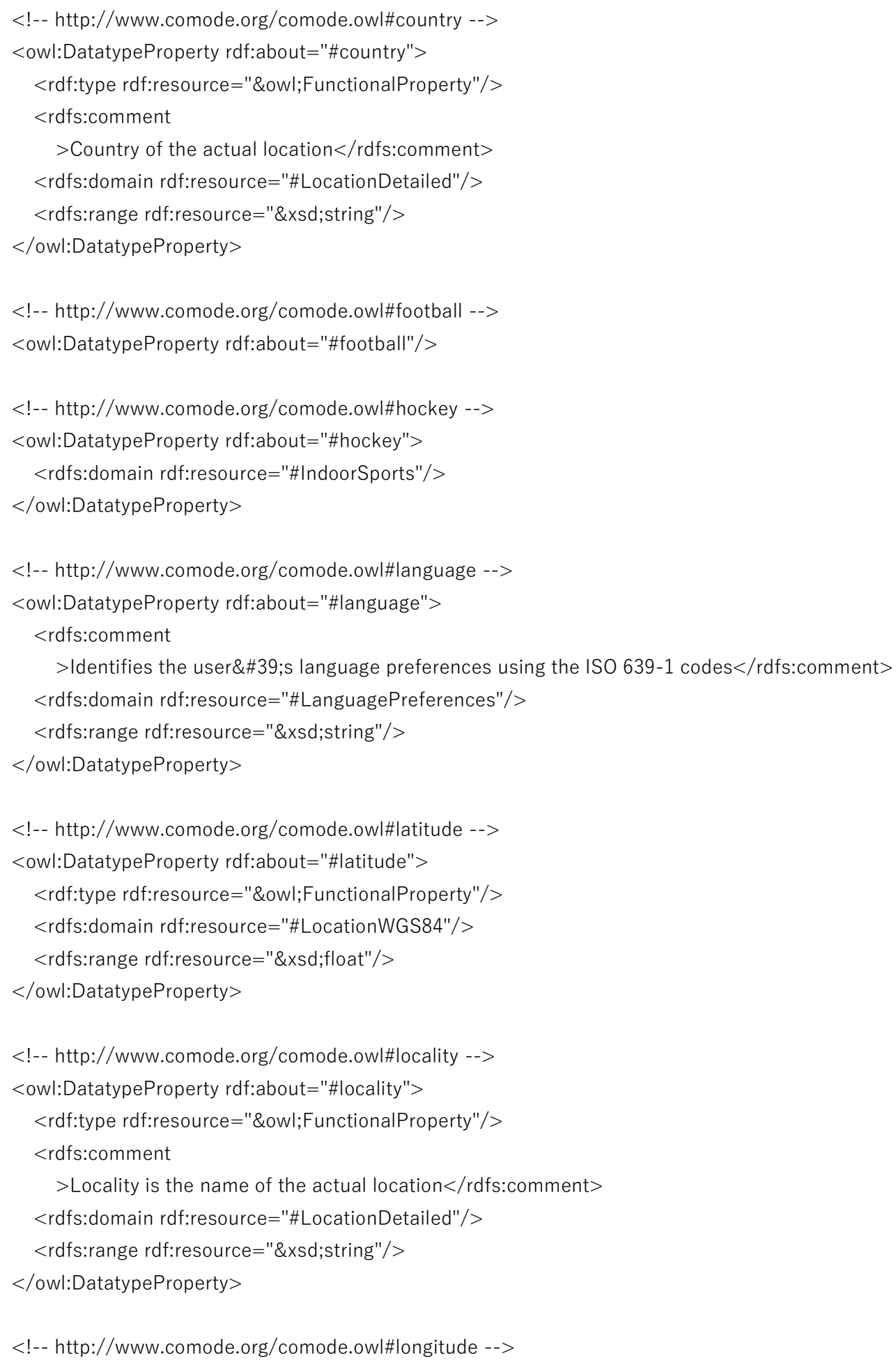




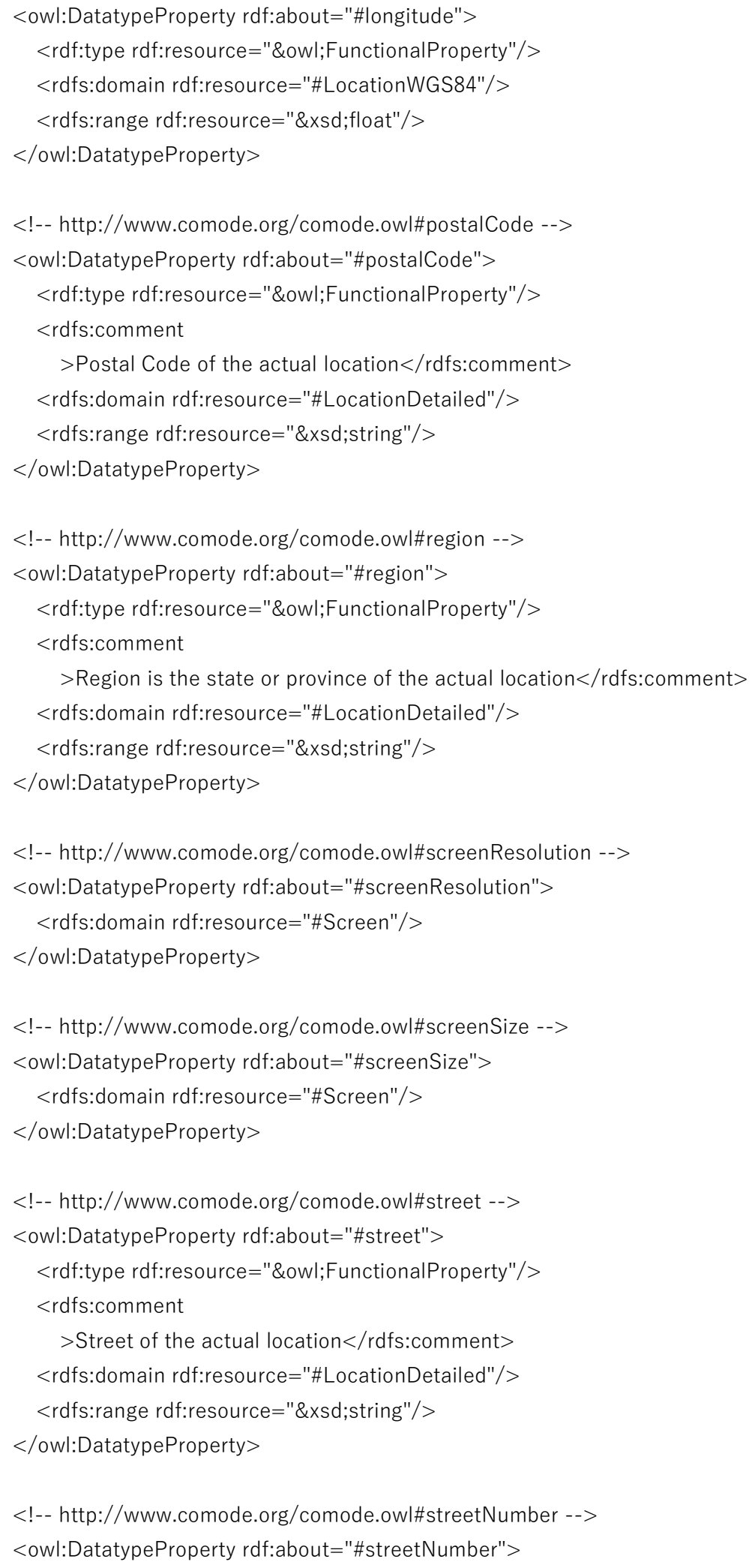




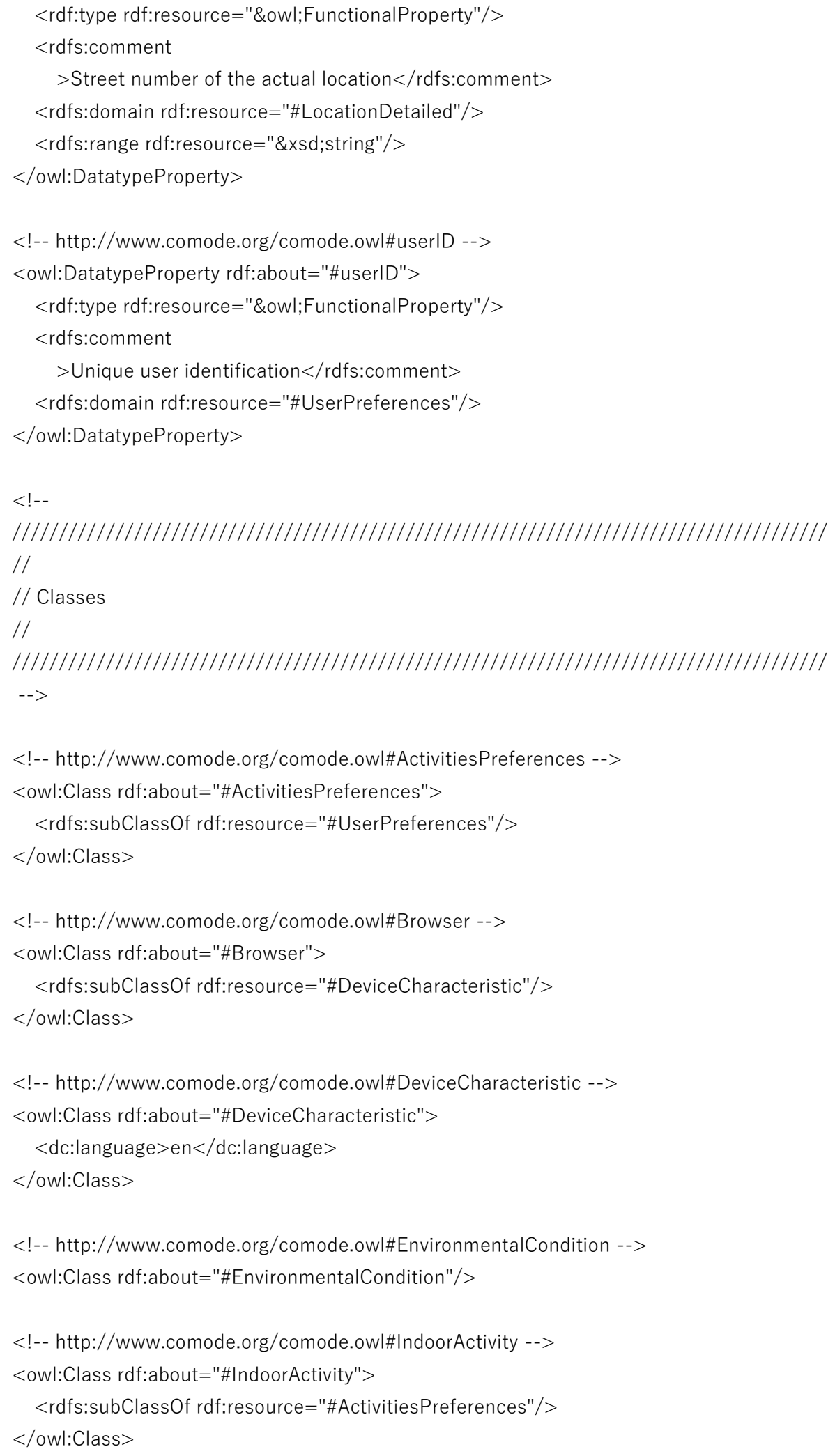




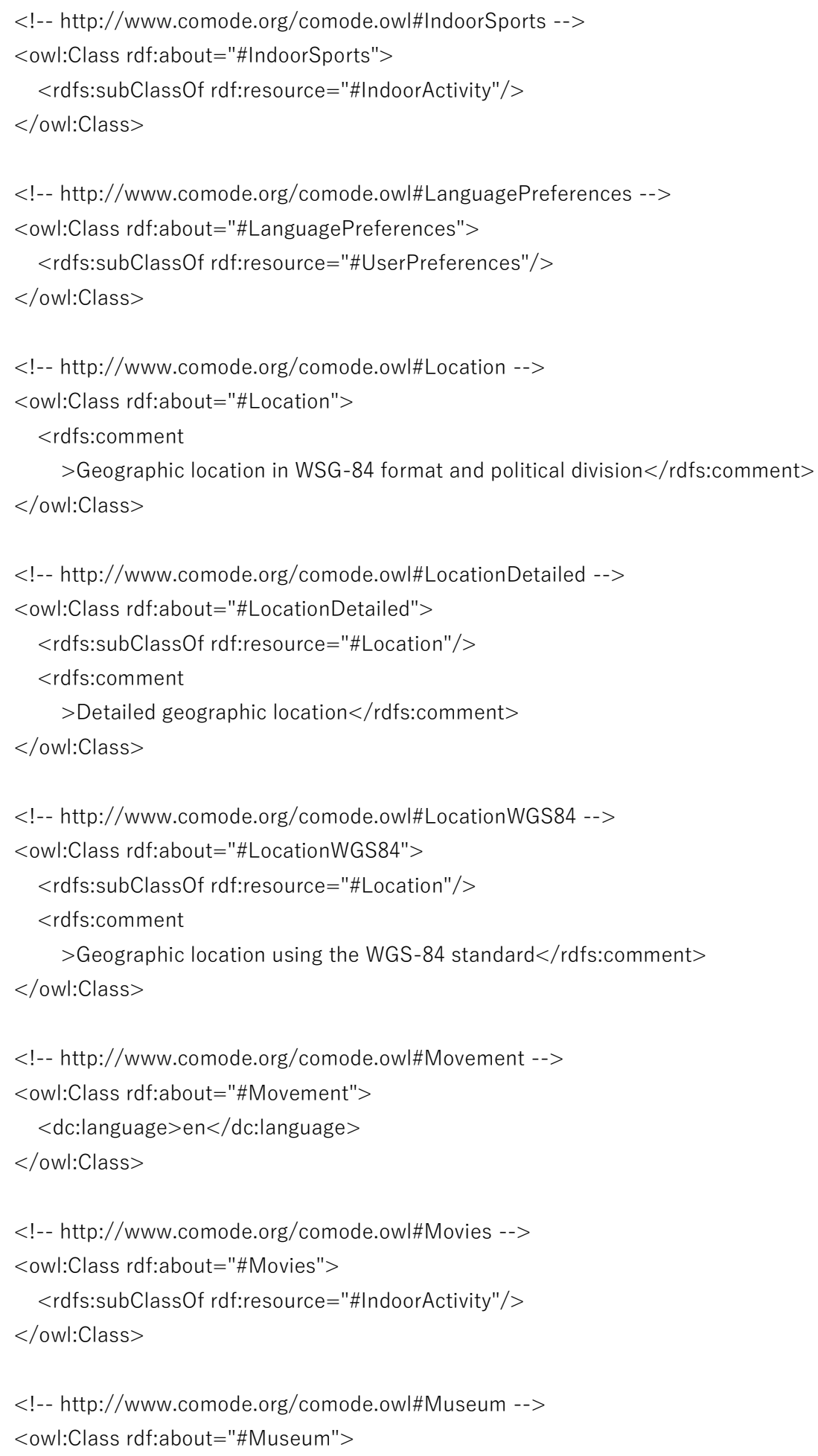


$<$ rdfs:subClassOf rdf:resource="\#IndoorActivity"/> $</$ owl:Class $>$

$<$--- http://www.comode.org/comode.owl\#Network --> <owl:Class rdf:about="\#Network"> $<$ rdfs:subClassOf rdf:resource="\#DeviceCharacteristic"/> $</$ owl:Class $>$

$<$ !-- http://www.comode.org/comode.owl\#OutdoorActivity --> <owl:Class rdf:about="\#OutdoorActivity">

$<$ rdfs:subClassOf rdf:resource="\#ActivitiesPreferences" $/>$ $</$ owl:Class $>$

$<$ !-- http://www.comode.org/comode.owl\#Picnic --> <owl:Class rdf:about="\#Picnic"> $<$ rdfs:subClassOf rdf:resource="\#OutdoorActivity"/> $<$ owl:Class $>$

$<$ !-- http://www.comode.org/comode.owl\#Processor -->

<owl:Class rdf:about="\#Processor">

$<$ rdfs:subClassOf rdf:resource="\#DeviceCharacteristic" $/>$

$</$ owl:Class $>$

$<$ !-- http://www.comode.org/comode.owl\#Reading -->

<owl:Class rdf:about="\#Reading">

$<$ rdfs:subClassOf rdf:resource="\#IndoorActivity"/>

$</$ owl:Class $>$

$<$ !-- http://www.comode.org/comode.owl\#Restaurant --> $<$ owl:Class rdf:about="\#Restaurant">

$<$ rdfs:subClassOf rdf:resource="\#IndoorActivity"/>

$</$ owl:Class $>$

$<$ !-- http://www.comode.org/comode.owl\#ResultsPreferences -->

<owl:Class rdf:about="\#ResultsPreferences">

$<$ rdfs:subClassOf rdf:resource="\#UserPreferences"/>

$</$ owl:Class $>$

$<$ !-- http://www.comode.org/comode.owl\#Screen -->

<owl:Class rdf:about="\#Screen">

$<$ rdfs:subClassOf rdf:resource="\#DeviceCharacteristic"/>

$</$ owl:Class $>$ 


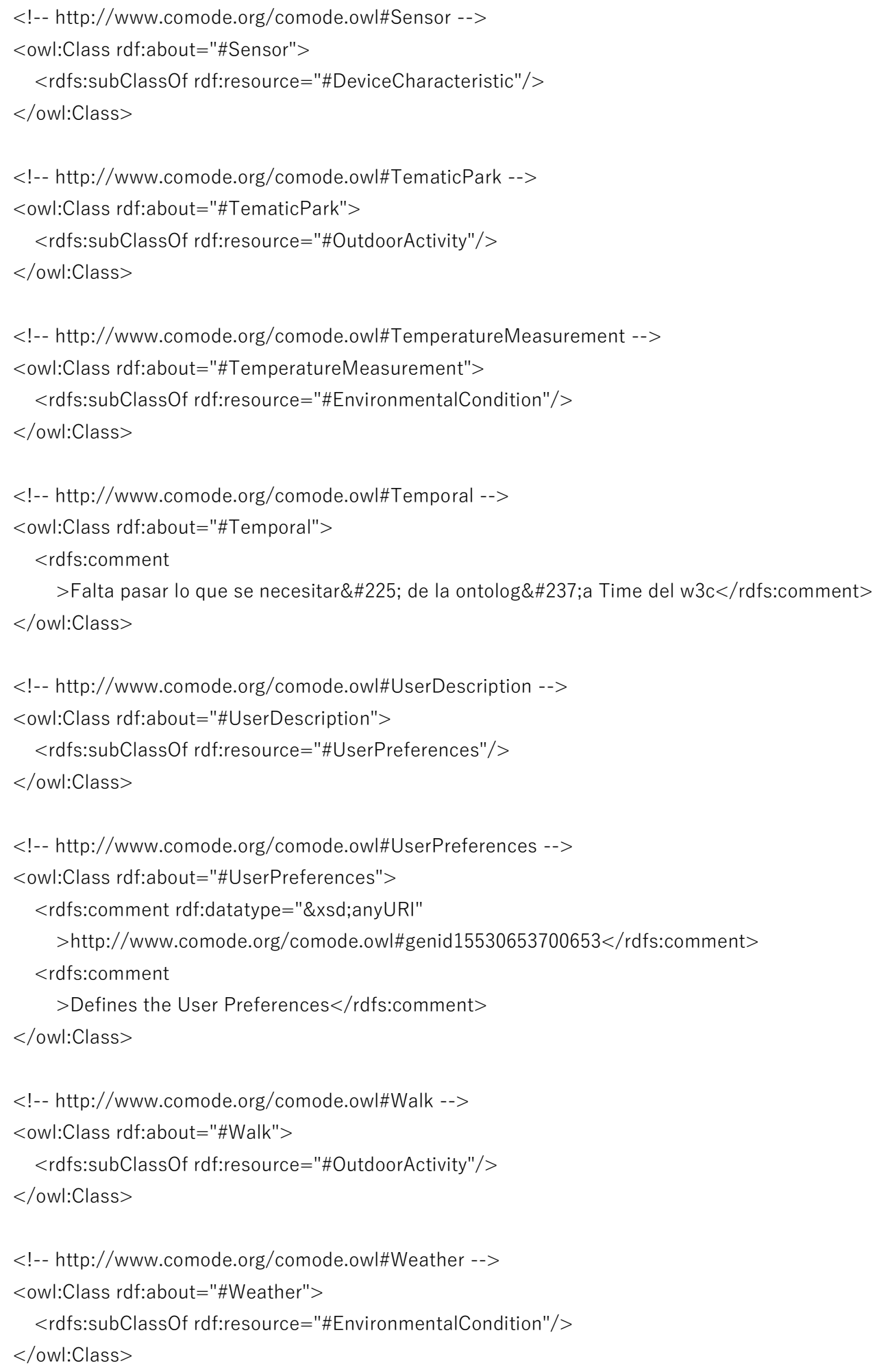




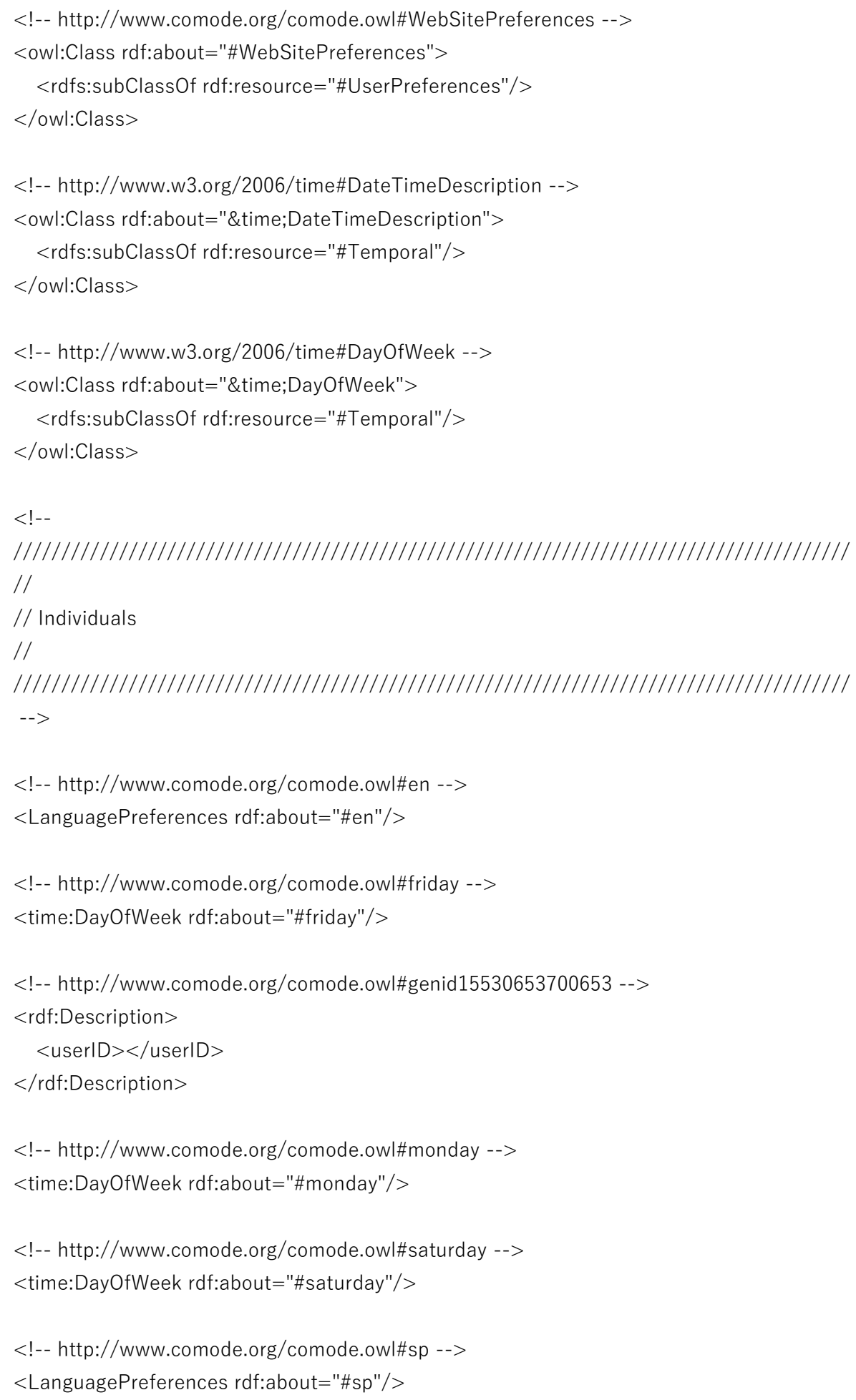




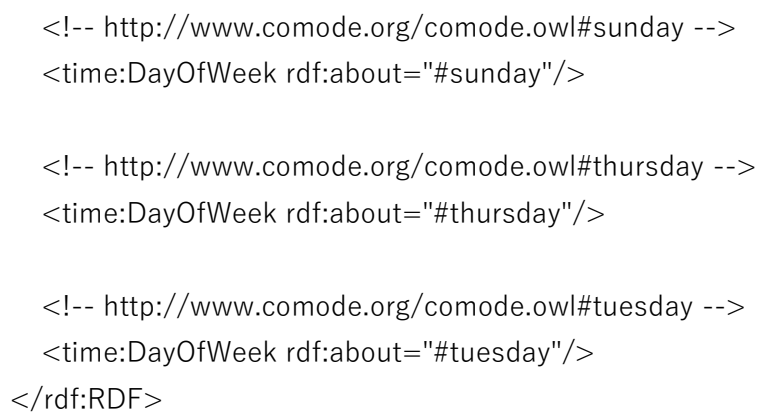




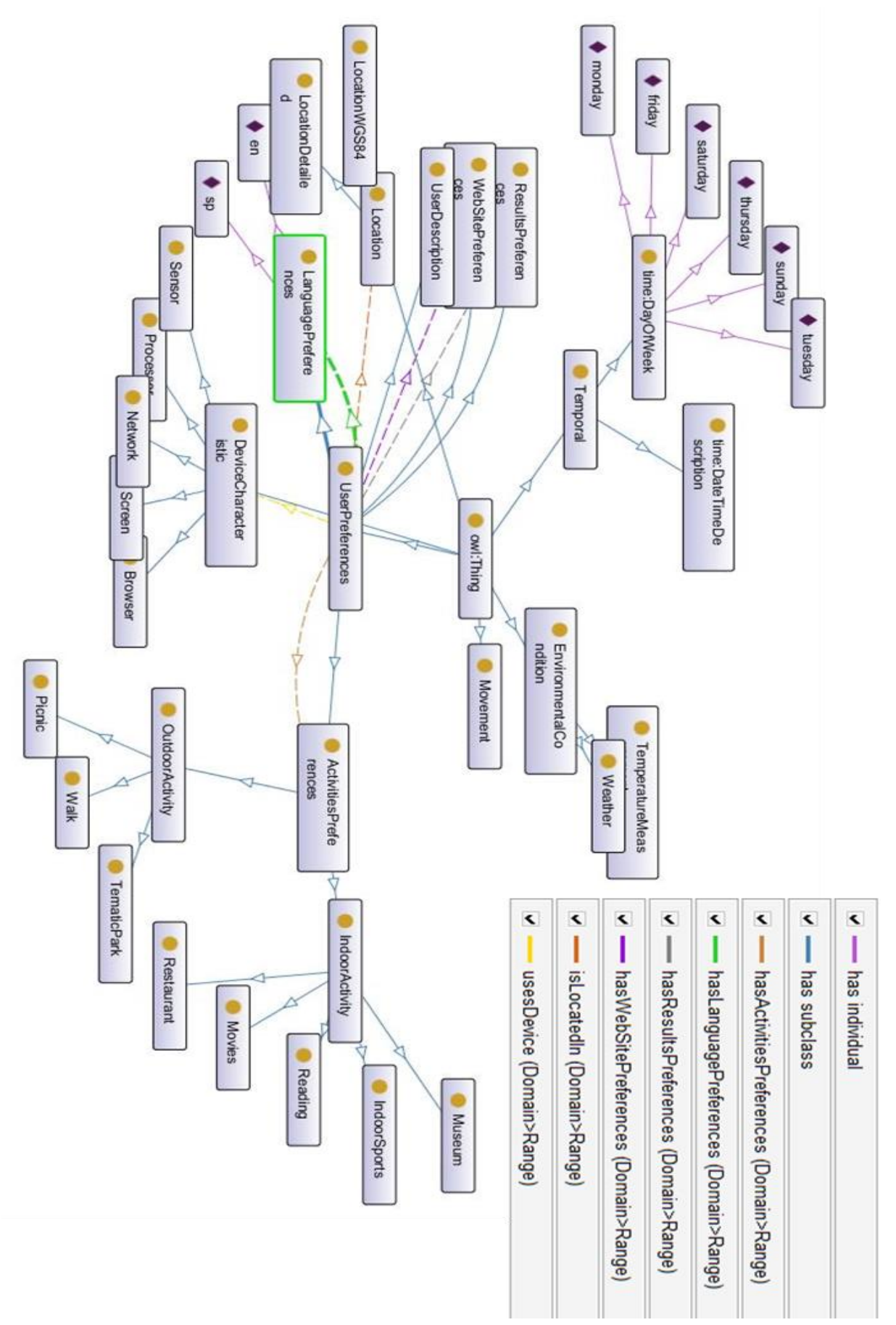




\section{Apéndice B: Preguntas del cuestionario de validación de los grupos de}

elementos base

\section{Versión en inglés}

1. User Profile

1.1. What is your gender?

1.2. What is your age range?

1.3. What is your studies level?

1.4. Are you related to computer science studies or work?

1.5. From which city are you connected from to complete this survey?

1.6. Please provide us your email address, this will not be matched with your answers and will be used solely to inform you the results of this investigation.

2. Internet Use Profile

2.1. Select all the Internet services and applications that you frequently use in desktop computers.

- $\quad[$ Web Search]

- $\quad[$ e-mail]

- $\quad[$ Web pages]

- $\quad$ Social Networks]

- $\quad[$ Blogs $]$

- $\quad$ [Chat \& Voice services]

- $\quad$ OOther]

2.2. Do you use mobile Internet connection? 
2.2.1. What kind of mobile device do you use to connect to Internet?

- $\quad$ [PDA (Personal Digital Assistant)]

- [Cellular phone]

- $\quad[$ Netbook $]$

- [Other]

2.2.2. What kind of Internet connection do you use on your mobile device?

- $\quad[E D G E / G P R S]$

- $\quad[3 G]$

- $\quad[\mathrm{WiFi}]$

- $\quad[$ WiMAX]

- [Other]

2.2.3. How often do you connect to Internet from mobile devices?

2.3. What are the usual tasks that you do or will do when connected to Internet from the mobile device?

- $\quad[$ Web Search]

- $\quad[e-m a i l]$

- $\quad$ Web pages]

- $\quad$ Social Networks]

- $\quad$ Blogs]

- $\quad$ [Chat \& voice services]

- $\quad$ OOther $]$

2.4. What type of content do you or will do usually access from a mobile device?

2.5. Which do you think is the most important reason to NOT use the mobile Internet access? 
- $\quad$ Cost of use]

- [Equipment characteristics]

- $\quad$ [Difficult of use]

- $\quad$ [Does not need it]

- $\quad$ [Does not know that can have this service]

- $\quad$ Other $]$

2.6. If the conditions for not using the mobile Internet access change, would you use it?

2.7. Do you think that a personalized application or service for mobile devices that considers the context would be useful?

3. Device and Network Characteristics

3.1. Kind of Browser (browser type, characteristics and capabilities)

3.2. Kind of Processor

3.3. Mobile device screen characteristics

3.4. Network connection characteristics

3.5. Characteristics of device's sensors (accelerometer, biometric, thermometer, etc.)

3.6. Localization method used by the device (GPS, aGPS, WiFi, etc.)

3.7. A classification that allows to identify the technical characteristics of mobile devices? The devices will be related to one level of this classification according to their technical characteristics.

3.8. Optional: Please feel free to write some other concepts related to the Device and Network that should be considered as a useful context for application or services in mobile devices 
4. User Preferences

4.1. Address of the pages that the user has visited more frequently

4.2. Classification type of the most recently visited pages

4.3. Preferred results, obtained from previous search queries and results.

4.4. Optional: Please feel free to write some other concepts related to the User Preferences that should be considered as a useful context for application or services in mobile devices

5. Physical Situation

5.1. Geographic location (coordinates)

5.2. Geopolitical location (country, city, street)

5.3. Type of place (airport, beach, downtown, etc.)

5.4. Type of situation (business, pleasure, etc.)

5.5. Optional: Please feel free to write some other concepts related to the Physical Situation that should be considered as a useful context for application or services in mobile devices

6. Temporal Conditions and Circumstances

6.1. Actual date and time

6.2. Actual season of the year

6.3. Relative actual time (early in the morning, at night, etc.)

6.4. Relative date (weekend, early month day, middle of the year, etc.) 
6.5. Optional: Please feel free to write some other concepts related to the Temporal Conditions and Circumstances that should be considered as a useful context for application or services in mobile devices

7. Environmental Conditions and Circumstances

7.1. Actual weather situation

7.2. Weather forecast

7.3. Actual sunrise and sunset time

7.4. Optional: Please feel free to write some other concepts related to the Environmental Conditions and Circumstances that should be considered as a useful context for application or services in mobile devices

8. User Movement Characteristics

8.1. Speed of user movement

8.2. Type of movement (inter-city, inside the city, etc.)

8.3. Actual type of transportation (feet, bicycle, train, etc.)

8.4. Optional: Please feel free to write some other concepts related to the User Movement Characteristics that should be considered as a useful context for application or services in mobile devices

\section{Versión en español}

1. Perfil del usuario

1.1. ¿Cuál es su sexo?

1.2. ¿Cuál es su rango de edad?

1.3. ¿Cuál es su nivel de estudios? 
1.4. ¿Sus estudios o trabajo están relacionados con las ciencias computacionales?

1.5. ¿Desde qué ciudad se ha conectado para completar esta encuesta?

1.6. Por favor provea su correo electrónico, no será enlazado con sus respuestas y será utilizado solamente para informarle de los resultados de la investigación.

2. Perfile de uso de Internet

2.1. Seleccione todos los servicios y aplicaciones de Internet que utilice frecuentemente en su ordenador de escritorio.

- [Búsqueda web]

- [correo electrónico]

- $\quad$ [Páginas web]

- [Redes sociales]

- $\quad[$ Blogs $]$

- [Chat y servicios de voz]

- $\quad$ Otro]

2.2. ¿Utiliza alguna conexión de Internet móvil?

2.2.1. ¿Qué tipo de dispositivo móvil utiliza para conectarse a Internet?

- $\quad$ [PDA (Asistente Personal Digital)]

- $\quad$ [Teléfono móvil]

- $\quad$ Netbook]

- $\quad$ OOtro]

2.2.2. ¿Qué tipo de conexión a Internet utiliza para conectarse en su dispositivo móvil?

- $\quad[E D G E / G P R S]$ 
- $\quad[3 G]$

- $[\mathrm{WiFi}]$

- $\quad[$ WiMAX]

- $\quad[O t r o]$

2.2.3. ¿Qué tan frecuente se conecta a Internet desde dispositivos móviles?

2.3. ¿Cuáles son las tareas que hace o haría al conectarse a Internet desde dispositivos móviles?

- $\quad$ [Búsqueda web]

- [Correo electrónico]

- $\quad$ Páginas web]

- $\quad$ Redes sociales]

- $\quad$ B Blogs]

- $\quad$ [Chat y servicios de voz]

- $\quad[$ Otro]

2.4. ¿Qué tipo de contenido consulta o consultaría desde un dispositivo móvil?

2.5. ¿Cuál es la razón más importante por la que NO utilizaría la conexión móvil a Internet?

- $\quad$ Costo]

- [Características del equipo]

- [Dificultad de uso]

- $\quad$ [No lo necesito]

- [No sabía que podía contar con ese servicio]

- $\quad[$ Otro $]$ 
2.6. Si las condiciones para NO utilizar el acceso móvil a Internet cambiaran ¿Lo utilizaría?

2.7. ¿Considera que una aplicación o servicio móvil personalizado que considere las condiciones del contexto o entorno podría ser de utilidad?

3. Características del dispositivo y la red

3.1. Tipo de navegador web (tipo de navegador, características y capacidades)

3.2. Tipo de procesador

3.3. Características de la pantalla del dispositivo móvil

3.4. Características de la conexión de red

3.5. Características de los sensores del dispositivo (acelerómetro, biométrico, termómetro, etc.)

3.6. Método de localización utilizado por el dispositivo (GPS, aGPS, WiFi, etc.)

3.7. ¿Una clasificación que permita identificar características técnicas de los dispositivos móviles? Los dispositivos serían relacionados con un nivel de clasificación de acuerdo con sus características técnicas.

3.8. Opcional: Por favor siéntase libre de escribir algunos otros conceptos relacionados con las características del dispositivo y la red que considere de utilidad como contexto en aplicaciones o servicios en dispositivos móviles.

4. Preferencias del usuario 
4.1. Dirección de las páginas que el usuario ha visitado más frecuentemente

4.2. Clasificación de las páginas visitadas recientemente

4.3. Resultados preferidos, obtenidos de búsquedas anteriores y sus resultados

4.4. Opcional: Por favor siéntase libre de escribir algunos otros conceptos relacionados con las preferencias de usuario que considere de utilidad como contexto en aplicaciones o servicios en dispositivos móviles.

5. Situación física

5.1. Ubicación geográfica (coordenadas)

5.2. Ubicación geopolítica (país, ciudad, calle)

5.3. Tipo de lugar (aeropuerto, playa, centro, etc.)

5.4. Tipo de situación (negocios, placer, etc.)

5.5. Opcional: Por favor siéntase libre de escribir algunos otros conceptos relacionados con la situación física que considere de utilidad como contexto en aplicaciones o servicios en dispositivos móviles.

6. Condiciones y Circunstancias Temporales

6.1. Fecha y tiempo actual

6.2. Estación actual del año

6.3. Tiempo real relativo (temprano en la mañana, en la noche, etc.)

6.4. Fecha relativa (fin de semana, inicio del mes, mitad del año, etc.)

6.5. Opcional: Por favor siéntase libre de escribir algunos otros conceptos relacionados con las condiciones y circunstancias temporales que 
considere de utilidad como contexto en aplicaciones o servicios en dispositivos móviles.

7. Condiciones Ambientales y sus Circunstancias

7.1. Situación actual del clima

7.2. Pronóstico del clima

7.3. Hora actual del amanecer y atardecer

7.4. Opcional: Por favor siéntase libre de escribir algunos otros conceptos relacionados con las condiciones ambientales y sus circunstancias que considere de utilidad como contexto en aplicaciones o servicios en dispositivos móviles.

8. Características del movimiento del usuario

8.1. Velocidad de movimiento del usuario

8.2. Tipo de movimiento (entre ciudades, dentro de la ciudad, etc.)

8.3. Tipo de transportación actual (a pie, bicicleta, tren, etc.)

8.4. Opcional: Por favor siéntase libre de escribir algunos otros conceptos relacionados con las características del movimiento del usuario que considere de utilidad como contexto en aplicaciones o servicios en dispositivos móviles. 


\section{Apéndice C: Elementos imaginarios utilizados en el experimento de mejora}

\section{en la recomendación de palabras en dispositivos móviles}

\begin{tabular}{|l|l|}
\hline \multicolumn{1}{|c|}{ Contexto } & \multicolumn{1}{|c|}{ Texto a buscar } \\
\hline $\begin{array}{l}\text { Imagine that you are in Madrid and you want to have a } \\
\text { nice dinner, today you are looking for a japanese place }\end{array}$ & $\begin{array}{l}\text { restaurant } \\
\text { japanese }\end{array}$ \\
\hline $\begin{array}{l}\text { Imagine that you are in Puerto Vallarta, in summer, and } \\
\text { you want to do some aquatic sports and scuba is one } \\
\text { of your favorites }\end{array}$ & scuba \\
\hline $\begin{array}{l}\text { You are a movies lover and have some free time, so, } \\
\text { you want to search for movies available today in the } \\
\text { city theaters. As a scifi lover, that's your first } \\
\text { preference to search for }\end{array}$ & movie scifi \\
\hline $\begin{array}{l}\text { When in Valladolid, Spain, you are looking for a sports } \\
\text { match, your preferences include football and rugby, but } \\
\text { you prefer the last one for today }\end{array}$ & rugby \\
\hline \begin{tabular}{l} 
It's weekend and you have free time... \\
\hline $\begin{array}{l}\text { Imagine that you are in Paris and have some free time, } \\
\text { a museum is a very good option for you today }\end{array}$
\end{tabular} & museum \\
\hline $\begin{array}{l}\text { When in winter, in the Swiss Alps, you are in a } \\
\text { mountain place and wants to practice some ski }\end{array}$ & ski \\
\hline $\begin{array}{l}\text { You are an italian food lover, and when you are in New } \\
\text { York wants to go to dinner, so, you are looking for a } \\
\text { beautiful italian restaurant }\end{array}$ & restaurant italian \\
\hline $\begin{array}{l}\text { There's cold outside, but you want to see some sports } \\
\text { competence, maybe basketball could be a good option }\end{array}$ & basketball \\
\hline $\begin{array}{l}\text { You love to go to movies, specially drama ones, now } \\
\text { you want to know what movies are playing in town }\end{array}$ & movie drama \\
\hline
\end{tabular}




\begin{tabular}{|l|l|}
\hline $\begin{array}{l}\text { You're near a mountain reserve, looking for a place to } \\
\text { stay for a nature-near vacation, a cabin could be a nice } \\
\text { place to stay }\end{array}$ & cabin \\
\hline $\begin{array}{l}\text { As a drama fan and a new boy in town, you are looking } \\
\text { for a theater with a great play }\end{array}$ & theater \\
\hline
\end{tabular}




\section{Apéndice D: Resultados completos en el experimento del sistema de envío}

de mensajes

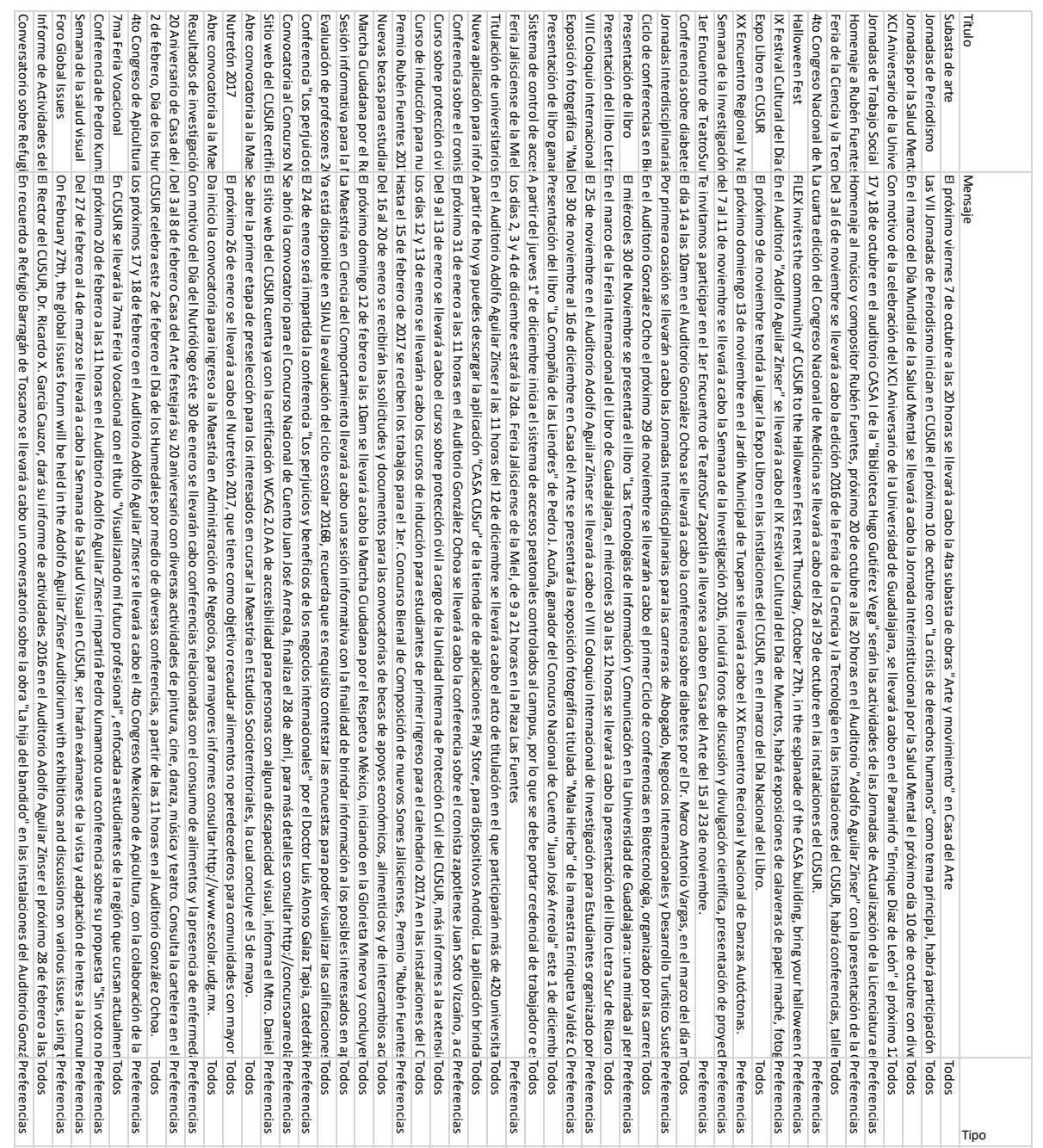

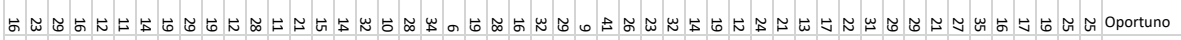

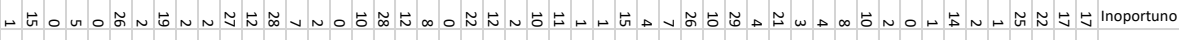

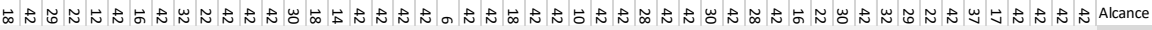

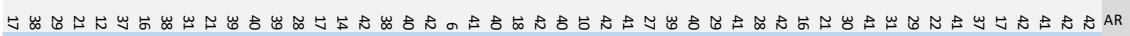

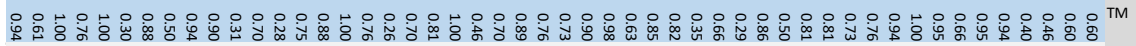

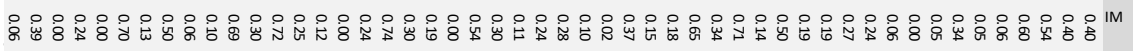

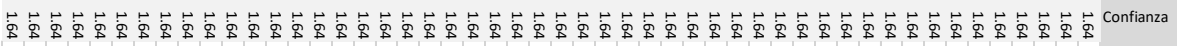

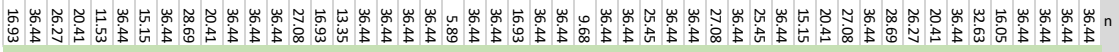

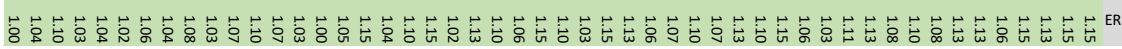


